Universidad Politécnica de Madrid

Escuela Técnica Superior de Ingenieros de Minas y Energía

\title{
Desarrollo de un modelo de creación de equipos de trabajo asociado a proyectos innovadores exitosos
}

\section{TESIS DOCTORAL}

DOCTORADO INVESTIGACIÓN, MODELIZACIÓN Y ANÁLISIS DEL RIESGO EN MEDIO AMBIENTE

Realizado por:

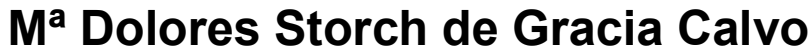

Ingeniera de Montes

2020

DIRECTORES:

D. Luis F. Mazadiego Martínez

D. Bernardo Llamas Moya

Dr. Ingeniero de Minas

Dr. Ingeniero de Minas 
Departamento de Ingeniería Geológica y Minera

Escuela Técnica Superior de Ingenieros de Minas y Energía

\section{Desarrollo de un modelo de} creación de equipos de trabajo asociado a proyectos innovadores exitosos

Realizado por:

\section{$M^{a}$ Dolores Storch de Gracia Calvo}

Ingeniera de Montes

2020

DIRECTORES:
D. Luis F. Mazadiego Martínez
D. Bernardo Llamas Moya
Dr. Ingeniero de Minas
Dr. Ingeniero de Minas 


\section{Agradecimientos}

Soy consciente de la dificultad de agradecer a todas las personas que hicieron posible que hoy llegara a publicar mi tesis. A medida que cumplo años me doy cuenta de lo agradecida que me siento a la vida, que me ha permitido conocer a tantas personas que dejaron una huella en mí y sé que gran parte de lo que soy se lo debo a ellas.

Quiero agradecer especialmente a las siguientes por su apoyo incondicional en esta aventura:

- A mis hijos, por enseñarme tanto cada día y hacerme sentir que nada es imposible.

- A mi familia, por su apoyo continuo en todas las misiones que emprendo.

- A mis Directores de tesis, por apoyarme para poder desarrollar el trabajo reflejado en este documento y cuyo resultado final es la publicación de mi tesis.

- A mis amigos, que me ayudan a equilibrar todas las facetas de mi vida y sin los cuales no tendría la energía para embarcarme en nuevas aventuras cada año.

- A mi grupo Forever, por hacerme sentir más joven cada año y asegurar que me despierte cada día con una sonrisa.

- A mi Fraternidad, por aportarme tantas cosas cada uno de ellos con su generosidad al compartir sus valores y forma de ver la vida .

- A mis hijos, principio y fin de mi vida. 


\section{Índice}

AGRADECIMIENTOS

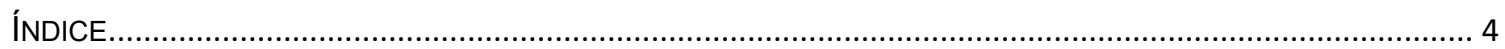

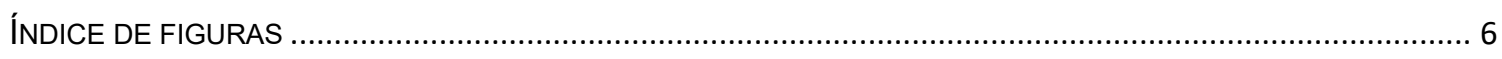

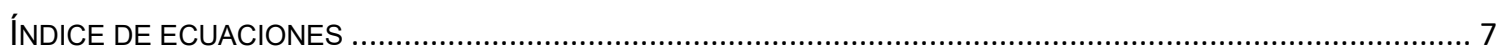

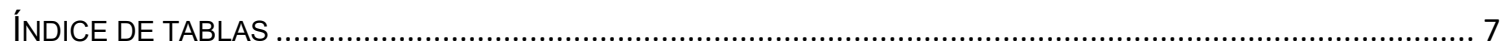

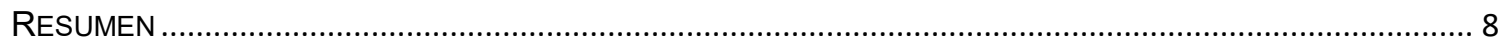

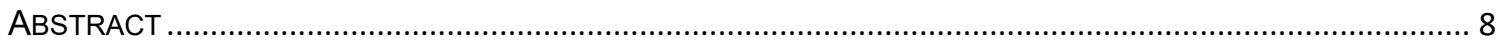

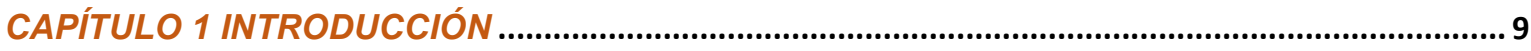

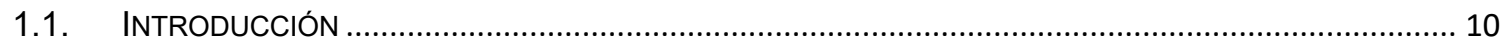

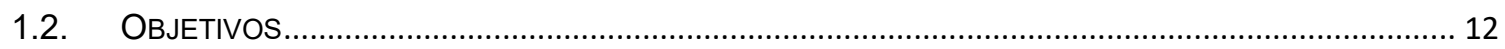

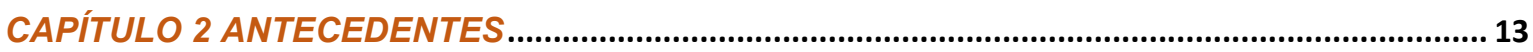

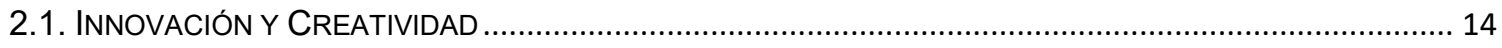

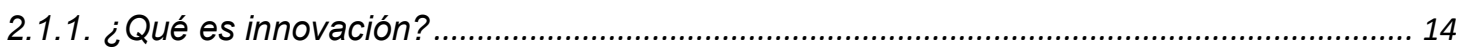

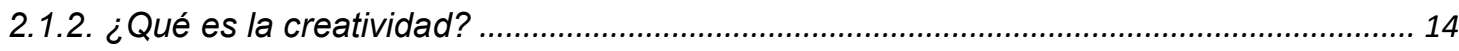

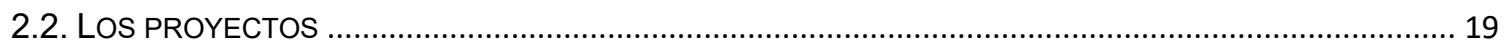

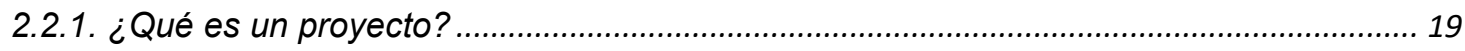

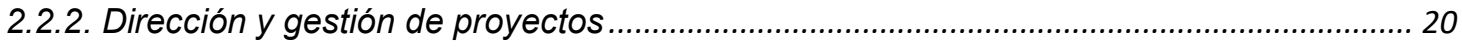

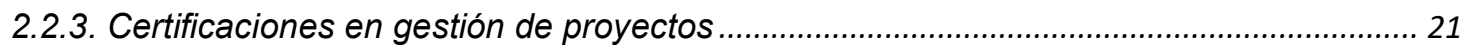

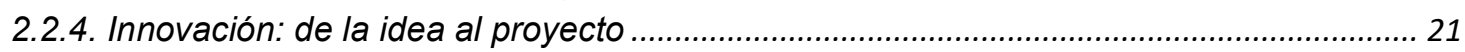

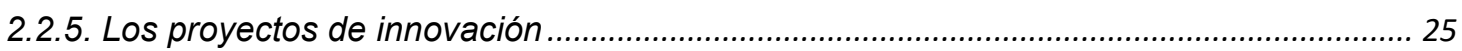

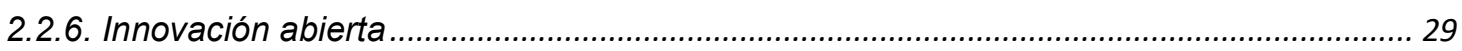

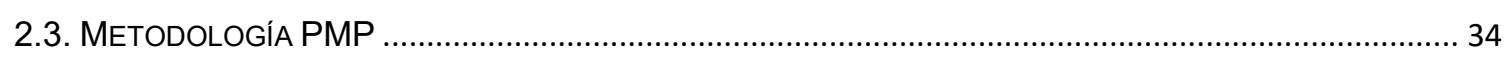

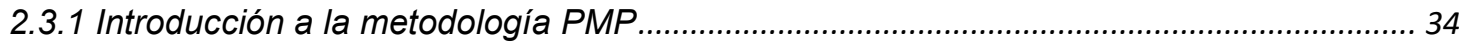

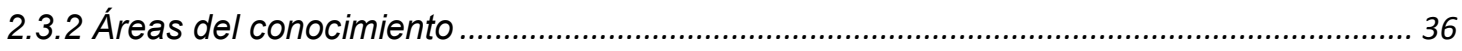

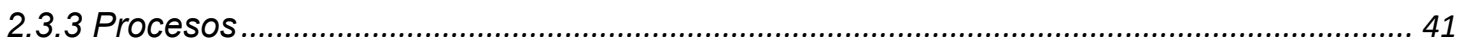

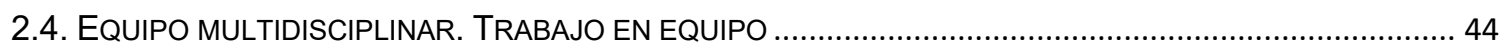

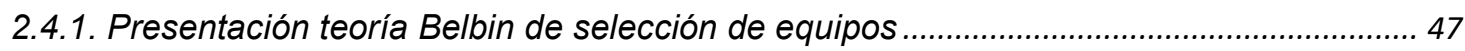

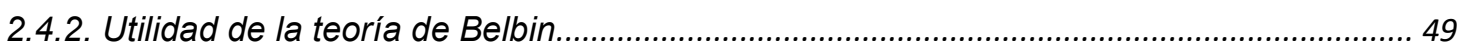

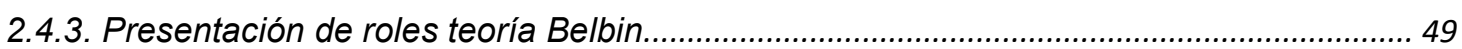

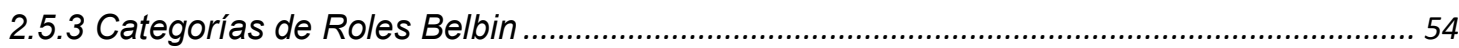

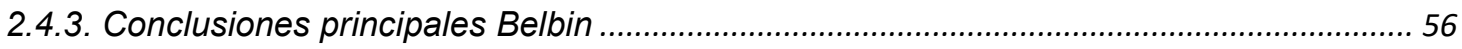

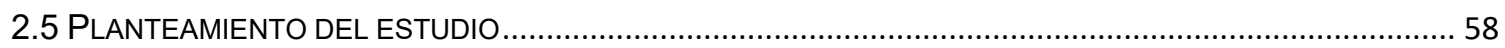

2.5.1. El papel de las habilidades transversales a través del marco lógico del proyecto. ........ 58

2.5.2. Propuesta de metodología de selección de proyectos basada en el PMI......................... 60

2.5.3. Propuesta de modelo de creación de equipos de trabajo asociados a proyectos de

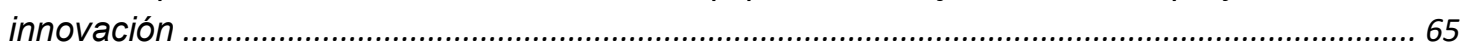

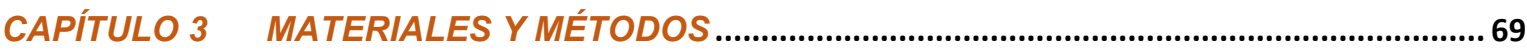

3.1. HABILIDADES TRANSVERSALES CLAVE A CONSIDERAR EN LOS PROYECTOS DE INNOVACIÓN ............ 72

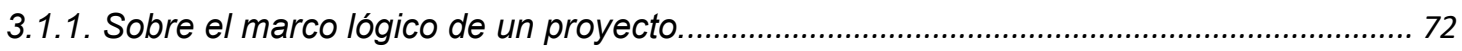

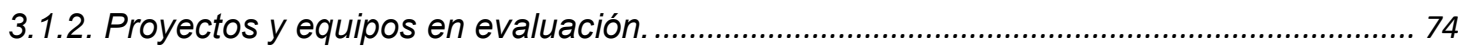

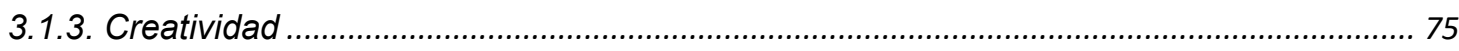

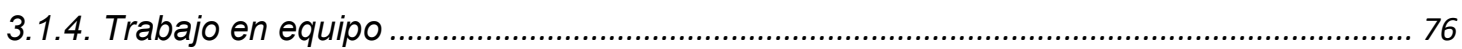

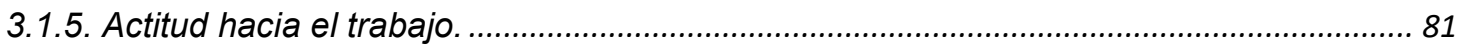


3.1.6. Comunicación

3.2. PRESENTACIÓN DEL MÉTOdO AHP Y APLICACIÓN A LAS ALTERNATIVAS PROPUESTAS ....................8.84

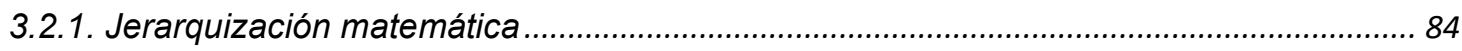

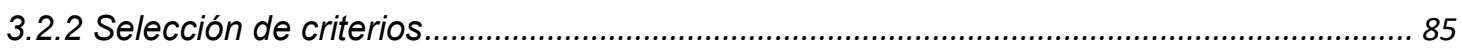

3.2.3 Descripción de las alternativas....................................................................................... 87

3.3 DESARROLLO DEL MODELO MATEMÁTICO Y SU APLICACIÓN A LOS PROYECTOS INNOVADORES .........89

3.3.1. Desarrollo del modelo matemático........................................................................... 92

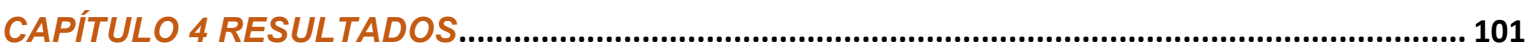

4.1. DISCUSIÓN Y RESULTADOS SOBRE EL PAPEL DE LAS HABILIDADES TRANSVERSALES A TRAVÉS DEL

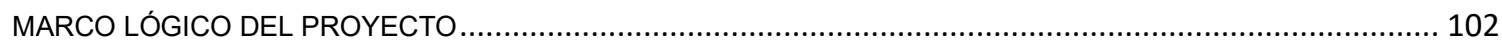

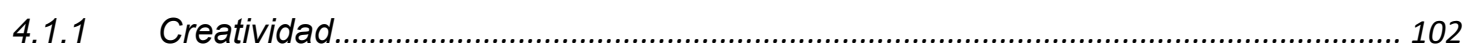

4.1.2 Trabajo en equipo............................................................................................. 106

4.1.3 Actitud hacia el trabajo..................................................................................... 108

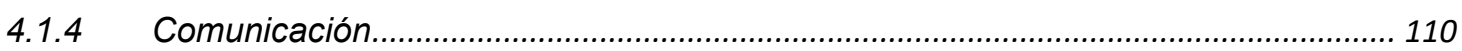

4.2. DisCUSIÓN Y RESULTADOS DEL MÉTODO AHP Y SU APLICACIÓN A LAS ALTERNATIVAS PROPUESTAS

4.3 DISCUSIÓN Y RESULTADOS DEL MODELO MATEMÁTICO Y SU APLICACIÓN A LOS PROYECTOS

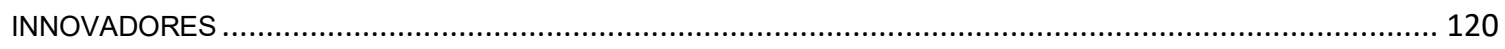

CAPÍTULO 5 CONCLUSIONES Y LÍNEAS FUTURAS DE INVESTIGACIÓN .............................. 129

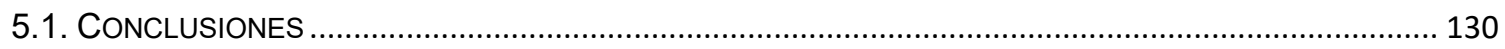

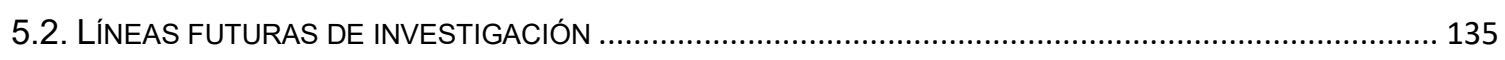

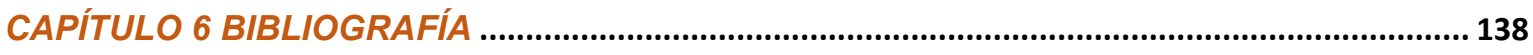

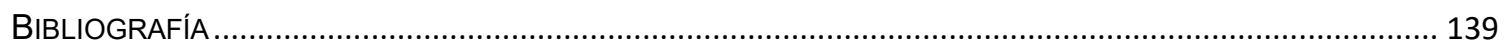

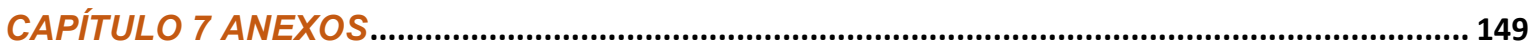

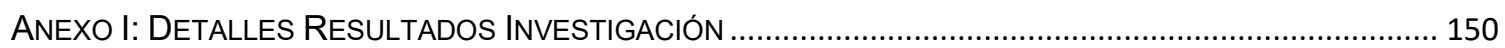

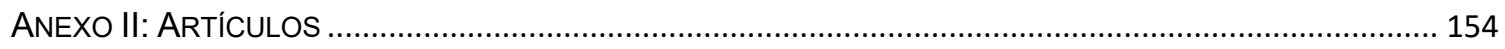

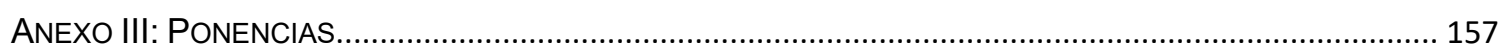

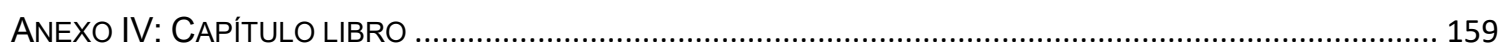




\section{Índice de figuras}

Figura 1. Definición de proyecto. Limitaciones al desarrollo.

pág. 19

Figura 2. Concepto de Innovación abierta: el proceso para incorporar y desarrollar proyectos innovadores: proceso de creación de valor. pág.30

Figura 3. La restricción triple (tradicional) y las restricciones del proyecto (Lledó P.

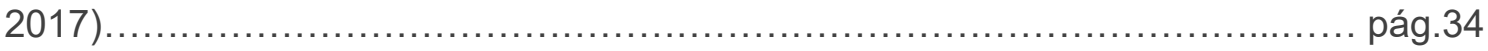

Figura 4. Áreas de Conocimiento PMP (Lledó P. 2017) .......................... pág.36

Figura 5. Matriz de estrategias de respuesta al riesgo (Lledó P. 2017)............. pág.40

Figura 6. Esquema de proceso y grupos de procesos (Lledó P. 2017).............. pág.41

Figura 7. Procesos según áreas de conocimiento y grupos de procesos........... pág.43

Figura 8. Marco lógico de cualquier proyecto y enfoque de innovación abierta... pág.60

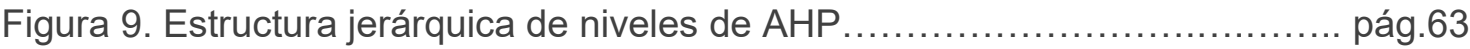

Figura 10. Planteamiento del estudio equipos de trabajo vs proyectos exitosos.. pág.65

Figura 11. Marco conceptual y lógico de un proyecto............................ pág.72

Figura 12. Comportamiento personal versus actitud hacia el trabajo.............. pág.82

Figura 13. Rúbrica de creatividad y comunicación............................. pág.83

Figura 14: Criterios de selección de proyectos. Árbol de toma de decisiones......pág.89

Figura 15. Evaluación de la creatividad considerando valores específicos. El gráfico se basa en la escala de cinco puntos de Likert. pág.106

Figura 16. Resultados del ejercicio de inversión pág.107

Figura 17. Roles del equipo según la teoría de Belbin. Identificación para los cuatro equipos. pág.108

Figura 18. Perfil de cada ingeniero frente a la obra, según C.G. T de Jung. pág..110

Figura 19. Evaluación de la comunicación. Habilidades escritas y orales de cada equipo. pág.112

Figura 20. Estructura jerárquica y selección de estructuras propuestas para la selección de proyectos innovadores bajo enfoque de innovación abierta. pág. 115

Figura 21. Evaluación de pesos.

pág.118

Figura 22. Diagnóstico de equipos de trabajo según la presencia de Roles... pág.126 Figura 23. Resultados Prueba de bondad de ajuste a la distribución normal (Saphiro Wilk) para la variable AHP pág.128

Figura 24. Resultados del análisis de la variable AHP en las distintas categorías de equipos de trabajo. pág.128

Figura 25. Prueba de homogeneidad de varianzas pág.129 
Figura 26. Resultados Test ANOVA para la variable AHP en las 3 categorías de equipos de trabajo. pág.130

\section{Índice de ecuaciones}

Ecuación 1. Ecuación AHP para evaluar alternativas en estudio. .pág.85

Ecuación 2. Fórmula para la obtención del valor de clasificación de un proyecto.pág.95

Ecuación 3. Ecuación de reciprocidad y transitividad de criterios AHP pág.115

Ecuación 4. Matrices de comparación por pares (AHP). pág.116

Ecuación 5. Cálculo del peso utilizando metodología AHP pág. 116

Ecuación 6. Suma de pesos normalizados pág.116

\section{Índice de tablas}

Tabla I: Estilos de liderazgo. pág.45

Tabla II: Roles de equipo teoría Belbin organizados en categorías principales (Fuente: Belbin Associates, UK, 2011) pág.54

Tabla III: Características y debilidades roles reflexión (Fuente: Belbin Associates, UK, 2011) pág.55

Tabla IV: Características y debilidades roles acción (Fuente: Belbin Associates, UK, 2011) pág.55

Tabla V : Características y debilidades roles sociales (Fuente: Belbin Associates, UK, 2011) pág. 56

Tabla VI: Explicación de la matriz de ponderación y valoración de un proyecto.. pág.95 Tabla VII. Aplicación criterios a metodología PMP. pág.96

Tabla VIII: Asignación de pesos a los criterios de selección de proyectos. pág97

Tabla IX. Subcriterios de selección cuantificables dentro de cada crit técnico....pág.119 Tabla X. Subcriterios de selección cuantificables dentro de cada crit organiz.... pág.120 Tabla XI. Evaluación de las alternativas (propuestas de proyectos). pág.121

Tabla XII: Resultados de la aplicación metodología AHP a proyectos. pág.123

Tabla XIII: Diagnóstico de equipos de trabajo según la presencia de roles pág. 125 


\section{Resumen}

A lo largo de esta tesis, se propone el estudio de los proyectos innovadores exitosos y de manera específica el papel que juegan los equipos de trabajo en los mismos para plantear un modelo de creación de equipos de trabajo que sirva como herramienta para desarrollar proyectos innovadores de éxito. La motivación final de esta línea de investigación es que si se conocen los aspectos que definen a los proyectos innovadores exitosos se podrá alimentar el modelo con las características que incluyen estos proyectos, predecir e incluso priorizar en una cartera de proyectos la asignación de recursos que serán necesarios.

Para ello se profundiza en el valor de las competencias de la creatividad, el trabajo en equipo o la comunicación como claves para los proyectos de innovación. También se estudian las características particulares de los proyectos de innovación, profundizando en la metodología propuesta por el Project Management Institute (PMI) y presentando una herramienta de jerarquización de proyectos basada en un modelo matemático utilizando metodología AHP.

Por último la profundización en los equipos de trabajo permite establecer una relación entre los proyectos innovadores exitosos y la composición de estos equipos, pudiendo así proponerse un modelo de creación de equipos como herramienta de diagnóstico y planificación de proyectos de innovación.

\section{Abstract}

Throughout this thesis, the study of successful innovative projects and specifically the role that work teams play in them is proposed to build a model for the creation of work teams that serves as a tool to develop innovative projects of success. The final motivation of this line of research is that if the aspects that define successful innovative projects are known, the model can be fed with the characteristics that these projects include, predict and even prioritize in a portfolio of projects the allocation of resources that will be necessary.

To this end, the value of creativity skills, teamwork or communication as keys to innovation projects is explored. The specific characteristics of innovation projects are also studied, delving into the methodology proposed by the Project Management Institute (PMI) and presenting a project ranking tool based on a mathematical model using AHP methodology.

Finally, the deepening of work teams allows establishing a relationship between successful innovative projects and the composition of these teams, thus being able to propose a teambuilding model as a diagnostic and planning tool for innovation projects. 


$$
\begin{gathered}
\text { CAPÍTULO } 1 \\
\text { INTRODUCCIÓN }
\end{gathered}
$$




\subsection{Introducción}

En este trabajo se plantea el análisis de los equipos de trabajo en proyectos innovadores, de cara a poder proponer un modelo que incremente la mayor eficiencia de los mismos.

Para poder afrontar este análisis es inevitable caminar sobre una serie de aspectos clave que sentarán las bases para poder plantear cómo debería ser el desarrollo de estos equipos:

En primer lugar, se revisarán conceptos relacionados con la innovación y las propuestas de valor que se pueden crear a partir de nuevas ideas, la importancia de la innovación abierta y, sobre todo, el peso decisivo de la competencia transversal de creatividad en la gestión de proyectos. El resultado de este primer análisis se concreta en una propuesta de rúbrica de evaluación de la creatividad a partir de los indicadores de Novedad, Funcionalidad e Impacto de los proyectos a través de un cuestionario Likert planteado a un panel de expertos.

En segundo lugar, se tratarán características particulares de los proyectos de innovación, qué son y cómo se definen en función de aspectos clave, en base a la metodología propuesta por el PMI (Project Management Institute). Se presentará la herramienta de jerarquización de proyectos basada en un modelo matemático utilizando la metodología AHP (Analyzed Hierarchy Process) que nos permitirá tener una valoración cuantitativa de los proyectos y minimizar así el riesgo de fracaso de los mismos pudiendo escoger financiar aquellos con mejores perspectivas de éxito. El estudio tendrá un enfoque multidisciplinar, considerando la toma de decisiones en un entorno global y con limitación de recursos económicos. Para ello, se abordará el problema mediante un algoritmo matemático de apoyo a la toma de decisiones. Como resultado de este análisis se plantea el diseño de una herramienta de selección de proyectos de innovación basado en un modelo matemático (AHP) y la metodología del PMI (Project Management Institute).

Si bien es cierto que la metodología PMI se utilizará para la toma de decisiones en algunos Criterios que denominaremos "técnicos" ( Alcance, Tiempo, Costes y Calidad ) la novedad de este trabajo supone utilizar otro acercamiento para valorar los criterios que se denominarán "organizativos" y que abarcan los Riesgos, Recursos Humanos, Comunicación e Interesados utilizando para ello, además de la metodología propuesta por el PMI, otra información adicional como la composición del equipo de trabajo para la evaluación del apartado de RRHH (basado en la teoría de Belbin) o la capacidad de 
Comunicación del equipo (que se medirá mediante su exposición oral) para el apartado de Comunicación.

En tercer lugar, se profundiza en los equipos de trabajo y los roles de equipo a través de la metodología de Belbin. Para ello, se estudia la relación entre la competencia de trabajo en equipo y los proyectos innovadores exitosos a partir del estudio de una muestra de 21 grupos de trabajo. Los resultados de este trabajo aplicando una metodología matemática estadística, nos permitirán concluir que existe una relación entre los proyectos de innovación exitosos y los equipos de trabajo de manera que se reconozca la importancia del equilibrio en los roles de equipo presentes.

Con todo ello se propone un modelo de creación de equipos de trabajo asociado a proyectos innovadores exitosos. 


\subsection{Objetivos}

La investigación presentada en esta memoria se enmarca en la línea de trabajo que se desarrolla en la Escuela de Ingenieros de Minas y Energía de la UPM y en el Grupo de Investigación de Organizaciones Sostenibles (GIOS) sobre los proyectos innovadores y su relación con los equipos de trabajo.

El objetivo global de esta Tesis Doctoral es analizar los equipos de trabajo en proyectos innovadores y proponer una aplicación en la metodología de selección de proyectos innovadores exitosos basada en la composición de estos equipos.

Además, se definen los siguientes objetivos parciales:

- Analizar el valor de la competencia de la creatividad en la gestión de proyectos.

- Proponer una herramienta de selección de proyectos de innovación basada en la metodología AHP.

- Estudiar la relación entre la competencia de los equipos de trabajo y los proyectos innovadores.

- Determinar si existe una relación entre los proyectos de innovación exitosos y los equipos de trabajo de manera que se reconozca la importancia del equilibrio en los roles de equipo presentes. 


$$
\text { CAPÍTULO } 2
$$

ANTECEDENTES 


\subsection{Innovación y Creatividad}

\subsection{1. ¿Qué es innovación?}

Antes de definir qué es innovación parece importante introducir el concepto de invención, como paso previo que permita entender el proceso de generación de algo nuevo a partir de lo existente. La invención es la creación de nuevos productos o procesos mediante el desarrollo de conocimiento nuevo o novedosas aplicaciones del conocimiento existente. La innovación se refiere a la aplicación de la invención mediante la generación de un nuevo producto o servicio, en muchas ocasiones asociado a la comercialización de dicha invención.

Una referencia obligada al hablar de innovación es Joseph Schumpeter (1942), que introduce el concepto de destrucción creativa como el proceso por el que los nuevos productos (innovaciones) introducidos por los emprendedores destruyen a las empresas establecidas y sus modelos de negocio (Schumpeter,1942). El crecimiento a largo plazo de las economías de mercado es fruto de la destrucción creativa (innovación) que desarrollan los emprendedores. Según su obra maestra "Capitalismo, socialismo y democracia" (Schumpeter,1942), la innovación es el determinante principal del desarrollo industrial. Una economía saludable nunca está en equilibrio, sino que está constantemente alterada por la innovación tecnológica.

Algunas de las mayores innovaciones en el último siglo han surgido de la creatividad de los individuos (o han sido desarrolladas por pequeñas nuevas empresas). Sin embargo, la gran mayoría de las innovaciones exitosas han llegado a partir de los esfuerzos de equipos orquestados sistemáticamente por las empresas. Y más que nada, lo que estas empresas han tendido a explotar no es tanto "invenciones" o "descubrimientos", sino el "cambio". La innovación se produce cuando las ideas creativas se aplican con éxito. Muchas ideas surgen por accidente, azar o incluso error. La innovación también puede ser social y entonces se refiere a un proceso de creación, desarrollo y difusión de prácticas en áreas diferentes de la sociedad. La innovación social tiene vocación de servicio público y lleva implícito un compromiso con las personas y la comunidad.

\subsection{2. ¿Qué es la creatividad?}

La creatividad es la capacidad para generar ideas originales que aporten valor en un área determinada (habitualmente se relaciona con el arte, pero es aplicable a todas las ciencias 
(Stein, 1962). No es por tanto un privilegio de músicos, pintores o artistas, sino que tenemos un potencial creativo que se puede desarrollar en todos los ámbitos de la vida. (Esquivias, 2004)

La creatividad es una habilidad que debe estar presente en el proceso innovador. La creatividad no debe ser considerada un don reservado a unos pocos elegidos sino una parte natural y necesaria del pensamiento de cada persona (Rogers, 1954). Los trabajos de Guilford en los años 40 fueron muy importantes ya que proponían un modelo de estructura de la inteligencia que marcó un antes y un después en el estudio de la creatividad (Guilford,1985). Este psicólogo americano propuso una diferenciación entre el pensamiento convergente y el pensamiento divergente. El primer tipo de pensamiento ofrece una solución correcta (concreta y racional) para cada situación. Las personas nos basamos en conocimiento previo y ordenamos de manera lógica la información disponible para llegar a una solución inequívoca que soluciona dicha situación. El pensamiento divergente, en cambio, contempla distintas alternativas de solución que desembocan en múltiples respuestas, de manera que pueden ser todas ellas correctas o no dependiendo del prisma con el que se mire. Este segundo tipo de pensamiento aumenta muchísimo los criterios de inventiva, originalidad, y flexibilidad (Simonton, 1984) (Simonton, 1988).

Otro aspecto fundamental es el funcionamiento del cerebro (Monreal, 2000). Sperry (1974) fue premio Nobel de Medicina y famoso neurólogo por su valioso descubrimiento acerca de las funciones del cerebro, al descubrir que los hemisferios cerebrales no procesan la misma información, sino que se distribuyen las tareas. El hemisferio izquierdo se ocupa de las labores de comunicación, análisis de la información, la escritura y el lenguaje corporal. Esta parte del cerebro por lo tanto se orienta al pensamiento convergente presentado por Guilford puesto que trabaja de forma lógica y racional, pero fracasa en las relaciones abstractas y complejas. Sin embargo, el hemisferio derecho se encarga de procesar las informaciones no verbales (las imágenes, sensaciones, emociones e informaciones espaciales) y es el terreno del pensamiento divergente que procesa ocurrencias, fantasías e intuiciones.

Si consideramos que "la creatividad es la capacidad de pensar más allá de las ideas admitidas, combinando de forma original conocimientos" (Welsh,1975), es evidente que está muy relacionada con el pensamiento divergente y por lo tanto con el hemisferio derecho. Pero para que la creatividad se materialice en una solución práctica, es necesario transformar las sugerencias originales en innovación que satisfaga las necesidades de la 
sociedad y para ello es necesaria la intervención del pensamiento convergente que se desarrolla en el hemisferio izquierdo. Como conclusión, los dos hemisferios están especializados pero interconectados; resumiendo, si del hemisferio derecho nace la innovación producto de la capacidad creativa de las personas, del hemisferio izquierdo surge la innovación como resultado de un razonamiento de estructura lógica encomendada a satisfacer una necesidad.

La creatividad se puede definir como la creación de un producto nuevo y útil (Sarkar \& Chakrabarti, 2008, 2011), desde ideas hasta objetos concretos (Mayer, 1999), que se considera multidimensional (Batey, Furnham y Safiullina, 2010; Runco, 2014). Se han incorporado otros conceptos a esta definición, como la llamada idoneidad (Zeng, Proctor y Salvendy, 2011) o la intención del público objetivo de comprar, adoptar y utilizar un producto creativo (Piffer, 2012). La creatividad es una interacción entre habilidades, procesos y el entorno en el que un individuo o grupo produce un producto nuevo y útil dentro de un contexto social (Plucker, Beghetto y Dow, 2004). La economía está considerando la creatividad como capital y, por lo tanto, como un motor del crecimiento económico (McWilliam y Dawson, 2008).

La creatividad puede considerarse el primer paso en el proceso de innovación (Shalley y Perry-Smith, 2001). Además, la creatividad y la innovación pueden afectar la felicidad corporativa en el lugar de trabajo (Kamel, J.A.N., Martins, C.V., Pessanha, M.B. et al , 2017), y, por ejemplo, la motivación de los trabajadores y su capacidad para cumplir sus objetivos (Lyubomirsky, 2008); en muchos casos, las actividades innovadoras se basan con frecuencia en la motivación intrínseca (Amabile y Gryskiewicz, 1989; Jaskyte y Kisieliene, 2006).

El campo de la ingeniería se dirige a la producción de ideas, productos y procesos (Fischer, Oget y Cavallucci, 2016), por lo que es relevante para abordar la resolución de problemas desde una perspectiva innovadora a través de la creatividad. Esta competencia transversal ha sido considerada como una característica importante que puede favorecer el éxito en entornos tanto educativos como profesionales (Daly, Mosyjowski y Seifert, 2014; Mourgues, Tan, Hein, Elliott y Grigorenko, 2016; Vargas Hernandez, Schmidt, Kremer, \& Lin, 2014). En un mundo cada vez más globalizado donde la tecnología impone cambios cada vez más rápidamente, se hace necesario establecer organizaciones innovadoras; esto requiere empleados creativos (Plambech y Konijnendijk van den Bosch, 2015), la materia prima intelectual para hacer este cambio, y un concepto de innovación abierta 
(Chesbrough, 2003). La innovación debe estar presente en cada proceso de las empresas si pretenden establecer ventajas competitivas. El diseño creativo de soluciones de ingeniería permite mejorar la calidad de vida de la sociedad y la situación del planeta (Amabile, 1998; Scott, Leritz y Mumford, 2004). Crear nuevos productos y mercados (Tena, 2010) es, por lo tanto, una de las competencias básicas para el ingeniero del siglo XXI (Kelly, 2013; Wyn, 2009): la innovación se ha convertido en un factor importante en el crecimiento económico y la competitividad corporativa (Yu-Shan, Hung-Chang, Yu-Hung, y Wan-Hsuan, 2018). La innovación requiere la capacidad de generar conceptos nuevos y útiles, descubrir problemas, identificar oportunidades de diseño y resolver contradicciones (Cropley, 2006).

El interés por adquirir la competencia de la creatividad durante la educación del individuo ha aumentado en los últimos tres décadas (Amabile y Pratt, 2016; Charyton, 2014; Jahnke, Haertel y Wildt, 2017). La educación universitaria puede mejorar la creatividad de sus ingenieros a través de la alineación del contenido del curso, la exposición y la capacitación de los ingenieros, la evaluación y el entorno favorable centrado en la adquisición de esta competencia (Daly et al., 2014). Diferentes estudios indican que la práctica y el entrenamiento en habilidades cognitivas específicas producen un aumento en los resultados creativos. Además, no solo es necesaria la creatividad en la generación de ideas, el desarrollo efectivo de conceptos es imperativo para la innovación (Daly, Yilmaz, Christina, Seifert y González, 2012).

Es por eso por lo que los maestros deben alentar y capacitar a los futuros ingenieros en esta competencia (Robinson, 2011) de especial relevancia para su campo. El entorno para poder desarrollar la creatividad se considera relevante (Cropley, 2006) y se pueden identificar diferentes aspectos (Davies et al., 2013): el entorno físico, la disponibilidad de recursos y materiales, la flexibilidad en el tiempo, la disponibilidad de un espacio fuera del aula, la pedagogía seguida, el uso de herramientas de juego y, finalmente, la relación entre los futuros ingenieros y el instructor. La creatividad aplicada a la ingeniería, conocida como creatividad funcional, se puede desarrollar a través de la resolución de problemas (Jesus García-García et al., 2010; Zhou, 2012a).

La buena disposición y la predisposición del profesor es un aspecto fundamental para establecer un entorno propicio para fomentar la creatividad (Hong, Hartzell y Greene, 2009): exponer a los estudiantes de gestión de proyectos a situaciones reales se considera una estrategia esencial para promover una mayor participación así como la respuesta 
sensible y adecuada a la tarea cada vez más compleja de la gestión de proyectos en el mundo real (Córdoba \& Piki, 2012; Meredith Belbin, 2010a).

El reconocimiento de la creatividad en la educación tecnológica es un desafío (Byrge \& Hansen, 2008; Cropley \& Cropley, 2010), ya que los ingenieros no están familiarizados con el mercado y no son vistos como inventores o empresarios (Jahnke et al., 2017).

Los enfoques que combinan los conceptos de creatividad en la Educación Superior en los diseños de cursos aún son raros (Zhou, 2012b), incluso si estas competencias deben considerarse como una de las más relevantes para los futuros ingenieros (Crosier, Purser, \& Smidt, 2007; Gordon et al., 2009). La creatividad se puede medir considerando tanto la evaluación cuantitativa como la cualitativa, y la mayoría de los estudios recientes se basan en una metodología cuantitativa (Long, 2014). Incluso si hay pocos cuestionarios diseñados para medir la creatividad en la enseñanza (Kampylis, Berki, y Saariluoma, 2009; Lemmy et al., 2010; Romina et al., 2004; Scott et al., 2010), los equipos de investigación prefirieron un nuevo enfoque para evaluar ideas y su capacidad para ser implementadas en un proyecto. 


\subsection{Los proyectos}

\subsection{1. ¿Qué es un proyecto?}

Existen numerosas definiciones del concepto de proyecto. Tomando como referencia la etimología del término, la Real Academia de la Lengua define el término proyecto como: "Designio o pensamiento de ejecutar algo" (3a acepción); también como "conjunto de escritos, cálculos y dibujos que se hacen para dar idea de cómo ha de ser y lo que ha de costar una obra de arquitectura o de ingeniería" ( $4^{a}$ acepción). La primera de ellas hace referencia a los aspectos creativos del proyecto, mientras que la segunda indica la composición documental del mismo.

Sin embargo, en el ámbito de la gestión y dirección de proyectos, las definiciones más habituales inciden en los aspectos del uso y control de recursos, tanto materiales como humanos, toma de decisiones, dirección de equipos de trabajo, etc.

Una definición clásica es la de Cleland y King (1975) que proponen que "un proyecto es una combinación de recursos humanos y materiales, reunidos temporalmente en una organización, para conseguir un propósito determinado".

La norma UNE 157001:2014 define los Criterios generales para la elaboración formal de los documentos que constituyen un proyecto técnico, siendo una norma de carácter orientativo (no obligatoria) de gran valor para la redacción de cualquier proyecto de ingeniería.

Por último, la norma ISO 8402, "un proyecto es un conjunto de actividades coordinadas, con un inicio y un final específicos, que persiguen una (1) meta concreta, con (2) restricciones de tiempo, (3) costes y recursos", tal y como se representa en la siguiente figura (Figura 1):

\section{Costes}

Alcance

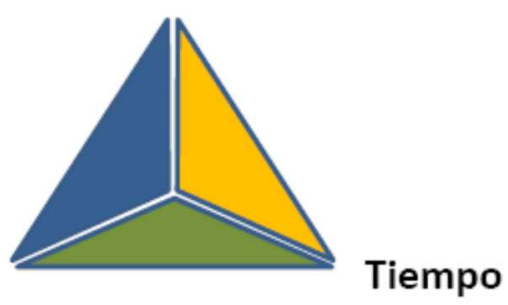

Figura 1. Definición de proyecto. Limitaciones al desarrollo 
El Project Management Institute (PMI), establece el proyecto como un "esfuerzo de carácter temporal llevado a cabo con objeto de crear un producto o servicio único" (PMI, 2017). De esta manera los proyectos existen para desarrollar un producto o servicio novedoso y, por lo tanto, un proyecto es siempre único.

\subsubsection{Dirección y gestión de proyectos}

Según el Project Management Institute (PMI) la gestión de proyectos ${ }^{1}$ "es la aplicación de conocimientos, aptitudes, herramientas y técnicas a las actividades del proyecto, encaminados a satisfacer o colmar las necesidades y expectativas de las entidades $y$ organizaciones involucradas en un proyecto".

Por otro lado, y continuando con esta definición, el International Project Management Association (IPMA) define la disciplina de gestión de proyectos en "la planificación, organización, seguimiento y control de todos los aspectos de un proyecto, así como la motivación de todos aquellos implicados en el mismo, para alcanzar los objetivos del proyecto de una forma segura, y satisfaciendo las especificaciones definidas de plazo, coste y rendimiento. Ello también incluye el conjunto de tareas de liderazgo, organización y dirección técnica del proyecto, necesarias para su correcto desarrollo".

Sintetizando, en el enfoque propuesto mediante estas definiciones se puede afirmar que:

- Dirigir es tomar decisiones, trasladar instrucciones, coordinar recursos, liderar grupos y asumir compromisos al máximo nivel jerárquico.

- Gestionar comprende la determinación de tareas a desarrollar día a día, adelantar las necesidades derivadas de las mismas, programar los medios disponibles, organizar los trabajos que deben efectuarse, asignar los recursos necesarios para ello, ejecutar las órdenes recibidas, supervisar el cumplimiento de estas y, adoptar las medidas para corregir las desviaciones que respecto al plan de trabajo puedan producirse.

La gestión y dirección del proyecto comienza antes de que empiece el proyecto, continúa a medida que se desarrolla y termina cuando finaliza el proyecto (proceso de cierre).

\footnotetext{
${ }^{1}$ Dirección y Gestión de proyectos: traducción del término en inglés “Project Management".
} 


\subsubsection{Certificaciones en gestión de proyectos}

Recientemente se ha establecido una serie de certificaciones que cada vez cuentan con mayor interés de cara a acreditar ante empresas y clientes el conocimiento en este campo.

Existen múltiples certificaciones, entre las que destaca PMP y Prince2.

Project Management Professional (PMP) es una certificación en gestión de proyectos expedida por el Project Management Institute (PMI) ${ }^{1}$, que acredita como gestor de proyectos a nivel universal. Se trata de una certificación base para la gestión de proyectos y su guía de referencia es el libro PMBOK que define procesos, nomenclatura, ciclos de vida y otros aspectos clave.

Es la certificación más extendida a nivel mundial, y para conseguir la certificación se exigen $4.500 \mathrm{~h}$ en liderazgo y dirección de proyectos durante un mínimo de 3 años de experiencia profesional, además de formación específica.

Prince2 es una metodología basada en procesos para la gestión eficaz de los proyectos. Es la certificación original del Reino Unido y se ha extendido como certificación utilizada por gobiernos europeos (Reino Unido, Holanda, Dinamarca entre otros). Prince2 describe los procedimientos para coordinar personas y actividades en un proyecto, como diseñar y supervisar el proyecto y los pasos a seguir si ocurre alguna desviación sobre lo planificado y las medidas correctoras a aplicar.

En esta tesis se utilizará el enfoque del PMI para valorar la influencia de las distintas áreas de conocimiento de la gestión de proyectos y su peso en la herramienta de decisión que se propone. Esta metodología está ampliamente desarrollada en el apartado 2.3

\subsubsection{Innovación: de la idea al proyecto}

Mediante la investigación científica se pretende generar nuevos conocimientos. Habitualmente la ciencia se hace en centros públicos de I+D, que son universidades y organismos públicos de investigación (OPIS).

Con los resultados de la investigación se puede avanzar hacia la investigación aplicada y el desarrollo tecnológico. El proceso de investigación aplicada y desarrollo tecnológico se realiza normalmente en las empresas. Pero, en muchas ocasiones, los centros de I+D también realizan investigación aplicada encargada por empresas mediante convenios de 
transferencia de conocimiento y de tecnología. También, los centros tecnológicos realizan habitualmente tareas de investigación aplicada a través de contratos con las empresas.

La investigación podemos decir que es el método por el que se aplican recursos intelectuales y económicos para generar conocimiento. La innovación, en cambio, es el proceso complementario por el que ese conocimiento se aplica para generar riqueza en forma de bienes productos y servicios de utilidad económica y/o social.

\subsubsection{Tipos de innovación}

Es importante diferenciar los distintos niveles de investigación en función del objetivo que persiguen. Así se distinguen los siguientes conceptos:

Investigación básica: esfuerzo para comprender los principios técnicos o científicos en un campo determinado.

Investigación aplicada: esfuerzo para comprender los principios técnicos o científicos con un objetivo comercial concreto.

Desarrollo: aplicación del conocimiento técnico para producir bienes o servicios de uso comercial

\subsubsection{Orígenes de los proyectos de innovación}

Si reflexionamos sobre las fuentes de oportunidad de los proyectos de innovación podemos observar que tienen habitualmente de los siguientes orígenes:

Cambios tecnológicos: Ahora permiten hacer algo que antes no se podía hacer o de manera más eficaz o eficiente. Algunos cambios tecnológicos posibilitan inmediatamente multitud de innovaciones mientras que otros no. Esto es debido a que en ocasiones es necesario desarrollar tecnologías complementarias o a tecnologías que necesitan ser inventadas antes de que una innovación pueda ser desarrollada.

Cambios políticos y regulatorios: mediante ayudas o subvenciones a la innovación se pueden orientar las líneas de innovación (por ejemplo, en España un caso claro fue el desarrollo de las energías renovables a finales del siglo XX). También en ocasiones se desarrollan nuevos productos o servicios para adaptarse a nuevas normas legales. Por último, en este apartado podemos encontrar la intervención del estado para fomentar la innovación. 
Cambios sociales: aquí se consideran tendencias sociales como la mayor consideración hacia la sostenibilidad que ha generado un reciente protagonismo de aspectos como los Objetivos de Desarrollo Sostenible (ODS) (Objetivos de Desarrollo Sostenible (UN), 2021); tendencias demográficas como el aumento de la población mayor que orienta el destino de fondos europeos para proyectos de innovación basados en esta nueva realidad o sencillamente cambios en la percepción de la sociedad sobre aspectos que orientan los proyectos de innovación.

\subsubsection{Agentes innovadores}

Es imprescindible conocer a los agentes que juegan un papel en la innovación ya que de su interacción se creará un entorno en el que se favorecerán unas u otras realidades debidas a los marcos de actuación.

Estos agentes son:

Los gobiernos, que proponen las políticas investigadoras e innovadoras de los países, financiando proyectos de innovación de terceros y ejerciendo como clientes de innovación.

Las empresas, que desarrollarán la innovación basada en investigación y desarrollo $(I+D)$ con un claro enfoque a mercado.

Las universidades y centros de investigación públicos o privados, mediante la colaboración con las empresas, se encargarán de liderar los estadios iniciales, de investigación básica y desarrollo de licencias tecnológicas para terceros desarrolladas por profesores, personal y estudiantes. En los últimos tiempos, estas instituciones han generado las herramientas para alcanzar el mercado, a través de instrumentos como spin-off o start-ups.

Los individuos, su participación como agentes innovadores es menor que en el pasado a nivel individual, si bien mediante la creación de redes de conocimiento están más presentes que nunca dando un valor renovado a la colectividad (inteligencia colectiva)

\subsubsection{Por qué las empresas hacen $1+D$}


Cuando nos preguntamos sobre las razones por las que las empresas hacen I+D parece evidente la relación con la necesidad de aplicar los posibles resultados al mercado, por la propia naturaleza de las mismas y su orientación hacia el beneficio.

Sin embargo, un análisis más detallado nos permite determinar al menos los siguientes objetivos:

- Adquirir nuevas tecnologías que sean la base a las cuales realizar el lanzamiento de nuevos productos.

- Desarrollar nuevos productos que sustituyan a otros existentes por obsolescencia.

- Diferenciar a sus productos de la competencia.

- Crear posiciones fuertes de propiedad intelectual.

- Protegerse con alianzas.

- Absorber/experimentar con ideas externas.

En función del sector de las empresas será más significativo alguno de estos objetivos o incluso una combinación de los anteriores

\subsubsection{La selección de los proyectos de innovación}

Cuando nos referimos a seleccionar proyectos de innovación ineludiblemente hablamos de gestión de la incertidumbre, ya que mediante la selección tendremos que descartar unos proyectos y escoger otros.

Para ello se puede contar con una serie de acciones estratégicas orientadas a manejar esta incertidumbre como son las siguientes:

- Buscar retornos suficientemente elevados para justificar el coste de soportar la actividad de innovar.

- Minimizar la magnitud de tus inversiones en activos no recuperables utilizando inputs genéricos, comenzando en pequeña escala y convirtiendo los activos fijos en las variables de decisión.

- Mantener la flexibilidad para cambiar de dirección estratégica

- Reasignarlos a aquellos grupos más dispuestos, o que puedan soportar su coste 
Existen distintas herramientas de toma de decisión para la selección de proyectos, que podemos categorizar según sean:

Cualitativas: comparan los proyectos sobre la base de las escalas o palabras

Cuantitativas: evalúan proyectos basados en los cálculos numéricos

Comparativas: enfrentan proyectos uno contra otro

Scoring: comparan proyectos contra escalas estándar

Sin embargo, no se ha encontrado ninguna referencia a la composición de los equipos de trabajo como aspecto a considerar en la toma de decisión de selección de proyectos, algo realmente novedoso en este estudio y que, además, tal y como se argumenta en los siguientes apartados, en el caso de los proyectos de innovación será absolutamente estratégico.

\subsubsection{Los proyectos de innovación}

\subsubsection{Fases de los proyectos}

Un proyecto de innovación se destaca por la característica del riesgo implícito en su ejecución. Otras características están relacionadas con los grados de libertad y el grado de definición (mayores en la investigación básica que en la etapa pre-comercial). También en un entorno cambiante, el ciclo de vida se está viendo modificado, con una fuerte participación del usuario/cliente.

Los proyectos de innovación tienen las mismas fases que cualquier proyecto si bien algunas de las actividades son especialmente originales por la particularidad inherente a la innovación.

- Fase de definición: como resultado de esta fase se decide realizar el proyecto o no. Incluye las siguientes actividades:

$\checkmark$ Análisis de viabilidad técnica y económica: si bien en los proyectos de innovación se analizan otras variables además de la económica para decidir su ejecución sigue siendo vital realizar este análisis

$\checkmark$ Definición de objetivos: se fijarán en función de las restricciones alcance, plazo, coste y calidad pudiendo ser cuantitativos o cualitativos. 
$\checkmark$ Identificación de recursos: es imprescindible asegurar los recursos humanos y de otro tipo al inicio del proyecto

$\checkmark$ Diseño de organización: la identificación del Jefe de Proyecto y las necesidades del equipo será fundamental para asignar las tareas

$\checkmark$ Integración del proyecto en la estrategia de la empresa: todo proyecto debe encajar en las líneas estratégicas de la empresa.

En esta fase, los proyectos de innovación llevarán implícitas características originales como una definición de objetivos más laxa que permita asumir el riesgo que conllevan, un análisis económico con indicadores diferentes a los que se exijan a un proyecto de inversión de la compañía o consideren la posibilidad de solicitar financiación específica (ayudas o subvenciones).

- Fase de diseño: en esta fase se desarrolla la programación de las acciones a seguir mediante las siguientes tareas:

$\checkmark$ Planificación de actividades: enumerar las distintas tareas que se van a realizar detallando los hitos de arranque y fin de cada una de ellas para facilitar así luego su situación temporal y costes asociados.

$\checkmark$ Planificación de recursos: identificar los recursos materiales y sobre todo conformar el equipo de trabajo

$\checkmark$ Planificación de tiempos: programación del cronograma asignado tiempos a las distintas actividades

$\checkmark$ Planificación de costes: identificar los costes asociados a las tareas descritas

$\checkmark$ Riesgos: identificar y analizar los riesgos asociados, así como su tratamiento

$\checkmark$ Documentación: entregables, planos, procedimientos... en definitiva toda la literatura necesaria para realizar la ejecución

En esta fase, los proyectos de innovación conllevan unos riesgos mayores a los de un proyecto tradicional, debido a la incertidumbre que conllevan.

- Fase de ejecución: Revisión y reajuste de la fase de diseño si es necesario. Las tareas son:

$\checkmark$ Desarrollo de las actividades diseñadas

$\checkmark$ Suministro de datos de control

- Fase de evaluación y cierre: es fundamental realizar un cierre adecuado que contemple:

$\checkmark$ Revisión de objetivos 
$\checkmark$ Análisis de resultados: técnicos, económicos y de conocimiento

$\checkmark$ Lecciones aprendidas

$\checkmark$ Transferencia tecnológica (traspaso a otras áreas de la empresa)

$\checkmark$ Los objetivos del proyecto

$\checkmark$ Factores críticos del proyecto (financieros, tecnológicos, legales sociopolíticos, recursos, coste..)

Es importante destacar que, en los proyectos de innovación, el error se asume como resultado de aprendizaje y representa una experiencia de éxito a la que no se debe renunciar. Adicionalmente, en los proyectos de innovación existe una actividad de gran relevancia que es la protección de resultados.

\subsubsection{Protección de Resultados}

Si nos preguntamos por qué es importante la protección intelectual de la innovación, parece que la respuesta inmediata sería: para prevenir la imitación por parte de otros competidores y proteger la tecnología durante un periodo que permita rentabilizar el esfuerzo financiero realizado para su desarrollo. Sin embargo, los competidores pueden imitar la innovación a través de las siguientes vías:

> Reingeniería de los productos (llegar a la misma solución de otra forma)

$>$ Contratando, atrayendo a equipos/personas relacionadas con la innovación que quiere imitarse

$>$ Imitando los proyectos de innovación

$>$ Estudiando las patentes que quieren imitarse

Una patente es un derecho exclusivo concedido por un Estado a un inventor para la utilización en exclusiva (o bajo la autorización del propietario por parte de terceros ) de la innovación patentada por un período limitado de tiempo a cambio de la divulgación de esta (derecho monopolístico)

En todo caso, las invenciones que pretenden patentarse deben ser:

- Novedosas, es decir que no hayan sido previamente inventadas (lo determinan las agencias estatales de patentes)

○ Útiles: Las invenciones deben funcionar, tener un uso y ser funcionales

Los elementos de una patente son:

- Especificaciones: explicación técnica del funcionamiento de la invención para conseguir que resultados. La especificación es la información que los inventores 
tienen que compartir a cambio de disponer de los derechos temporales de utilización exclusiva.

- Cobertura: detalle de los componentes que la integran y las distintas combinaciones que se protegen para conseguir que utilidades. Las coberturas se emplean para proteger una invención respecto a otras que pretendan patentarse.

Entre las ventajas de patentar se pueden destacar las siguientes:

- Retrasar la imitación y protege durante un tiempo los ingresos de la innovación

- Motiva la innovación

- Protección legal de la propiedad intelectual

- Protege la innovación de la compañía a lo largo de la cadena de valor

- Puesta en valor del conocimiento: vía licencias, o venta del activo patentado

- Estrategia defensiva

- Facilita la obtención de financiación a las nuevas empresas (reducen el riesgo)

Como dicho anteriormente, patentar no supone poder controlar todos los aspectos relacionados con la protección intelectual y surgen al menos las siguientes desventajas:

- No siempre frena la imitación. Al contrario, podría acelerarla y por este motivo surge la disyuntiva entre patentar o mantener en secreto

- La ganancia puede ser mayor por mantenerlo en secreto

- La velocidad del cambio tecnológico podría hacer irrelevante la gestión de patentes

- Dificultad y altos costes para probar imitación de productos patentados

- Impacto negativo en el desarrollo de complementarios

- Desviación atención: burocracia versus innovación es un dilema que se debe enfrentar en ocasiones sobre todo si los recursos son limitados

- Perjudica el desarrollo tecnológico de la sociedad (o no...). Cada día más se habla del conocimiento en abierto como se verá en el apartado siguiente y el valor de la innovación abierta frente a la tradicional protección del conocimiento.

Como alternativa a las patentes surge otra fórmula que son los secretos comerciales. En este caso, la prevención de imitación puede lograrse manteniendo las cosas en secreto y reduciendo la difusión de información sobre productos, servicios o cómo se producen.

Las leyes de secretos comerciales confieren garantías a los propietarios intelectuales en el caso de que alguien se aproveche de ellos sin su consentimiento

Los secretos son más convenientes cuando: 
- Los secretos no pueden ser patentados

- El ciclo tecnológico del producto es corto

- Es difícil identificar/acotar el secreto comercial

- La patente es difícil de respetarse/hacerse valer

- La patente se define escuetamente

Las patentes son mejores cuando:

- Los secretos serían fácilmente identificables

- Las patentes se hacen con una definición y cobertura amplia

- Patentes fáciles de defender

- El ciclo de vida del producto es largo (aprox. 20 años)

\subsubsection{Innovación abierta}

Innovación abierta es un término promovido por Henry Chesbrough, profesor y director ejecutivo del centro de innovación abierta en la Universidad de California (Berkeley). La idea principal de la Innovación Abierta (Open Innovation) es concebir la innovación como un sistema abierto en el que tanto agentes internos como externos a la organización participan en dicho sistema.

El concepto Open Innovation (OI) se define como un proceso de innovación, mediante el cual las ideas internas y externas son combinadas en sistemas y procesos donde los requisitos están definidos por un modelo de negocio. (Kratzer et al., 2017). Consiste en una nueva estrategia de innovación en la que las empresas abren sus procesos de innovación al exterior mediante la colaboración con agentes externos que desempeñan un papel de liderazgo. (Gobio, 2016). En este concepto, en lugar de contar con un sistema de innovación cerrado, donde el conocimiento y los medios pertenecían exclusivamente a la organización, se propone abrir el proceso para universidades, centros de investigación o terceros, facilitando una nueva forma de colaboración con entidades externas.

La Ol se ha consolidado como un proceso esencial, ya que los mercados se han vuelto más dinámicos e impredecibles, donde un mundo tecnológico e hiperconectado permite la circulación y adquisición de conocimientos con una amplia y autonomía. Proyectos abiertos como Linux, Wikipedia y otros softwares de ingeniería como gvSIG, openDtect, entre otros, son referencias en sus sectores en términos de colaboración y desarrollo de la innovación. Durante los últimos años, se ha escrito mucho sobre cómo las empresas deberían 
implementar este concepto (Chesbrough, 2003), qué recomendaciones se pueden hacer para aplicar en todos los campos, cuál es el papel de las comunidades y los usuarios en la Ol (Chiaroni et al., 2011) o cuáles son las perspectivas de futuro de este concepto que parece haber llegado para permanecer como una sólida alternativa de innovación (Randhawa et al., 2016; Huizingh, 2011).

En los últimos años, se ha investigado sobre la aplicación de Ol en ingeniería (Saaty, 1980) y más específicamente en el sector energético (Randhawa et al., 2016; Wallin y Von Krogh, 2010). Artículos recientes han puesto el enfoque del éxito de Ol en las personas y la cultura corporativa (Greco et al., 2017). En este contexto, la aplicación de Ol en el sector energético ya se está investigando como una solución para unir los diferentes intereses de los interesados, tales como académicos, gobiernos y empresas (Kratzer et al., 2017) (Figura 2).

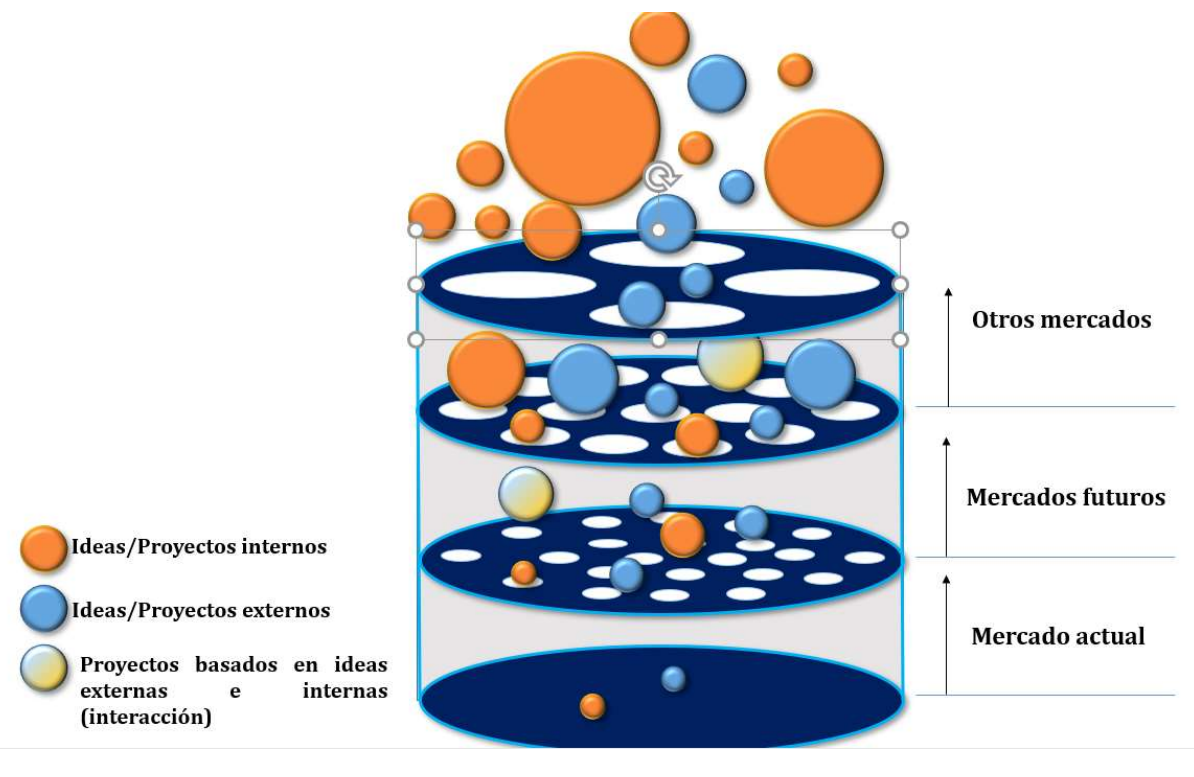

Figura 2. Concepto de Innovación abierta: el proceso para incorporar y desarrollar proyectos innovadores: proceso de creación de valor (M. Dolores Storch de Gracia et al, 2018)

Por lo tanto, la razón por la que se incorpora el concepto de innovación abierta en el presente estudio es porque será un elemento fundamental que considerar a la hora de captar las ideas y posibles proyectos innovadores. De esta manera, mediante la innovación abierta se asegura que se abre el alcance hacia al exterior, captando ese conocimiento e incorporándolo al proceso de creación de valor.

La innovación abierta supone un paradigma que asume que las empresas pueden y deben usar ideas externas, así como ideas y vías internas y externas al mercado para poder 
avanzar en su tecnología. La idea central de la innovación abierta es que, en un mundo de conocimiento ampliamente distribuido, las empresas no pueden confiar totalmente en su propia investigación, pero deben, en cambio, adquirir o licenciar procesos o invenciones (es decir, patentes) de otras empresas. Este acercamiento supone reconocer que el conocimiento ya no es propiedad de la empresa, sino que reside en universidades, empleados, proveedores, clientes y competidores (si las empresas no utilizan los conocimientos que tienen dentro, alguien lo hará...).

Durante el siglo XX la innovación se desarrolló principalmente en el seno de las entidades y por lo tanto en un modo cerrado pero los monopolios de conocimiento de la economía industrial se descomponen y no se prevé que los países industrializados monopolicen la investigación científica avanzada. Las premisas principales de la innovación tradicional incluyen pensar que los mejores expertos en este campo de conocimiento trabajan con nosotros, que para aprovechar nuestra I+D tenemos que descubrir, desarrollar y distribuir el producto por nosotros mismos, que la organización que introduzca primero una innovación en el mercado vencerá, si somos quienes más y mejores innovaciones introducimos en el mercado venceremos y que se debe controlar la propiedad intelectual para que la competencia no se aproveche de ellas.

Sin embargo, "las organizaciones de éxito hoy en día tienen fronteras abiertas y permeables, y compiten extendiéndose más allá de sus cuatro paredes para aprovechar conocimientos, recursos y capacidades externas a ellas". (Stanko, 2017) Entre las razones por las que surge esta corriente se puede destacar que los usuarios o clientes cada vez son más exigentes, los adelantos científicos y tecnológicos se aceleran, el ciclo de vida de los productos es cada vez menor, la globalización aumenta, la movilidad de las personas es cada vez mayor, el nivel de educación y acceso a la información aumenta y las tecnologías se democratizan. Las premisas fundamentales de la innovación abierta suponen asumir que no siempre los mejores expertos trabajan en nuestra empresa, el I+D externo puede añadir mucho valor a la organización, tanto o más que el I+D interno, la I+D no tiene por qué desarrollarse internamente para ser rentable y un modelo apropiado de negocio es más relevante que ser el primero en el mercado. Además, tanto las ideas que surgen del interior como del exterior son fundamentales para la empresa y se puede obtener gran beneficio de la propiedad intelectual realizando compraventa de IPs (Intelectual Properties).

Al preguntarse sobre los elementos clave de la innovación abierta se puede pensar en que el modelo de negocio: aporta cómo la organización genera valor en la cadena de valor, las tecnologías externas: cubren las carencias existentes en la estrategia de innovación de la 
empresa y en la gestión del conocimiento serán aspectos clave la identificación, acceso e incorporación del conocimiento necesario para el desarrollo de nuevos productos o servicios. En este ecosistema las Start-up y Spin-off como organizaciones muy flexibles, adaptativas y enfocadas en actividades concretas favorecen la creación de organizaciones en red. Además, la propiedad intelectual debe ser parte integral de cualquier estrategia tecnológica. Por este motivo, es imprescindible situar la propiedad intelectual en el nivel estratégico.

Según Eric Von Hippel, existe un grado de perturbación entre las distintas fuentes de innovación. Las fuentes de innovación pueden estar al otro lado de las fronteras de la organización, incluso los propios clientes/usuarios pueden ser la fuente de innovación, o los proveedores, fabricantes, o incluso, las distribuidoras o asociaciones distintas. La lista de fuentes de innovación recogería así a los trabajadores, socios, clientes/usuarios, competidores, consultores, asociaciones, departamentos comerciales, departamentos de I+D, think tanks, academia, laboratorios y otras instituciones.

Los beneficios de la innovación abierta son claros:

- Se reducen los costes en los procesos de innovación: especialmente en la fase de generación de ideas, pero adicionalmente en el desarrollo y en la salida de la organización (al aprovechar distintos canales)

- Se genera una aceleración de la innovación: al permitir reducir los ciclos de creación de servicios y productos.

- Incrementa la creatividad en la organización: la fase de generación de nuevas ideas es más diversa que si se desarrollara en los departamentos de I+D

- Establecimiento de un ecosistema innovador: más allá de la creación de alianzas para la colaboración

- Facilita la co-creación de servicios y productos junto a fabricantes y usuarios

- Incrementa el posicionamiento estratégico y de marca a través del acercamiento a los usuarios/clientes.

Sin embargo, no podemos dejar de mencionar los principales obstáculos para su implantación:

- La apertura supone una pérdida de control que hay que estar dispuesto a ceder

- La apertura obliga a que se produzca un cambio en la cultura organizacional para que las personas se sientan cómodas abriendo sus trabajos y se sientan seguros ante posibles juicios de terceros. 
- Gestionar la propiedad intelectual en este entorno sigue siendo un reto con muchas preguntas

- La presencia de una brecha digital y en competencia digital que hace que algunos empleados no puedan estar conectados.

- El modelo de negocio se complica al tener que redefinir la estrategia financiera una vez que no viene de los contenidos

Existen cada vez más ejemplos de Innovación abierta como la creación de comunidades (Lego, Coca Cola,), la escucha activa de los usuarios (Twitter), la apertura de fronteras a ideas del exterior (Peugeot) o el desarrollo de plataformas abiertas (Google, Amazon, etc...) 


\subsection{Metodología PMP}

\subsubsection{Introducción a la metodología PMP}

La metodología PMP (Project Management Professional) propone la definición de la dirección de proyectos como "la aplicación de conocimientos, habilidades, herramientas y técnicas a las actividades del proyecto para satisfacer los requisitos del Proyecto" (PMI, 2017).

Tradicionalmente se ha indicado que un proyecto se basa principalmente en tres requisitos, tiempo, coste y alcance tal y como muestra la figura 3 a).

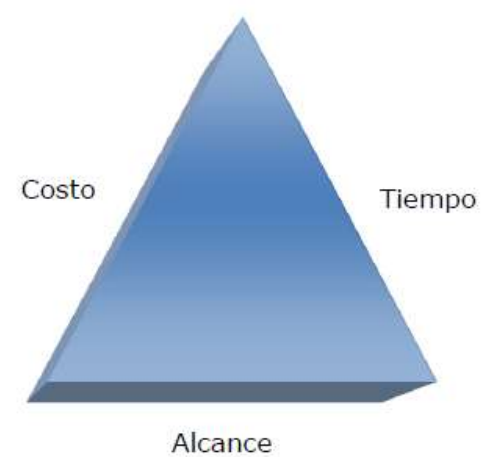

a)

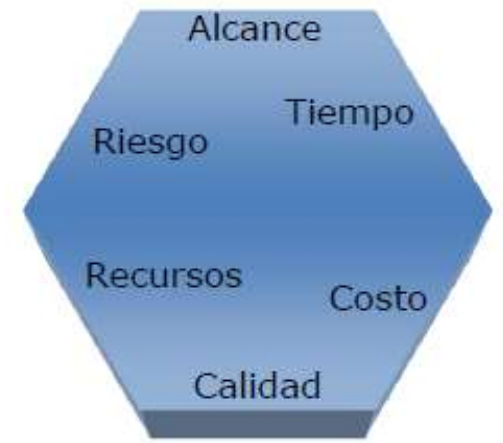

b)

Figura 3. La restricción triple (tradicional) y las restricciones del proyecto (Lledó P. 2017)

Aunque es fundamental que estos sean siempre completados, la metodología del PMP establece que también son necesarios otros requisitos para que el proyecto se complete adecuadamente.

Por este motivo, en la actualidad en la ecuación de restricciones del proyecto se han incorporado nuevos elementos de manera que se consideran las siguientes variables: alcance, tiempo, costo, calidad, recursos y riesgo (PMI, 2017) tal y como se muestra en la figura $3 \mathrm{~b}$ ).

A la hora de definir un proyecto, el PMI (Project Management Institute) lo denomina como "actividad en grupo temporal para producir un producto, servicio, o resultado, que es único". Así mismo, establece que es "temporal" ya que tiene un comienzo y un fin definido, y por lo tanto tiene un alcance y recursos definidos y es "único" ya que no es una operación 
rutinaria, sino un conjunto específico de operaciones diseñadas para lograr una meta particular (PMI, 2017).

Por ello, todo proyecto debe de estar correctamente definido; con unas directrices, a priori, establecidas. En la propia definición viene implícito que cada proyecto es único y, por lo tanto, debe de ser tratado de manera distinta a otros proyectos (PMI, 2017).

\section{Proyecto exitoso}

En la década del 60'se define que un proyecto es exitoso basándose exclusivamente en su calidad. A partir de la década del 80'se define el éxito de un proyecto cuando, además de respetar la calidad, cumple con los presupuestos y plazos definidos en el plan del proyecto. En la década del 90' no basta con cumplir la calidad, presupuesto y plazos para que un proyecto sea exitoso, sino que, además de estos objetivos, es necesario que el proyecto cubra la "satisfacción del cliente". A estas cuatro características de proyecto exitoso agregamos a partir del nuevo siglo también la "sostenibilidad o cuidado".

En la actualidad, para que un proyecto sea exitoso en la actualidad se considerarán los requisitos siguientes:

- Alcance de calidad

- Presupuesto

- Plazo

- Beneficios del proyecto (Objetivos del cliente)

- Sostenibilidad

La clave de un proyecto de éxito pasará por definir claramente los principales parámetros exitoso en las fases iniciales del proyecto. Según el PMI, lograr proyectos con éxito significará que (PMI, 2017):

- Se tiene un cliente satisfecho

- Se cumple con el alcance acordado entre las partes

- Se cumplen los plazos, presupuestos y calidad

- Se trabaja con recursos humanos comprometidos con el proyecto

- No se comenten errores de interpretación debidos a mala comunicación

- Se previene en vez de reparar, con una buena gestión de riesgos

- No hay un desgaste con procesos de adquisiciones y contrataciones que dificultan el proyecto

- Se gestionan correctamente los múltiples interesados del proyecto 


\subsection{2 Áreas del conocimiento}

Con base en la Guía del PMBOK® (PMI, 2017) existen diez áreas del conocimiento:

1. Gestión de la Integración

2. Gestión del Alcance

3. Gestión del Cronograma

4. Gestión del Coste

5. Gestión de la Calidad

6. Gestión de los Recursos

7. Gestión de las Comunicaciones

8. Gestión de los Riesgos

9. Gestión de las Adquisiciones

10. Gestión de los Interesados

La gestión de la integración cubre las otras nueve áreas del conocimiento. Además, las 9 áreas no son independientes entre sí, sino que se generan interrelaciones entre ellas.

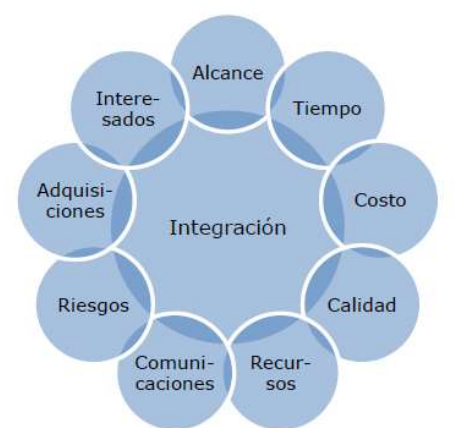

Figura 4. Áreas de Conocimiento PMP (Lledó P. 2017)

Se repasan a continuación las áreas de conocimiento: 


\subsubsection{Integración}

Durante la gestión de la integración, se realiza la coordinación de todos los procesos del proyecto y sus interrelaciones, pero también se definen las reglas para crear y transferir el conocimiento, se gestionan los recursos compartidos y asignan recursos, además de decidir sobre las solicitudes de cambios y analizar alternativas, monitorear los avances del proyecto, recolectar datos para obtener información del proyecto y comunicar el grado de avance a los interesados así como asegurar que se complete todo el trabajo y cerrar las fases

\subsubsection{Alcance}

El éxito de un proyecto supone implementar procesos de gestión del alcance que aseguren que el trabajo requerido, y sólo ese, se lleve a cabo. Para ello será necesario crear una estructura de desglose del trabajo (EDT) que implica dividir el proyecto en componentes menores para facilitar la planificación del proyecto. Es de vital importancia realizar este proceso en la planificación de los proyectos para asegurar el posterior éxito del mismo.

\subsubsection{Cronograma}

Un cronograma es un esquema que incluye todas las actividades con sus plazos. Puede tener distintos formatos: diagramas de barras (Gantt), cronogramas de hitos, o diagramas de red. Un buen cronograma será fundamental para conocer cuándo y cómo se van a entregar los servicios, productos o resultados acorde al enunciado del alcance. También el. cronograma servirá como herramienta principal de comunicación para gestionar a los interesados e informarles del estado de avance del proyecto. Los procesos que incluye una adecuada gestión del cronograma suponen en primer lugar una planificación de la gestión del cronograma, definición de actividades, secuenciación de dichas actividades, estimación de la duración de las mismas, desarrollo del cronograma y para finalizar un adecuado control del cronograma.

\subsubsection{Coste}

Cualquier proyecto tiene una limitación de presupuesto por lo que la gestión e los costes será fundamental para alcanzar un proyecto exitoso. 
Los procesos que se incluyen en este capítulo incluyen planificar adecuadamente los costes, estimar los costes, determinar el presupuesto y controlar los costes.

Planificar los costes supone establecer y documentar lo necesario para gestionar los costes a lo largo del proyecto. En esta etapa es necesario determinar el nivel de precisión, variaciones y limites que se permiten a los costes.

Estimar los costes contempla obtener un primer cálculo a partir de datos de otros proyectos o de la suma de menores partes y a partir de estos recursos obtener un coste aproximado de cada actividad del proyecto.

Determinar el presupuesto implica conocer la planificación y estimación de costes pero también el cronograma y la disponibilidad de recursos.

Por último, en el control de costes se sigue el avance de los costes del proyecto y se informa de cualquier desviación cambio que necesite ser aprobado.

\subsubsection{Calidad}

Según la American Society for Quality la definición de calidad es la siguiente: "El grado en el que un proyecto cumple con los requisitos". La gestión de la calidad implicará por tanto que el proyecto satisfaga las necesidades por las que se acometió. Para esto será necesario que se conviertan las expectativas y necesidades de calidad de los interesados en requisitos del proyecto. , se logre la satisfacción del cliente si el proyecto produce lo planificado y el producto cubre las necesidades reales., se prioricen acciones de prevención en lugar de inspección y se busque de forma permanente la perfección mediante la mejora continua

\subsubsection{Recursos}

Los recursos pueden ser físicos (equipos, materiales, insumos, instalaciones, infraestructuras, ...) o humanos. El conocimiento para gestionar recursos físicos suele ser diferente al necesario para la gestión de recursos humanos. "Los proyectos no son sólo planillas de cálculos, diagramas de Gantt y planes. Las personas serán las que harán realidad un proyecto exitoso y de allí la importancia de saber liderarlos, motivarlos y retribuirlos de manera apropiada" (PMI, 2017) 
Un plan de gestión de recursos debe incluir guías para la identificación y adquisición de los recursos., un organigrama del proyecto: estructura jerárquica del equipo, roles, responsabilidades, autoridad, competencias, necesidades y planes de capacitación, métodos para desarrollar al equipo, plan de reconocimientos y recompensas, convenios colectivos de trabajo, normas de seguridad laboral, métodos para monitorear la disponibilidad de recursos y para terminar el plan de liberación de recursos que favorecerá para una transición anticipada y gradual de los próximos proyectos.

\subsubsection{Comunicaciones}

La habilidad más importante para dirigir un proyecto es saber comunicar. Para una comunicación exitosa él se deben considerar dos aspectos fundamentales (PMI, 2017):

$1^{\circ}$ Definir la estrategia de comunicación comprendiendo las necesidades del proyecto y de los interesados.

$2^{\circ}$ Gestionar y monitorear la efectividad de las comunicaciones

\subsubsection{Riesgos}

El riesgo es algo incierto que, si se llegara a producir, afectaría de forma positiva o negativa los objetivos del proyecto. De esa manera, un evento desconocido podría ser algo malo (amenaza) o bueno (oportunidad). La incertidumbre existe cuando no se conoce la probabilidad de ocurrencia de un evento, sin embargo, en una situación de riesgo se puede estimar la probabilidad de ocurrencia. "El riesgo no se cuantifica sólo por su probabilidad de ocurrencia, sino también por su impacto sobre los objetivos del proyecto (alcance, tiempo, costo, calidad)". (PMI, 2017)

Una buena estimación de los beneficios o costes que se pueden esperar de un evento de riesgo se puede obtener multiplicando su probabilidad de ocurrencia por el impacto.

Valor monetario esperado $=$ Impacto $\mathrm{x}$ Probabilidad

Según el impacto y la probabilidad de cada riesgo que se identifica, se puede trabajar con matrices de estrategias de respuesta al riesgo como la que se muestra a continuación. 


\begin{tabular}{|c|c|c|c|c|c|}
\hline Impacto & $\begin{array}{c}\text { Muy bajo } \\
1\end{array}$ & $\begin{array}{c}\text { Bajo } \\
2\end{array}$ & $\begin{array}{c}\text { Moderado } \\
3\end{array}$ & $\begin{array}{c}\text { Alto } \\
5\end{array}$ & $\begin{array}{c}\text { Muy alto } \\
10\end{array}$ \\
\hline $\begin{array}{c}\text { Muy baja } \\
1\end{array}$ & Aceptar & Aceptar & Aceptar & Aceptar & $\begin{array}{c}\text { Transferir } \\
\text { o Mitigar }\end{array}$ \\
\hline $\begin{array}{c}\text { Baja } \\
2\end{array}$ & Aceptar & Aceptar & Aceptar & $\begin{array}{l}\text { Transferir } \\
\text { o Mitigar }\end{array}$ & Evitar \\
\hline $\begin{array}{c}\text { Moderada } \\
3\end{array}$ & Aceptar & Aceptar & Aceptar & $\begin{array}{l}\text { Transferir } \\
\text { o Mitigar }\end{array}$ & Evitar \\
\hline $\begin{array}{c}\text { Alta } \\
4\end{array}$ & Aceptar & Aceptar & $\begin{array}{l}\text { Transferir } \\
\text { o Mitigar }\end{array}$ & Evitar & Evitar \\
\hline $\begin{array}{c}\text { Muy alta } \\
5\end{array}$ & Aceptar & $\begin{array}{c}\text { Transferir } \\
\text { o Mitigar }\end{array}$ & $\begin{array}{l}\text { Transferir } \\
\text { o Mitigar }\end{array}$ & Evitar & Evitar \\
\hline
\end{tabular}

Figura 5. Matriz de estrategias de respuesta al riesgo (Lledó P. 2017)

\subsubsection{Adquisiciones}

Si bien no es necesario que el director de proyecto sea experto en adquisiciones, se puede poner en riesgo el éxito del proyecto si no maneja adecuadamente algunos conocimientos sobre esta materia. (Lledó P. 2017). Los principales roles del director de proyecto en la gestión de las adquisiciones suponen confirmar que el contrato se adecúa a as necesidades del proyecto, asegurar que el contrato incluye todos los requisitos del alcance, confirmar que el plazo de contratación esté incluido en el cronograma del proyecto, se incorporan actuaciones de mitigación de riesgos en el contrato, comprender todos los términos del contrato, negociar el contrato para asegurar la relación con el vendedor (winwin) y gestionar el contrato y sus cambios.

\subsubsection{Interesados}

La gestión de interesados supone "identificar, analizar y desarrollar relaciones con todas aquellas personas u organizaciones que se verán afectadas por el proyecto o que afectarán de alguna forma al proyecto". (PMI, 2017)

El director del proyecto deberá administrar las expectativas de los interesados y supervisar los impactos de aquellos en el proyecto. Los buenos directores de proyecto desarrollarán estrategias de comunicación y gestión con los interesados para que se involucren en las decisiones principales del proyecto y de esto modo se facilite la ejecución 


\subsubsection{Procesos}

El ciclo de vida del proyecto incluye las diferentes fases del proyecto desde su comienzo hasta su fin. Puede haber dos tipos de relación entre las fases de un proyecto (PMI, 2017):

- Predictivo: mientras no finaliza la fase anterior, no comienza su sucesora. Este ciclo de vida supone seguir un plan desde el inicio hasta el cierre del proyecto. En estos casos, el alcance, tiempo y coste están bien definidos en las fases iniciales del proyecto (inicio y planificación).

- Adaptativo: al finalizar la fase 1 comienza 2, y al finalizar 2 comienza de nuevo 1, y así sucesivamente de manera iterativa. Este tipo de interrelación es muy frecuente en metodologías ágiles.

\section{Grupos de procesos}

No se debe confundir el ciclo de vida de un proyecto con los grupos de procesos que son cinco: inicio, planificación, ejecución, monitoreo-control y cierre.

Se concibe un proceso como se muestra en el siguiente gráfico:

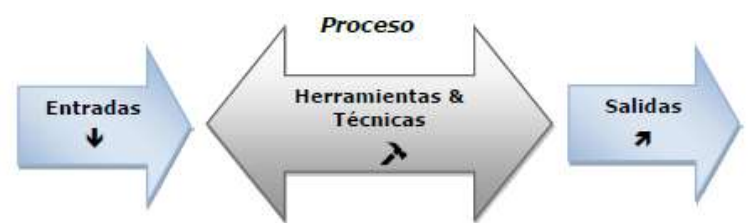

Cuando existen procesos relacionados, las salidas de un proceso suelen ser entradas del próximo proceso.
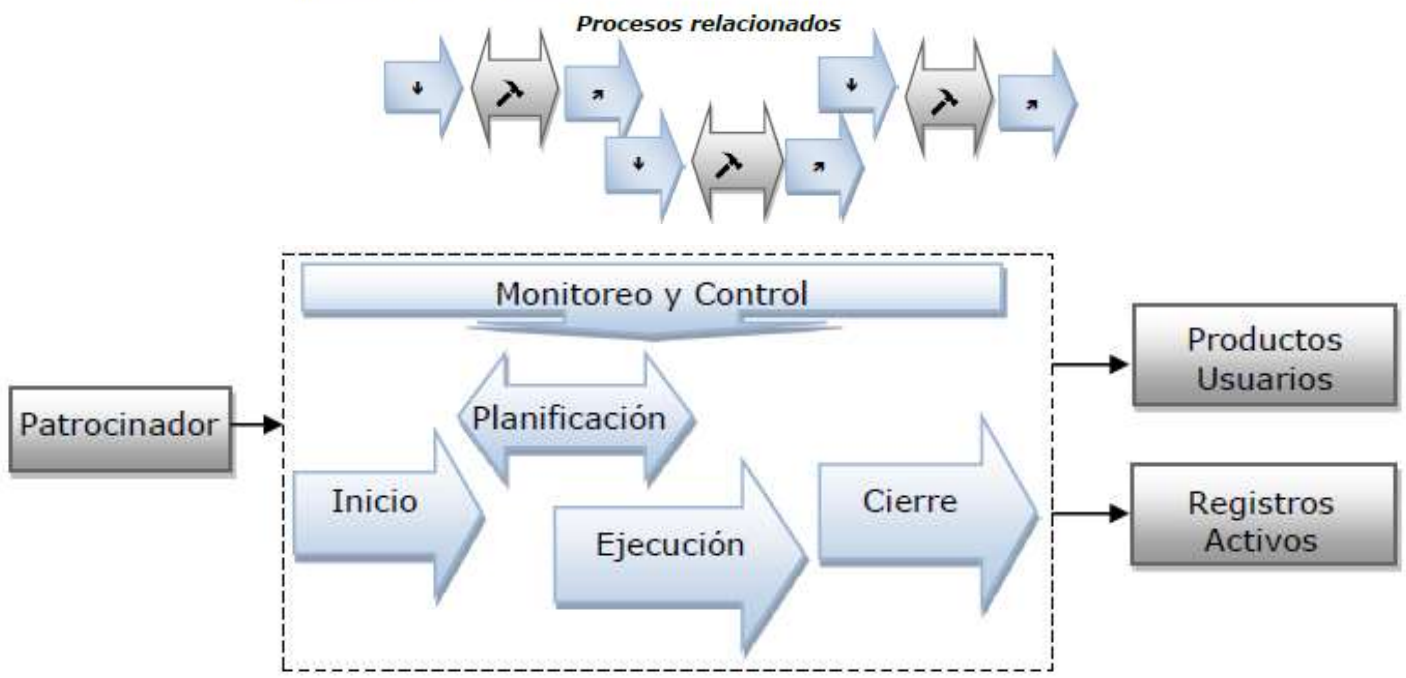

Figura 6. Esquema de proceso y grupos de procesos (Lledó P. 2017) 
En proyectos grandes, estos cinco grupos de procesos se pueden repetir para cada fase del proyecto.

Cada uno de estos grupos de procesos tiene procesos específicos con sus entradas, herramientas y salidas. Todo proyecto requiere procesos y los procesos, a lo largo del ciclo de vida del proyecto, pueden ser (Lledó P. 2017):

- Únicos: ejemplos de este tipo de procesos son "Desarrollar el Acta de Constitución" o "Cerrar el proyecto";

- Periódicos: como puede ser la "Adquisición de Recursos";

- Continuos: un ejemplo sería la "Definición de actividades" en proyectos con ciclo de vida adaptativo

Se puede pensar en las entradas del proceso respondiendo a las siguientes preguntas: ¿qué necesito para comenzar? Las herramientas servirán para procesar esas entradas y obtener las salidas de esa forma: ¿qué obtengo como resultado? . Tanto en la Guía del PMBOK® como en las Normas ISO21500, se hace mención de los siguientes cinco grupos de procesos de la dirección de proyectos:

1. Procesos de inicio: se definen los objetivos del proyecto por la organización, se identifica a los principales interesados, el patrocinador designa al director de proyecto y autoriza de manera formal el inicio del proyecto.

2. Procesos de planificación: se define el alcance del proyecto por los interesados y se afinan los objetivos; se desarrolla el plan para la dirección del proyecto por el equipo que será la guía para un proyecto exitoso.

3. Procesos de ejecución: se aseguran todos los recursos para implementar el plan para la dirección del proyecto por el director del proyecto.

4. Procesos de monitoreo y control: se supervisan el avance del proyecto y aplican acciones correctivas por el director del proyecto y su equipo.

5. Procesos de cierre: se aceptan formalmente los entregables del proyecto por el cliente.

Se identifican 49 procesos para la dirección de proyectos según la siguiente figura: 


\begin{tabular}{|c|c|c|c|c|c|}
\hline Área & Inicio & Planificación & Ejecución & Control & Cierre \\
\hline Integración & 1 & 1 & 2 & 2 & 1 \\
\hline Alcance & & 4 & & 2 & \\
\hline Cronograma & & 5 & & 1 & \\
\hline Coste & & 3 & & 1 & \\
\hline Calidad & & 1 & 1 & 1 & \\
\hline Recursos & & 2 & 3 & 1 & \\
\hline Comunicaciones & & 1 & 1 & 1 & \\
\hline Riesgos & & 5 & 1 & 1 & \\
\hline Adquisiciones & & 1 & 1 & 1 & \\
\hline Interesados & 1 & 1 & 1 & 1 & \\
\hline TOTAL & $\mathbf{2}$ & $\mathbf{2 4}$ & $\mathbf{1 0}$ & $\mathbf{1 2}$ & $\mathbf{1}$ \\
\hline
\end{tabular}

Figura 7. Procesos según áreas de conocimiento y grupos de procesos

Así, los dos procesos del grupo de inicio son:

1. Desarrollar el Acta de Constitución del proyecto (Integración)

2. Identificar a los Interesados (Interesados)

No siempre es necesario desarrollar todos los procesos; en cada proyecto, los procesos a aplicar dependerán del tipo de proyecto, el contexto, los recursos de la organización, etc. Cabe resaltar que los grupos de procesos no son campos independientes entre sí, y adicionalmente no es necesario que termine un grupo al $100 \%$ para que empiece el siguiente grupo. 


\subsection{Equipo multidisciplinar. Trabajo en equipo}

La clave de un buen trabajo en equipo es la participación efectiva. No se puede asumir que se va a lograr un buen trabajo en equipo con solo reunir a suficientes personas con talento para realizar una tarea conjunta, ni siquiera, aunque los objetivos sean claros. Por ejemplo, el deporte está lleno de ejemplos de equipos que fracasaron a pesar de haber reunido al mayor número de grandes figuras. En estos casos. la combinación era inadecuada porque no fueron capaces de integrar sus esfuerzos para alcanzar el objetivo principal de la victoria del equipo. El mismo tipo de analogía también ocurre en muchos equipos empresariales. Por supuesto el talento individual es indispensable para el éxito en cualquier organización, pero cada vez más las empresas consideran que trabajo en equipo es esencial. La excelencia en el trabajo en equipo se consigue a través de varios ingredientes. Uno de ellos es el liderazgo ya que puede proporcionar una visión al equipo y favorecer su éxito. Sin embargo, el trabajo en equipo es un proceso plural. No lo puede desarrollar una sola persona. "Cuando la gente se une para formar un equipo, cada miembro aporta un conjunto personal de conocimientos, destrezas, valores y motivaciones". (Buvik, 2016); (Buvik, 2017).

Es inevitable mencionar a Daniel Goleman si se habla de liderazgo, ya que este autor fue definitivo a la hora de aplicar su gran teoría de la inteligencia emocional en el liderazgo. En su libro "Primal leadership: realizing the power of emotional intelligence" (D. Goleman, R. Boyatzis y A. Mckee, 2002), Goleman aplicó su teoría de la inteligencia emocional al mundo de la empresa y las relaciones con los trabajadores, con el objetivo de analizar las características de un buen líder. Es habitual encontrar líderes empresariales con gran preparación técnica y experiencia en el negocio, pero suelen adolecer de conocimiento sobre el manejo de las emociones propias y ajenas.

Para Goleman, el líder debe ser emocionalmente inteligente, y para ello saber leer y aprovechar las emociones de los miembros del equipo para crear un clima de trabajo idóneo. A grandes rasgos considera que el liderazgo puede ser resonante ( si el líder sintoniza con los sentimientos del equipo y los dirige hacia un estado emocionalmente positivo mediante el optimismo y el entusiasmo) o disonante (si el líder promueve las emociones negativas y favorece los sentimientos de rencor, frustración o rabia)

De acuerdo con Goleman, Boyatzis y Mckee existen seis estilos de liderazgo y los mejores líderes saben hacer uso con flexibilidad de los seis estilos y pasar por ellos si las circunstancias lo demandan. Cada estilo se asienta sobre competencias particulares y 
genera un impacto distinto sobre el clima por lo que pueden resultar apropiados según sea la situación a resolver. Los cuatro primeros alientan la resonancia, mientras que los otros dos pueden ser necesario peso deben ser utilizados con cuidado por ser disonantes.

Tabla I: Estilos de liderazgo

\begin{tabular}{|c|c|c|c|c|c|}
\hline Visionario & Coaching & Afiliativo & Democrático & Timonel & Autoritario \\
\hline $\begin{array}{l}\text { Mediante } \\
\text { visión } \\
\text { inspiradora } \\
\text { guían a las } \\
\text { empresas } \\
\text { hacia una } \\
\text { visión global } \\
\text { dando } \\
\text { confianza a } \\
\text { sus equipos. } \\
\text { Se gestiona } \\
\text { desde un } \\
\text { único } \\
\text { objetivo }\end{array}$ & $\begin{array}{l}\text { Desarrollan } \\
\text { personas, a las } \\
\text { que impulsan a } \\
\text { ser el } \\
\text { conductor. Con } \\
\text { él se tiene } \\
\text { responsabilidad } \\
\text { y visión a corto } \\
\text { y medio plazo }\end{array}$ & $\begin{array}{l}\text { Es blando y } \\
\text { paternalista. } \\
\text { Procurará } \\
\text { buenas } \\
\text { relaciones } \\
\text { personales } \\
\text { en el equipo }\end{array}$ & $\begin{array}{l}\text { el que pide } \\
\text { opinión a sus } \\
\text { colaboradores } \\
\text { y decide } \\
\text { considerando } \\
\text { a sus } \\
\text { subordinados }\end{array}$ & $\begin{array}{l}\text { Es limitativo } \\
\text { ya que para } \\
\text { él las } \\
\text { personas son } \\
\text { un } \\
\text { instrumento } \\
\text { para su } \\
\text { propio logro. } \\
\text { Solo mide } \\
\text { objetivos } \\
\text { cueste lo que } \\
\text { cueste y no } \\
\text { pide a nadie } \\
\text { lo que no se } \\
\text { pide a si } \\
\text { mismo }\end{array}$ & $\begin{array}{l}\text { Dirige con } \\
\text { autoridad, } \\
\text { delega muy } \\
\text { poco y se } \\
\text { debe utilizar } \\
\text { sólo en } \\
\text { situaciones } \\
\text { críticas ya } \\
\text { que no sirve } \\
\text { para motivar }\end{array}$ \\
\hline & & & & & \\
\hline & Liderazgo res & ante & & Liderazgo & sonante \\
\hline
\end{tabular}

Los autores anteriores establecen que en la inteligencia emocional tiene un gran peso la genética, pero también se puede adquirir por lo que se puede desarrollar aun partiendo de distinto nivel de partida mediante motivación y compromiso. El desarrollo del liderazgo requiere también reeducar el cerebro emocional mediante la práctica y repetición ( $D$. Goleman, R. Boyatzis y A. Mckee, 2002).

Otro autor clave para entender la relación entre liderazgo y equipo es Dale Carnegie, el cual considera que el optimismo es el talento fundamental de cualquier líder. El optimismo aporta seguridad y confianza en creer que la tarea saldrá bien y consigue que el líder motive y logre la confianza necesaria para tener éxito. La actitud de los líderes optimistas hace que conserven la capacidad para ser felices a pesar de los obstáculos y favorecen que puedan liderar con éxito. El libro más conocido de Carnegie es "Como ganar amigos e influir sobre las personas" (D. Carnegie, Editorial Simon \& Schuser 1936). La gran aportación de Carnegie fue proponer que el líder además de influir en los demás, debe agradarles y saber tratar con ellos, relacionarse de una manera asertiva, criticar objetivamente y de manera constructiva y hacer crecer su liderazgo mediante la mejora de las relaciones con los demás. 
Otro aspecto fundamenta en la perspectiva del equipo es la noción de sinergia y debe siempre por tanto ser un objetivo al alcance de todos los equipos en todas las empresas (Chiocchio, F. ,2015). En este sentido, parece muy necesario diferenciar lo que es un grupo de lo que es un equipo: Un grupo es un conjunto de personas con un objetivo común, entre cuyas características destaca que es demasiado numeroso como para que se generen roles de equipo (relaciones de dependencia). Un equipo es "un número limitado de personas, seleccionadas para trabajar juntas de manera responsable y coordinada en favor de un objetivo compartido y de tal manera que cada una pueda realizar una contribución distintiva (interdependencia)". (RAE, 2018)

Además en el trabajo en equipo se destaca algunas acciones que se facilitan:

- reconocer la contribución única de cada persona al equipo

- estudiar de manera más eficiente la situación de partida

- comunicación interpersonal que permite más energía dirigida hacia la tarea

- asignar de manera eficiente el trabajo en base a las fortalezas y experiencia de cada miembro

- calidad en la toma de decisiones a través de la sabiduría de cada miembro del equipo

Sin embargo, el trabajo en equipo supone algunas necesidades entre las que se destacan:

- disponer de las personas apropiadas en el momento adecuado

- asignar funciones concretas a cada persona integrante del equipo

- generar un sistema de comunicación entre los distintos miembros del equipo

Como conclusión, se puede decir que existen grandes ventajas en el trabajo en equipo pero construir y gestionar equipos es difícil, e incluso los mejores directores se equivocan a veces. (Gil, 2012). Para que la gente encuentre una razón para trabajar como miembro de un equipo, necesita un objetivo común y un sentido de identidad. (Gómez, 2016)

Es importante destacar que existen técnicas en la formación de equipos, y puede hacerse BIEN o MAL. Cuando se hace bien, un equipo eficaz puede superar todas las expectativas razonables dadas a sus miembros individuales, es decir, un equipo tiene un efecto sinérgico $(1+1>2)$. (Duhigg,2016). Esto es especialmente cierto cuando las habilidades perspectivas y experiencias de los miembros son diversas pero complementarias. La diversidad permite responder a cada desafío a su manera y en equipo se aumenta la 
productividad, fomenta el compromiso y estimular la innovación (Amiguet, 2017). Sin embargo, si se hace mal, los equipos se pueden convertir en catalizadores de fallos de comunicación, límites de roles poco claros, mala asignación de trabajos o roles; todo esto obstaculiza el éxito de todos los involucrados (individuo/equipo/organización). (Drummond, 2017)

\subsubsection{Presentación teoría Belbin de selección de equipos}

El Dr. Meredith Belbin definió los roles de equipo durante una investigación única sobre equipos que se desarrolló en la Henley Business School (Belbin, 2018) y que se basaba en un juego de simulación de negocio. En 1969, se le propuso al Dr. Belbin utilizar este business game como inicio de un estudio sobre el comportamiento de los equipos. Este fue el comienzo de una extensa investigación que ayudó al Dr. Meredith Belbin a publicar en 1981 su "Teoría de roles de equipo Belbin". Esta teoría, enorme y vigente hoy en día, es considerada una de las principales dentro del área de la psicología y cuya consecuencia es la manera de desarrollar y entender el trabajo en equipo.

La teoría de Belbin propone, como se establece en el epígrafe anterior que a la hora de configurar un equipo se hacer bien o mal. Si se van a construir equipos se deben configurar bien y aquí es donde la teoría de Belbin puede ayudar. Belbin propone que el resultado del trabajo en equipo es efectivo cuando sus miembros trabajaran como "jugadores de equipo" - donde cada jugador entiende cuán importante es para todos cooperar y trabajar con un objetivo común. Cuando todos hacen su trabajo bien, esto incrementa las metas que el equipo puede conseguir (Belbin, 1981). Es clave para esto que cada persona sepa lo que aporta al equipo (desde el punto de vista funcional y de comportamiento). Belbin sugiere que cada persona tiene un doble papel: un rol funcional (determinado por "Qué hace en el equipo") y un rol de equipo (determinado por "Cómo lo hace"). El niño genio, el trabajador constante, el productor de ideas, el esclavo leal a la compañía... son gente que conocemos o con los que hemos trabajado... Individualmente tienen limitaciones importantes, pero si les damos un papel en un equipo pueden generar un equipo imbatible. Se podría concluir por tanto que si bien nadie es perfecto, un equipo puede serlo.

Muchas empresas buscan a la persona adecuada para desarrollar una buena gestión y se preocupan de las cualidades, experiencias y logros de las personas Sin embargo todos sabemos que la persona IDEAL no existe. Al enumerar las cualidades del buen gestor 
vemos que muchas cualidades son excluyentes: debe ser enérgico pero sensible a las personas, dinámico pero paciente, comunicarse bien, pero escuchar atentamente, tomar decisiones, pero reflexionar. Todo a la vez no es posible y aunque lo fuera, aunque encontráramos a esta maravillosa persona podría irse un día. Sin embargo, un equipo sí puede reunir estas cualidades y no suelen irse todos a la vez y por esta razón el éxito de la gestión se debe fundamentalmente al equipo. Un equipo puede atesorar las cualidades necesarias, puede renovarse reclutando nuevas personas y acumular gran cantidad de experiencia compartida y puede estar en 10 lugares a la vez. Todos hemos visto como una persona con gran éxito en un equipo cuando ha cambiado de equipo no ha lucido tanto, hemos visto equipos eficaces que se destruyen por el ascenso de individuos sin considerar al resto del equipo; también hemos visto equipos que producían una calidad y cantidad de trabajo mucho mayores que la suma del trabajo que los individuos hubiera podido producir individualmente. (Maxwell, 2001)

Toda esta exposición, habitualmente enfocada en la empresa es posible trasladarla a las aulas, y de ahí el objetivo principal de este trabajo, ya que cada vez más se busca enfocar el aprendizaje de los alumnos hacia el mundo profesional, donde el trabajo en equipo está cada vez más valorado (Borrell, 2004). Además, la manera de trabajar en la empresa se traslada mucho más actualmente a las aulas, donde se trabaja cada vez más de manera colaborativa. La conclusión es que sin ignorar o descuidar al individuo, se debe prestar mucha mayor atención a los equipos: a su selección, desarrollo y formación, pero sobre todo a su motivación, composición, psicología y comportamiento. El primer problema que enfrentamos es que la psicología ha estado tradicionalmente orientada a individuos y el conocimiento de equipos de éxito es muy escaso. El Dr. Meredith Belbin de la Universidad de Investigación de formación industrial obtuvo una respuesta convincente y ampliamente documentada que ayudó de manera crucial a entender el funcionamiento de los grupos y como hacerlos trabajar mejor.

El descubrimiento fundamental de Belbin, tal y como se introdujo al comienzo de este apartado, es que todos los miembros de un equipo de gestión tienen un doble papel. El primer papel, el papel funcional, es obvio (ingeniero de producción, contable, ejecutivo de marketing, etc....) pero el segundo papel que llama el "papel de equipo" es mucho menos evidente y sin embargo todos somos un poco conscientes de él desde que entramos en un equipo (todos sabemos que Manuel tiene ideas genial, Juan quiere que se tomen las decisiones y asignen tareas y Fran echa por tierra las propuestas de los otros..) pero 
además sabemos que Manuel, Juan y Fran exhiben esas características en cualquier equipo .

\subsubsection{Utilidad de la teoría de Belbin}

El Dr. Belbin desarrolló identificó los roles de equipo mediante la observación de equipos durante 7 años y consiguió un nivel de predicción casi perfecto. Buscaba identificar 4 factores en sus pruebas: Inteligencia, Dominio, Introversión/Extroversión y Estabilidad/Ansiedad.

Adicionalmente la teoría de Belbin se basa en 3 premisas principales (Belbin, 1981):

1. Si formas un equipo con individuos con el conocimiento de donde encaja cada perfil podrás dejar que la energía del equipo se centre en la tarea para la que se formó en vez de consumir tiempo en conocer lo que espera cada uno de ellos del otro

2. Todos nosotros tenemos patrones de comportamiento en grupos o situaciones de equipo (conocidos como Roles de equipo)

3. El equipo puede mayor que la suma de las partes por la sinergia que se produce por la diversidad de roles.

A las premisas anteriores se añaden otras que se consideran al aplicar la teoría de Belbin: 1. Las personas útiles en el equipo son aquellas que poseen puntos fuertes o características que satisfacen una necesidad, no duplicando aquellas que ya existen.

2. Los equipos son una cuestión de equilibrio se necesitan personas que se equilibren mutuamente en sus roles de equipo.

3. En una persona pueden observarse uno o dos roles de equipo. Si se observan dos, uno de ellos será dominante y el otro secundario.

\subsubsection{Presentación de roles teoría Belbin}

La teoría de Belbin dio lugar a la identificación de nueve roles de equipo que los integrantes de los equipos suelen adoptar (Belbin M., 2018):

1. Coordinador

2. Motor

3. Cerebro

4. Monitor/Evaluador 

5. Implementador
6. Investigador de recursos
7. Cohesionador
8. Finalizador
9. Especialista

Así, las características principales de cada rol son las siguientes (Belbin M., 2018):

1. Coordinador: es el miembro del grupo que preside el equipo y coordina los esfuerzos para satisfacer los objetivos externos; establece la agenda, es tranquilo, confiado y responsable de mantener el equilibrio del equipo. Es el líder social; Motiva, organiza y controla las actividades del equipo, logrando metas comunes en base a un trabajo solidario, compartido e interdependiente. Es una persona madura y segura de sí misma. Dirige al equipo llevándolo por la mejor dirección de manera consciente o inconsciente. Es el que define los objetivos del grupo y se encarga de la toma de decisiones. Recibe también el nombre de responsable o líder. También se encarga de dar un buen control a los elementos de distinta naturaleza que intervienen en el proyecto. Sus hechos deben radiar seguridad, confianza y provocar la correlación necesaria para que el grupo no se separe. La debilidad que presenta es que tiende a manipular descargándose así trabajo personal. Puede delegar tanto trabajo al resto del equipo que al final él tenga una carga de trabajo menor.

Adjetivos que lo definen: sensato, seguro de sí mismo, identifica el talento. Aclara las metas y delega eficientemente. Características: estable, dominante, extrovertido.

2. Impulsor/Motor: es el emprendedor de tareas e influye en las decisiones del equipo; Está dispuesto a ser impopular si el trabajo lo exige. Es el líder de tareas Es quien aguijonea y estimula al equipo hacia la acción. Es la persona que se ocupa de presionar al equipo, de hacer que las cosas ocurran ejerciendo presión. Puede llegar a ser ofensivo para los demás ya que es una persona orientada a la acción. Este sujeto se caracteriza por ser dinámico, proactivo, y en constante búsqueda de recursos nuevos. No se debe confundir con el rol de especialista en el sentido teórico o investigador; pero su enérgica actitud se transmite al resto de integrantes y puede ser positivo para situaciones complejas o de crisis. La debilidad que puede presentar es la de provocador de situaciones tensas donde a veces puede ofender 
los sentimientos de la gente. Puede parecer malhumorado y mordaz en su deseo de lograr que se hagan las cosas.

Adjetivos que lo definen: desafiante, trabaja bien bajo presión, activo. Tiene iniciativa y coraje para vencer obstáculos. Características: ansioso, dominante, extrovertido.

3. Cerebro/Creativo/Planta: es la fuente de sugerencias, ideas originales y propuestas del equipo; Es la persona de las ideas, genera ideas y desarrolla formas innovadoras de solucionar problemas; altamente creativo y bueno resolviendo problemas de manera poco convencional. Es la principal fuente de innovación e ideas para el equipo. Es la persona que aporta nuevas ideas, nuevas formas de hacer las cosas, es un rol muy importante en el equipo. Destaca por ser una persona que aporta opiniones y sugerencias originales, por tener una gran cantidad de ideas. Esto conlleva a que sus funciones principales sean las de solventar problemas y situaciones de crisis que puedan darse durante el desarrollo de las tareas. Es imaginativo, innovador, curioso. La debilidad que puede presentar es tender a ignorar los incidentes. Puede estar muy distraído como para llevar a cabo una comunicación eficaz, es decir, ser despistado, olvidadizo o absorto.

Adjetivos que lo definen: librepensador, imaginativo. Genera ideas y resuelve problemas difíciles. .Características: muy inteligente, dominante, introvertido).

4. Monitor/evaluador: es el analizador desapasionado, analítico y objetivo; puede molestar a sus compañeros de equipo con sus críticas, pero casi nunca se equivoca. Analiza sugerencias e ideas, tanto internas como externas al equipo y evalúa su adecuación y viabilidad con los objetivos del grupo; .Juzga todas las ideas, es el crítico del equipo, juzga con precisión, puede suponer una persona molesta, pero simplemente está mirando el trabajo desde otra perspectiva. Tener poca iniciativa y capacidad para inspirar a otros son las dos debilidades que presenta este rol. A la hora de tomar una decisión puede ser muy lento. Excesivamente crítico. Mientras el CEREBRO sintetiza, el MONITOREVALUADOR analiza.

Adjetivos que lo definen: perspicaz, serio y estratega. Entiende todas las opciones y juzga con precisión. Características: muy inteligente, estable, introvertido.

5. Implementador/trabajador de la empresa: Es el organizador útil, organizador práctico, el que convierte las decisiones y las estrategias en tareas finitas y manejables que las personas realmente pueden emprender. Trabaja duro para 
convertir ideas en hechos, puede molestar a sus compañeros de equipo porque es reacio al compromiso. Necesita estabilidad; Es la fuente principal de transformación de ideas en acciones dentro del equipo. Se encarga de que el trabajo pase de los planes a la realidad. Hacen que las cosas ocurran en el tiempo. La debilidad que puede presentar es una cierta inflexibilidad en algunas situaciones a la par que lento en responder a nuevas posibilidades. A la hora de abandonar sus planes para dar lugar a cambios positivos no lo realiza de una forma dinámica.

Adjetivos que lo definen: eficaz, efectivo, de confianza. Convierte las ideas en acciones y organiza el trabajo que debe hacerse. Características: Estable, controlado.

6. Investigador de recursos: con mucha probabilidad es el miembro más agradable del equipo; Relajado y sociable, su interés se despierta con facilidad. A menudo astuto y entusiasta, encuentra los recursos necesarios y cala enseguida cualquier oposición. Explora los recursos del exterior y establece contactos que pueden ser útiles para el equipo. Es la persona que se ocupa de los contactos, siempre tiene a quien llamar para pedir información. Contacto con el exterior, información para ejecutar la teoría. Las fuentes son su principal fortaleza: estudios, análisis, reportes, etc. Trata de extraer de sus tareas lo mejor y así aplicarlas al actual proceso. La persona que posee este rol suele ser un buen comunicador y analista de situaciones. La debilidad que puede presentar es el exceso de optimismo ya que hace que pierda el interés una vez que el entusiasmo inicial ha desaparecido. Puede olvidarse de hacer un control de las iniciativas propuestas.

Adjetivos que lo definen: extrovertido, entusiasta, sociable. Busca oportunidades y desarrolla contactos. Características: Estable, dominante, extrovertido.

7. Cohesionador/Trabajador de equipo: es el miembro más sensible del equipo, el más capaz de percibir las corrientes emocionales en el equipo y las necesidades y preocupaciones de cada miembro. Es el comunicador interno más activo, soporte del grupo sociable; une el equipo y ayuda a solventar cualquier conflicto interpersonal y profesional que se produzca en el seno del equipo. Es el rol que fomenta las relaciones armoniosas y la unidad entre los miembros del equipo. Es la persona que siempre tiene una broma, una palabra de ayuda, está cerca de los demás para que todo el equipo esté unido, cohesionado y exista un espíritu de equipo tan necesario. Numerosas veces esta persona es el responsable o el propio líder; en otras situaciones esta tarea la asume otro miembro del equipo. Un elevado sentido de la justicia, la diplomacia y los elogios son características que le definen. 
Debido a que se caracteriza por comprender lo que otra persona siente, recae sobre él la función de mitigar enfrentamientos ocasionales. La debilidad que puede presentar es la indecisión en momentos cruciales, puede tender a mitigar las confrontaciones. Puede dudar a la hora de tomar decisiones poco conocidas.

Adjetivos que lo definen: cooperador, perceptivo, hábil. Escucha y evita enfrentamientos. Características: Estable, extrovertido, poco dominante.

8. Finalizador/Detallista: se preocupa por lo que puede fallar y nunca descansa hasta que él / ella haya revisado personalmente todos los detalles y se haya asegurado de que todo se haya hecho y no se haya pasado por alto. Su máxima preocupación es el orden y las fechas y compromisos. decidido y comprometido, aunque se le puede considerar interesado en terminar el trabajo cueste lo que cueste. Es el rol a través del cual se realiza un continuo seguimiento de las tareas del equipo, buscando el cumplimiento de los plazos y los niveles mayores de perfección. Revisa que el trabajo se haya realizado con la calidad adecuada, con la corrección de fallos, con la concreción exacta. Está relacionado con la calidad. La debilidad que puede presentar es tender a preocuparse excesivamente y ser reacio a delegar. Puede ser culpado por ser demasiado perfeccionista en su trabajo.

Adjetivos que lo definen: concienzudo, codicioso, detallista. Busca errores. Minucioso. Características: Ansioso, introvertido.

9. Especialista: se introdujo para el caso cuando la experiencia técnica es necesaria para el desempeño de ciertas tareas. Es importante aprovechar el conocimiento ya existente en el equipo, y las habilidades del Coordinador son apropiadas para sacar a la luz este conocimiento especializado latente pero este perfil será el encargado de proporcionar la experiencia técnica en áreas clave; puede molestar a los demás por centrarse única y exclusivamente en su área de especialización.. Aporta el saber especializado sobre el que se basa el producto o servicio del equipo. Se caracteriza por tener conocimientos determinados y por, de manera puntual, apoyar al resto del equipo. Es obediente, interesado y tiene la capacidad de concentrarse en una sola cosa a la vez. En el resto de los temas posee un bajo perfil. La debilidad que puede presentar es una limitación en la contribución de algunas áreas. Puede saturar con mucha información a los otros miembros del equipo.

Adjetivos que lo definen: autosuficiente, entregado, con intereses limitados. Aporta conocimientos y cualidades específicos. Características: Dedicado, independiente, con intereses limitados. 


\subsubsection{Categorías de Roles Belbin}

En función de cuál es el enfoque principal de cada rol se establecen 3 categorías de manera que se pueden diferenciar los perfiles según prioricen la tarea (roles de acción), las ideas (roles de reflexión) o las personas (roles sociales). (Belbin M., 2018)

Se puede observar la distribución de roles en estas 3 categorías en la siguiente tabla

\section{Tabla II: Roles de equipo teoría Belbin organizados en categorías principales}

(Fuente: Belbin Associates, UK, 2011)

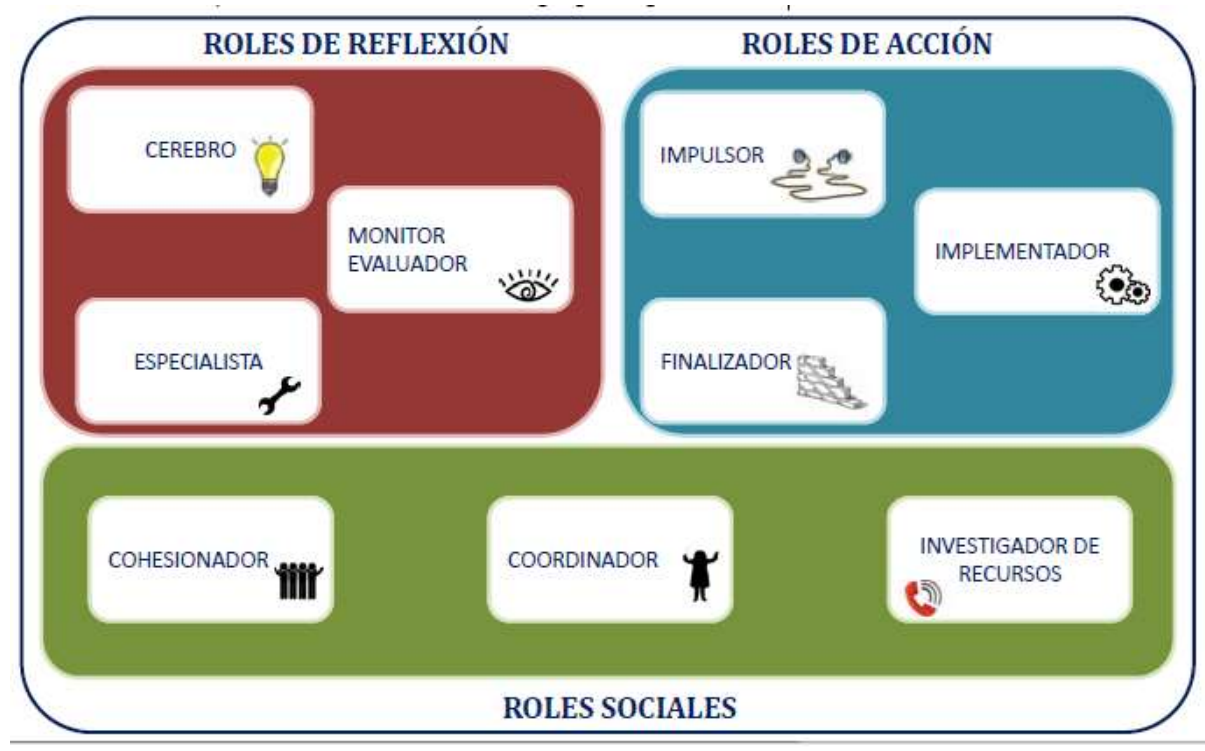

\section{ROLES ORIENTADOS A LAS IDEAS}

Se describen las características de estos roles y específicamente las debilidades "permitidas" que son aquellas inherentes al rol y aquellas que no deberían aparecer para que este rol aporte al equipo en la siguiente tabla. 
Tabla III: Características y debilidades roles reflexión (Fuente: Belbin Associates, UK, 2011)

\begin{tabular}{|c|c|c|c|}
\hline ROL & CARACTERISTICAS & DEBILIDAD PERMITIDA & $\begin{array}{l}\text { DEBILIDAD NO } \\
\text { PERMITIDA }\end{array}$ \\
\hline $\begin{array}{l}\text { CEREBRO } \\
\text { 米 }\end{array}$ & 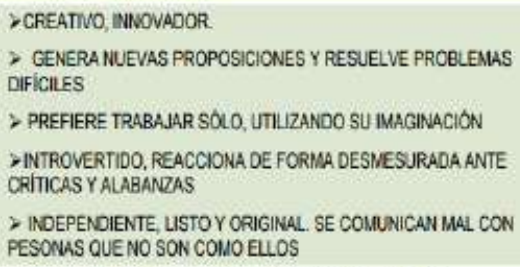 & $\begin{array}{l}\text { NTERESADO ENLAS IDEAS DEIA } \\
\text { DE LADOLLS ASUNTOS } \\
\text { PRACTICOS } \\
\text { DIFICULTAD PARA } \\
\text { COMUNICARSE EFICAZMENITE }\end{array}$ & $\begin{array}{l}\text { POCA COOPERACION CON LOS } \\
\text { DEMGS, ALTO SENTDO DE } \\
\text { "PROPIEDAD DE UNA IDEA" }\end{array}$ \\
\hline $\begin{array}{l}\text { MONITOR } \\
\text { EVALUADOR }\end{array}$ & $\begin{array}{l}\text { DSERIO, PRUDENTE, CONTROLADO EMOCIONALMENTE. } \\
\text { > REFLEXINO EN LA TOMA DE DECISIONES } \\
\text { D BUENA CAPACIOAD PARA ANALIZAR PROELEMAS Y EVALUAR } \\
\text { SUGERENCIAS IDEAS. } \\
\text { > PEACIBE TOOAS LAS OPCIONES. } \\
\text { > JUZGA CON EXACTITUD. }\end{array}$ & $\begin{array}{l}\text { POCA INICIATIVA PARA INSPIRAR } \\
\text { A OTROS } \\
\text { DEMASIADO CRITICO }\end{array}$ & CINISMO SIN LÓGICA \\
\hline ESPECIALISTA & $\begin{array}{l}\text { DAPORTA CUALIDADES Y CONOCIMENTOS TECNICOS } \\
\text { ESPECIFICOS. } \\
\text { > CUMPUDOR } \\
\text { > ASIGNA UN TIEMPO A UNA COSA }\end{array}$ & $\begin{array}{l}\text { CONTRIBUYYE SOLLO CUAANDO SE } \\
\text { TRATA DE UN TEMA QUE } \\
\text { CONOCE BIEN } \\
\text { SE EXPLAYA EN TECNICISMOS }\end{array}$ & $\begin{array}{l}\text { IGNORAR LOS FACTORES DE } \\
\text { FUERA DE SU PROPIL AREA DE } \\
\text { COMPETENCIA }\end{array}$ \\
\hline
\end{tabular}

\section{ROLES DE ACCIÓN}

En la siguiente tabla se describen las características de estos roles y específicamente las debilidades "permitidas" que son aquellas inherentes al rol y aquellas que no deberían aparecer para que este rol aporte al equipo.

Tabla IV: Características y debilidades roles acción (Fuente: Belbin associates, UK, 2011)

\begin{tabular}{|c|c|c|c|}
\hline ROL & CARACIERISTICAS & DEBILIDAD PERMITIDA & $\begin{array}{l}\text { DEBIL IDAD NO } \\
\text { PERUITIDA }\end{array}$ \\
\hline IMPULSOR & $\begin{array}{l}\text { D MOTIVADO, NECESIDAD DE CONSEGIR NUEVOS LOGROS. } \\
\text { > RETADOR, DINAMACO, TRABANA BIEN BANO PRESION. } \\
\text { > INICIATIVA Y CORAJE PARA SUPERAR OBSTACULOS. } \\
\text { > CAPACDAD PARA AFRONTAR LOS CAMBIOS }\end{array}$ & $\begin{array}{l}\text { PROVOCADOR } \\
\text { PROPEKSO A LA FRUSTRACION }\end{array}$ & $\begin{array}{l}\text { NCAPACIOAD PARA } \\
\text { REOONDUCIR SITUACODNES } \\
\text { NEGATIVAS }\end{array}$ \\
\hline IMPLEMENTADOR & $\begin{array}{l}\text { DISCIPLINADO, LEAL, CONSERVADOR, EFICIENTE } \\
\text { CONTROL EMOCIONAL } \\
\text { D TRANSFORUWN LAS IDEAS EN ACCIONES } \\
\text { DORGANIZADCR CON CAPACIDAD PARA ENFRENTARSEA } \\
\text { DISTINTAS TAREAS. }\end{array}$ & $\begin{array}{l}\text { INFLEXIBLE EN OCASIONES } \\
\text { LENTO EN RESPONDERA } \\
\text { NUEVASPOSIBLLDADES }\end{array}$ & OBSTRURE CAMEIO \\
\hline $\begin{array}{l}\text { FINALIZADOR } \\
\\
+3838\end{array}$ & $\begin{array}{l}\text { DESUERADO, CONCIENZUDO } \\
\text { > PERSEVERNATES } \\
\text { > REALEA LAS TAREAS EN EL PLAZO ESTABLECIDO } \\
\text { > BUSCA ERRCRES Y OMSIONES }\end{array}$ & $\begin{array}{l}\text { PERFECCIONISMO } \\
\text { PREOCUPACION EXCESNA }\end{array}$ & COUPORTAMIENTO OESESIVO \\
\hline
\end{tabular}




\section{ROLES ORIENTADOS A LAS PERSONAS}

En la siguiente tabla se describen las características de estos roles y específicamente las debilidades "permitidas" que son aquellas inherentes al rol y aquellas que no deberían aparecer para que este rol aporte al equipo.

Tabla V: Características y debilidades roles sociales (Fuente: Belbin Associates, UK, 2011)

\begin{tabular}{|c|c|c|c|}
\hline ROL & CARACTERISTICAS & DEBIUIDAD PERMIIDA & $\begin{array}{l}\text { DEBILIDAD NO } \\
\text { PERMITIDA }\end{array}$ \\
\hline COORDINADOR & 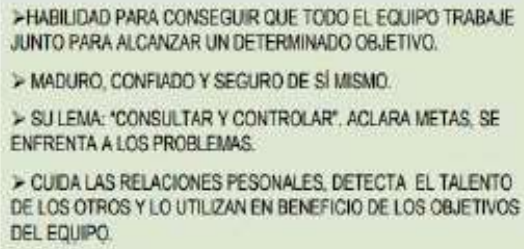 & $\begin{array}{l}\text { TMANPULADOR'. } \\
\text { PEREZOSO' SI ENCUENTRAA } \\
\text { ALGUIEN QUE PUEDA HACER EL } \\
\text { TRABANO }\end{array}$ & $\begin{array}{l}\text { ASUMIR TODO EL CREOITO POR } \\
\text { EL ESFUERZO DEL EQUIPO }\end{array}$ \\
\hline COHESIONADOR & $\begin{array}{l}\text {-COOPERADOR SOCIABLE, APACIBLE, } \\
\text { D DIPLCMATICO } \\
\text { PFLEXBLE, ADAPTACION A DIFERENTES SITUACIONES Y } \\
\text { PERSONAS } \\
\text { > ESCUCHA Y EVTA ENFRENTAMIENTOS }\end{array}$ & $\begin{array}{l}\text { INDECISO } \\
\text { INFUUENCIABIE }\end{array}$ & $\begin{array}{l}\text { EVITARSITUACIONES DE } \\
\text { PRESION }\end{array}$ \\
\hline $\begin{array}{l}\text { INVESTIGADOR } \\
\text { DERECURSOS }\end{array}$ & $\begin{array}{l}\text {-EXTROVERTIDO, ENTUSIASTA } \\
\text { - MUY CONUNICATIVO. } \\
>\text { BUSCA OPORTUNIDADES. } \\
\text {-DESARROULA CONTACTOS. } \\
>\text { CARACTER RELLNADO. } \\
\text { - CAPACIDAD PARA OETECTAR LAS POSBBLIDADES EN } \\
\text { CUALQUIERASUNTO. }\end{array}$ & $\begin{array}{l}\text { DEMASIADO OPTIMISTA } \\
\text { PIERDE NTERES CUANDOEL } \\
\text { ENTUSIASMO INICIAL HA } \\
\text { DESAPARECIDO }\end{array}$ & $\begin{array}{l}\text { DEFRAUDAR LA CONFIANRA } \\
\text { DEL EQUIPO POR DESCUIDAR } \\
\text { EL SEGUIMENTO DELOS } \\
\text { ACUERDOS }\end{array}$ \\
\hline
\end{tabular}

\subsubsection{Conclusiones principales Belbin}

Las principales conclusiones de la teoría de Belbin son (Belbin, 1981) son absolutamente sorprendentes y útiles para el trabajo en equipo.

Entre ellas, se expone que el rol del equipo muestra la "tendencia a comportarnos, contribuir e interrelacionarlos de una manera particular". La ausencia de un papel debilita al equipo, pero también si hay demasiados con el mismo rol. Por lo tanto, a la hora de reclutar personas en el equipo de trabajo, además de las aptitudes de Belbin, deben seleccionarse personas capaces de complementar los puntos fuertes y compensar debilidades.

Si hay menos de 9 personas se adoptan varios roles (principal y secundario) mientras que en grandes equipos se suelen formar subgrupos donde aparecen estos roles en cada uno de ellos. 
El conocimiento de los roles en equipos establecidos ayuda menos que en los nuevos equipos donde la combinación de roles se ha mostrado muy efectiva. Además, de especial relevancia para esta investigación es la conclusión de Belbin que determina que la construcción de equipos a través del equilibro de papeles es más importante en áreas de trabajo bajo presión o de acción rápida, así como en ambientes donde la creatividad es necesaria $(I+D \ldots)$

Los equipos formados por mayoría de gente muy inteligente generalmente fracasan.

Distintos estudios han demostrado la vigencia de la teoría de Belbin y su aplicación a los equipos de trabajo. Entre ellos se destaca la aportación de Nicoleta Meslec y Petru Lucian Curseu, que estudiaron el impacto del equilibrio de los roles en la calidad del trabajo en equipo y tres indicadores de desempeño en grupos de aprendizaje colaborativo (complejidad cognitiva grupal, desempeño percibido y desempeño objetivo). Los resultados mostraron que el equilibrio de roles del grupo predice positivamente el desempeño del grupo en las fases preliminares del proyecto grupal, pero no en las fases posteriores. Además, el equilibrio de roles grupales predice positivamente la complejidad cognitiva del grupo. Los resultados se mantienen solo cuando el equilibrio de roles se conceptualiza como una propiedad de configuración de los grupos en lugar de una suma de roles individuales. Los resultados del estudio tienen implicaciones para el diseño de grupos de aprendizaje colaborativo (Meslec N., Lucian Curseu Petru,2015)

Otro estudio muy interesante fue desarrollado por Aitor Aritzeta, Stephen Swailes y Barbara Senior proponiendo un "modelo de roles de Belbin en equipos trabajo: desarrollo, validación y aplicaciones para la creación de equipos" (Aritzeta et al, 2017).

En este estudio se propuso el uso del modelo a seguir en equipo desarrollado por Belbin para proporcionar una evaluación exhaustiva de la validez del modelo. Las propiedades del Cuestionario de autopercepción de roles de equipo utilizado para evaluar el comportamiento predecible de un apersona en un equipo se examinó junto con 43 estudios empíricos que probaban asociaciones teóricas entre roles de equipos y otros rasgos de comportamiento. Los resultados del estudio demostraban que había una validez convergente adecuada y proporcionando nuevas ideas sobre aspectos del trabajo en equipo. 


\subsection{Planteamiento del estudio}

\subsubsection{El papel de las habilidades transversales a través del marco lógico del proyecto.}

La motivación del estudio planteado en esta tesis (artículo 1) es analizar y resaltar el papel de las habilidades transversales a través del marco lógico de un proyecto (Craft \& Jeffrey, 2008; Ramazani \& Jergeas, 2015). Convencionalmente, el éxito del proyecto se ha atribuido a los aspectos humanos de los proyectos (Ewin, Luck, Chugh y Jarvis, 2017). Y estas cuestiones humanísticas son más significativas en los primeros puntos del marco lógico de un proyecto.

Se eligieron cuatro propuestas de proyectos como ejemplos y se utilizaron para impulsar el experimento (los campos de conocimiento eran la energía y los recursos naturales). Si bien hay muchos estudios centrados en las habilidades de creatividad durante la generación de ideas, poca investigación ha explorado qué sucede después de que las ideas creativas se desarrollan en cursos de ingeniería (Starkey, Toh y Miller, 2016). Además, la evaluación de la creatividad, como proceso de implementación de una idea a un proyecto, también debería ayudar a identificar a los mejores inventores y diseñadores. En consecuencia, el objetivo del estudio es evaluar las habilidades básicas que son clave para el éxito de la fase de aprobación de una propuesta de proyecto.

El resultado esperado del estudio es establecer un ejercicio práctico para definir e identificar el grado de creatividad en el ámbito de la gestión de proyectos. El principio fundamental del presente estudio es medir la creatividad, el trabajo en equipo, las habilidades de comunicación y actitudes hacia el trabajo de los ingenieros de minas en sus primeras etapas de su vida profesional. Este análisis consistió en la inversión simulada en proyectos e ideas de ingenieros, que fueron evaluados por seis expertos de diversos sectores públicos y privados, incluidos la energía, los servicios, la construcción y la minería. El diseño de este ejercicio, como una herramienta novedosa para medir las habilidades sociales, consiste en evaluar los parámetros objetivos y subjetivos de la propuesta del proyecto y el equipo de ingeniería.

Este estudio comprende el análisis de cuatro habilidades transversales: 
1. Creatividad: el objetivo es estudiar la capacidad de los ingenieros para proponer una idea innovadora y desarrollarla para obtener financiamiento para desarrollar un proyecto. Se consideraron dos prácticas: (a) una prueba de competencias que completaron los inversionistas que consideraron Diferentes aspectos: novedad, funcionalidad (enfoque técnico, económico y social) e impacto. y (b) un ejercicio para inversionistas, como una innovación importante presentada en este documento. La metodología se basa en el pensamiento divergente, donde el juicio humano se aplica ampliamente para evaluar la creatividad (Long, 2014). El ejercicio está inspirado en la técnica de evaluación consensual de Amabile (CAT) (Baer \& McKool, 2009; Denson, Lammi, Susan y Amico, 2015), como la técnica de evaluación de productos más popular para medir la creatividad (Gabriel, Monticoloa, Camargoa, y Bourgault, 2016).

2. Trabajo en equipo: evaluar el papel de cada persona en un equipo y su capacidad para colaborar y proponer un proyecto innovador, considerando una prueba de autopercepción inspirada en la metodología propuesta por Belbin (Meredith Belbin, 2010b); Se propone en este trabajo una metodología de autoconocimiento de roles de equipo en la que se plantea una revisión individualizada por parte de cada estudiante, que permita interpretar correctamente los resultados y confirmar si se siente reflejando en los resultados obtenidos. Será importante destacar que se trata de una autopercepción que arroja un resultado de gran interés pero que no considera la percepción del entorno ni tiene la complejidad del análisis de Belbin completo.

3. Actitud hacia el trabajo: la capacidad de cada ingeniero para incorporar diferentes habilidades y capacidades en un equipo específico (perfil y prueba de Jung). Para evaluar estas capacidades se utilizó un cuestionario que a partir de 12 preguntas permite analizar la tendencia o contribución a 4 aspectos: equipo, innovación, proceso y objetivo.

4. Habilidades de comunicación: esta competencia se evaluó como resultado de la combinación de la expresión oral y escrita. La evaluación de esta competencia se realizó a través del análisis de la estructura de la comunicación tanto para la comunicación escrita (estilo, recursos necesarios, extensión y normas gramaticales) como para la comunicación oral (estilo, recursos necesarios, gestión del tiempo, técnicas de comunicación oral y escucha activa al interlocutor). 


\subsubsection{Propuesta de metodología de selección de proyectos basada en el PMI}

El modelo energético está experimentando una transformación continua hacia la descarbonización del sistema: tanto en la generación eléctrica como en el sector del transporte. Para la gobernanza energética, es crítico saber cómo manejar un complejo "trilema energético" que involucra demandas en conflicto de seguridad energética, mitigación del cambio climático y competitividad (especialmente en países desarrollados (Consejo Mundial de la Energía, 2016; Gunningham, 2013; Heffron et al., 2015).

En el mercado energético, la innovación, considerada como un proceso de generación de valor, permite a las empresas mantener o aumentar su posición en el mercado (Abernathy y Clark, 1985).

La gestión de la innovación se ha vuelto más flexible (Markham y Lee, 2013), considerando no solo la innovación generada por la propia empresa, sino también, y de manera más prominente la innovación abierta $(\mathrm{Ol})$. La innovación abierta propone una nueva estrategia de innovación por la que van las organizaciones,

más allá de sus límites y desarrollar la cooperación con organizaciones o profesionales externos para mejorar la eficiencia en los procesos de innovación (Figura 8).

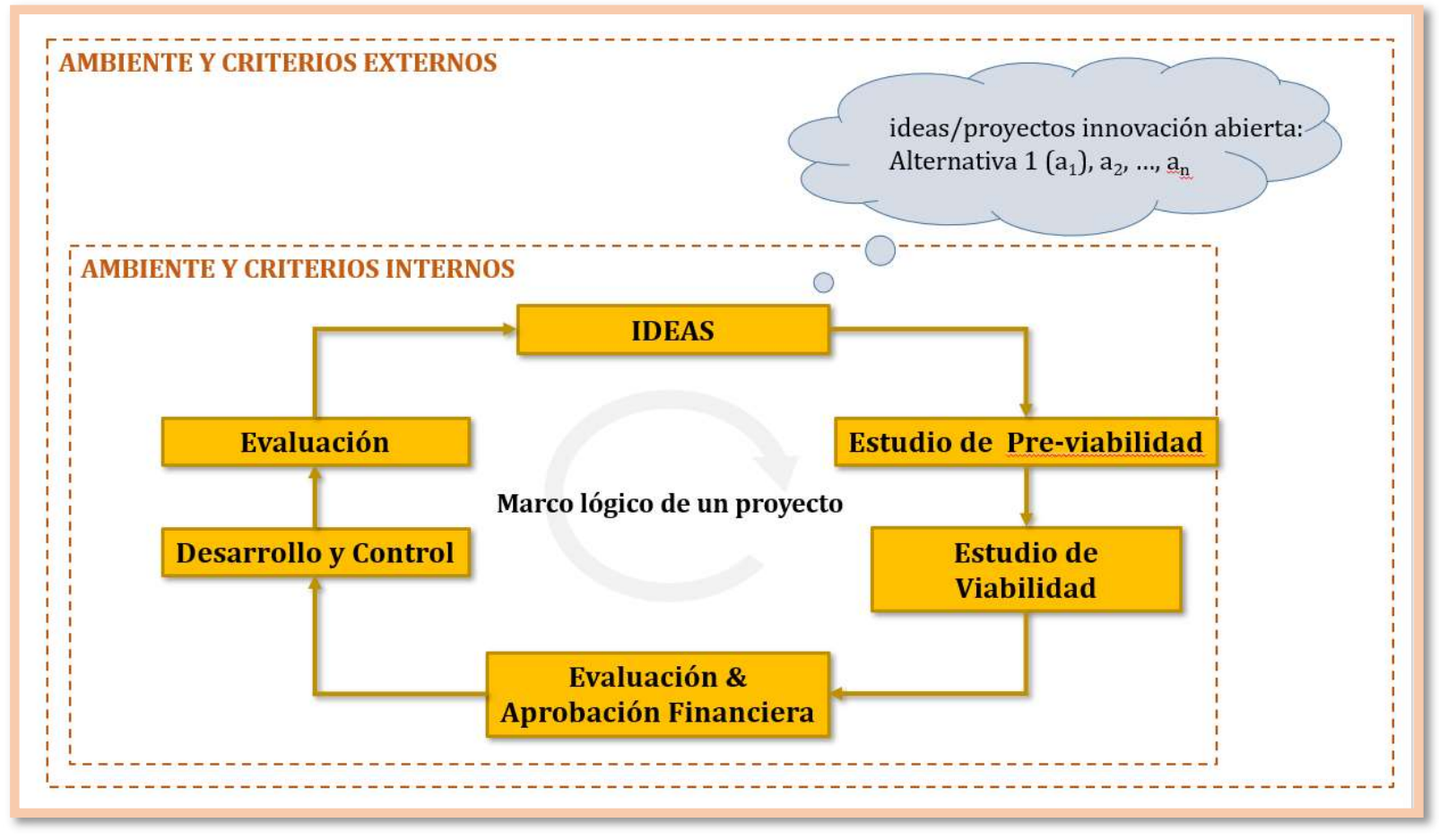

Figura 8. Marco lógico de cualquier proyecto y enfoque de innovación abierta. 
Pero ¿cómo lidiar con la evaluación de proyectos en un mundo hiperconectado con cambios tecnológicos acelerados? Ante la proliferación de proyectos innovadores, es necesario establecer una metodología que permita a las empresas seleccionar cuál de ellas ofrece más garantías de éxito o retorno de la inversión. Las herramientas de apoyo a la decisión permiten la selección y jerarquía de diferentes alternativas - en este caso, propuestas de investigación - según una serie de criterios (Enea y Piazza, 2004; Subramanian y Ramanathan, 2012).

Los métodos de selección basados en criterios múltiples, soportados por algoritmos matemáticos, permiten la evaluación de criterios tanto cuantitativos como cualitativos. En general, estos métodos pueden ser clasificados de acuerdo con la toma de decisiones multi-objetivo o la toma de decisiones multi-atributo. Esta metodología considera una serie de alternativas frente a una serie de atributos o criterios. La mejor opción generalmente se selecciona comparando cada uno de los criterios con las alternativas (Pohekar y Ramachandran, 2004; Saaty, 2006).

En el sector energético, estas técnicas se han aplicado de forma rutinaria para la selección de diferentes alternativas (San Cristóbal, 2011; Schmoldt et al., 2001), con la metodología del proceso de jerarquía (AHP) enunciada por Saaty (1977), uno de los algoritmos ampliamente utilizado en la toma de decisiones. AHP permite acercarse a la toma de decisiones considerando un desglose y una comparación entre criterios para determinar pesos y valores. Incluso si el proceso de red analítica (ANP) admite criterios dependientes (Saaty, 1996; Cheng y Li, 2004; Nisel y Özdemir, 2016), en este caso, todo el proceso considerado consiste en criterios independientes, como lo define una metodología bien conocida. Otros métodos fueron revisados en este estudio, como Promethee (Olson, 2001) y los métodos de Vikor (Opricovic y Tzeng, 2004).

\subsubsection{Revisión de la literatura y desarrollo de hipótesis}

\section{SECTOR ENERGÉTICO E INNOVACIÓN.}

La transformación del sistema energético pasa por una redefinición del principio de sostenibilidad, basada en tres principios: medio ambiente, competitividad y seguridad de suministro. Este desarrollo tecnológico se basará en la evolución tecnológica que Incluye avances en los tres vectores de sostenibilidad. Tecnologías como la energía distribuida, redes inteligentes, factor de carga de energía renovable, almacenamiento de energía, captura y almacenamiento de $\mathrm{CO}_{2}$ son, entre otras, las tecnologías necesarias y su 
desarrollo depende del cumplimiento de los objetivos antes mencionados. Este hecho convierte al sector energético en un sector propicio para la implementación del enfoque OI.

\section{METODOLOGÍA DE GESTIÓN DE PROYECTOS (PMP)}

La metodología PMP ha sido descrita anteriormente y en el caso de proyectos innovadores, la metodología anterior es igualmente aplicable, adaptándolo a las características intrínsecas de estos proyectos como se detalla en diferentes estudios.

Cada vez más, se pueden ver ejemplos de la aplicación de herramientas PMP en el caso de gestión integrada de proyectos innovadores, haciendo referencia a procesos similares como cierre de proyectos de planificación, presupuestación, control y monitoreo o innovación, entre otros. (Wallin y Von Krogh, 2010).

\section{HERRAMIENTAS PARA APOYAR LA TOMA DE DECISIONES: ALGORITMOS} MULTICRITERIO.

La evaluación multicriterio y los métodos de toma de decisiones incluyen la selección entre un conjunto de alternativas, optimización con varias funciones objetivas concurrentes, y toma de decisiones, procedimientos de evaluación racionales y consistentes (Greco et al., 2017). Estos métodos permiten la valoración de los criterios tanto cuantitativos como cualitativos y, en general, las alternativas son clasificadas según si la toma de decisiones es multi-objetos o multi-atributos. En este caso, se han considerado alternativas o atributos o criterios y la mejor opción está basada en la comparación entre las diferentes alternativas (Saaty, 1977).

Estos métodos no consideran la posibilidad de hallar una solución óptima, pero dependiendo de las preferencias del agente de decisión y variables y objetivos predefinidos, el desarrollo del problema principal será seleccionar las mejores alternativas o aceptar alternativas que parecen buenas y que reducen el valor de aquellas que se ven mal, de manera que el resultado final es una clasificación de las alternativas en consideración (Saaty, 2006). Entre los procedimientos y algoritmos matemáticos considerados, el método AHP destaca y las ventajas que ofrece esta metodología son la simplicidad y la claridad (Saaty, 1977). El AHP descompone el problema principal a través de una estructura jerárquica, permitiendo un análisis detallado de cada uno de los niveles de criterios considerados (Figura 9) (West et al., 2014). 
El método utiliza comparaciones por pares para medir el impacto de los artículos en un nivel (Liberatore y Nydick, 2008). El número de elementos en cada nivel debe ser al menos dos pero menor de siete (Ishizaka y Labib, 2011). Además, AHP hace posible realizar el análisis de sensibilidad y estudiar otras posibles soluciones haciendo cambios en los pesos relativos que definen la jerarquía estructura. La metodología AHP ofrece tres funciones básicas: la capacidad de descomposición del problema, una evaluación basada en una escala y la capacidad de síntesis (Thomas et al., 2013).

La asignación de peso para cada criterio se establece en base a la construcción de una serie de matrices que deben cumplir con los siguientes axiomas: reciprocidad, homogeneidad y la prioridad.

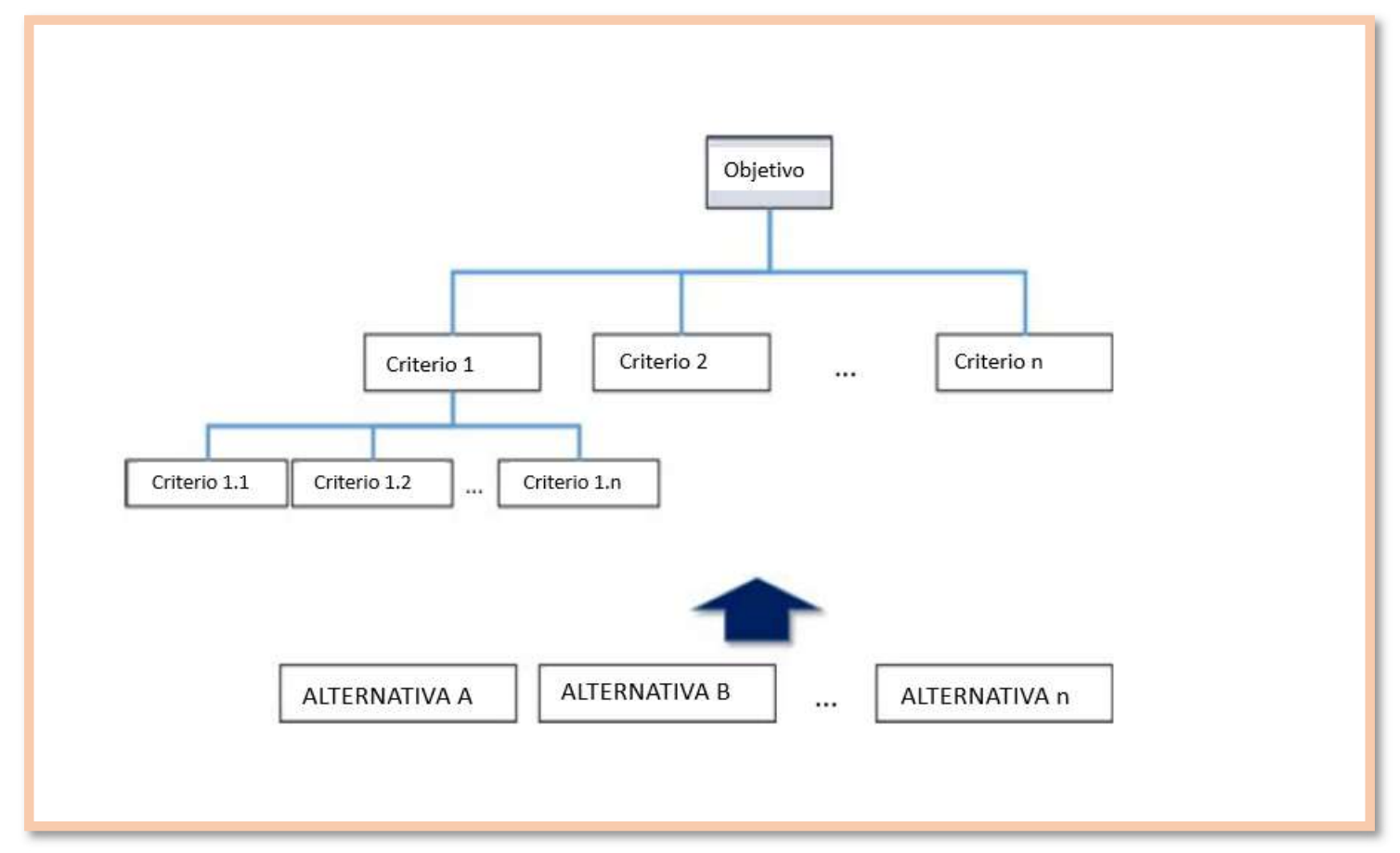

Figura 9. Estructura jerárquica de niveles de AHP

\section{PROPÓSITO DEL ESTUDIO}

El uso de algoritmos multicriterio para la toma de decisiones en el sector energético es común (Sipahi y Timor, 2010), ambos para la selección de proyectos de ubicación de almacenamiento de gas natural (Çetin Demirel et al., 2017), y para casos incipientes de estudio, como el almacenamiento geológico de CO2. (Llamas y Cámara, 2014) o el almacenamiento de aire comprimido en el subsuelo (Llamas et al., 2017). Además, también se ha propuesto la metodología ANP para la selección de proyectos de I + D (Henriksen y 
Traynor, 1999; Meade y Presley, 2002; Mohanty et al., 2005; Cheng y Li, 2005) y otros problemas de gestión (Chen et al., 2012).

La gestión de la cartera como un proceso de decisión racional es necesaria para definir adecuadamente los criterios que deben tenerse en cuenta. Con el fin de evaluar el atractivo de las propuestas de proyectos, los criterios apropiados deben ser determinados. La identificación de estos criterios se llevará a cabo en el presente estudio, considerando la metodología descrita en la guía PMBOK para la gestión de proyectos emitida por el Project Management Institute (PMI) (2017), que se ha convertido en la más reconocida certificación profesional en gestión de proyectos. Gracias a esta metodología probada, donde se ha definido el proceso de independencia, la metodología AHP es la más ampliamente recomendada metodología de decisión multicriterio. Este enfoque nunca ha sido considerado para los proyectos innovadores, a pesar de ser una forma reconocida de evaluar propuestas de proyectos.

El PMI propone considerar la factibilidad y ejecución de un proyecto en base a varias restricciones que incluyen alcance, tiempo, costo, riesgo, recursos, calidad y grupos de interés (PMI, 2017). Será difícil evaluar en profundidad todas estas variables y la interrelación entre ellos desarrollar un plan realista y alcanzable. Basado en estas restricciones e incertidumbres, es posible desarrollar las áreas de conocimiento que conducirán a los procesos que tienen lugar en un proyecto. La metodología propuesta aquí permite evaluar proyectos innovadores, desde el inicio (idea) hasta la fase de aprobación. Por lo tanto, el problema de priorizar los proyectos de investigación plantea varias restricciones, basadas en criterios internos y externos, que deben evaluarse para seleccionar aquellos proyectos innovadores que mejor se adapten a la empresa.

Una vez que se implementó la herramienta de selección, se aplicó a un conjunto de propuestas de investigación para priorizar aquellos que sean más atractivos para ser financiados a través de fondos privados o públicos.

La secuencia recomendada fue la siguiente:

- presentación de estudios de caso;

- aplicación de la metodología desarrollada.

- clasificación de resultados y priorización basada en los resultados obtenidos; y

- búsqueda de financiación externa. 


\subsubsection{Propuesta de modelo de creación de equipos de trabajo asociados a proyectos de innovación}

Es muy complejo seleccionar los proyectos de innovación que serán exitosos. En un entorno en el que los recursos son limitados (tiempo y dinero) se hace necesario tener una herramienta que nos ayude a escoger aquellos proyectos que tienen más probabilidad de éxito.

La gestión de proyectos es una de las temáticas más relevantes en el éxito de un proyecto. Existen distintas metodologías, de entre la que destaca la propuesta por M Dolores Storch et al, 2019. Dicha metodología se basa en la reputada metodología del PMI (PMI, 2017), que considera criterios técnicos y organizacionales. De entre estos últimos, predomina el criterio de recursos humanos, como elemento clave en el éxito de un proyecto. De entre todos los criterios organizacionales, tanto la selección del director de proyecto como del "equipo" se considera clave (M Dolores Storch et al, 2019).

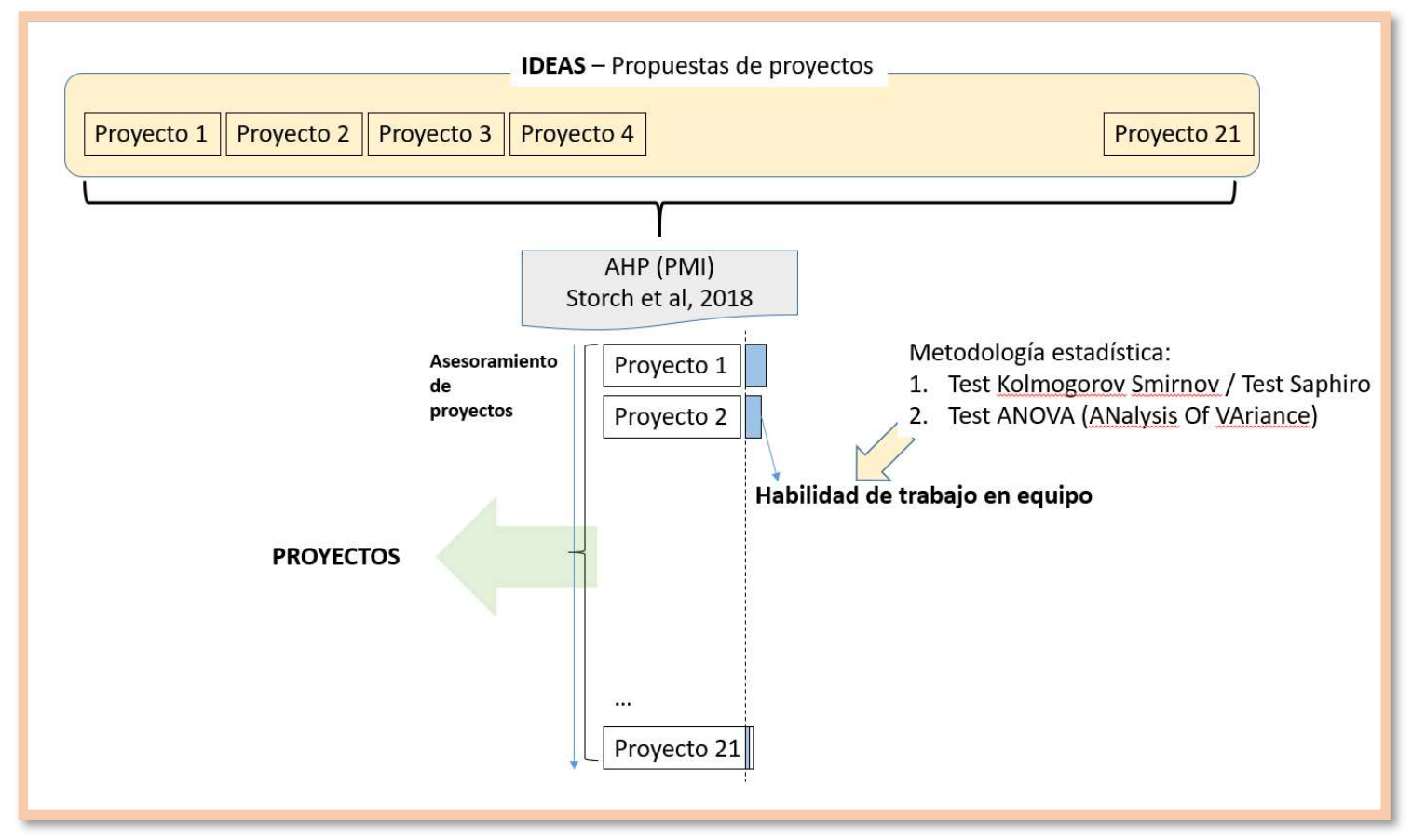

Figura 10. Planteamiento del estudio equipos de trabajo vs proyectos exitosos

La toma de decisiones es un proceso de selección y evaluación entre diferentes alternativas, basado en un conjunto de criterios, para alcanzar uno o más objetivos, 
seleccionando la mejor opción posible. A través de la metodología multicriterio planteada y el enfoque del PMI se propone una herramienta de predicción del éxito de los proyectos Por otro lado, dentro de las competencias transversales, el trabajo en equipo destaca por la importancia que puede tener la ausencia o presencia de determinados roles que faciliten el éxito del conjunto.

\section{Clasificación de proyectos (M Dolores Storch et al, 2019)}

En el artículo anterior, el proceso de jerarquía analítica (AHP) se demostró como una opción adecuada para evaluar propuestas innovadoras, gracias a su integración con la metodología PMI. En esta metodología PMI se proponen 8 criterios:

- 4 criterios técnicos que incluyen alcance, tiempo, coste y calidad

- 4 criterios organizacionales considerando recursos humanos, comunicación, riesgo y partes interesadas.

La resolución de un problema basado en múltiples criterios se resuelve mediante la búsqueda de mejor alternativa, para lo que se puede utilizar algoritmos matemáticos. De entre los algoritmos, destaca el AHP, por su vasta aplicación en la resolución de problemas de diferentes ámbitos, incluyendo problemas de ingeniería (Bernardo Llamas et al, 2019).

\section{Descripción de la muestra y proyectos.}

Se han considerado 121 alumnos que conformaron 21 grupos de trabajo y presentaron una propuesta de proyecto en la asignatura Evaluación de Proyectos y Gestión del Riesgo del Máster de Ingenieros de Minas impartido por la Escuela Superior de Ingenieros de Minas y Energía (UPM). Se estructuraron en equipos de entre 4 y 6 personas, y no se tuvo en consideración la diferenciación de género. Los estudiantes se ha analizado la presencia de roles en cada grupo mediante un cuestionario de autoconocimiento en el cual se reparten 70 puntos respondiendo a distintas situaciones que posicionan al sujeto en los 3 tipos de Roles (Sociales, Reflexión, Acción).

La mayoría de los grupos eran de 6 personas (16 grupos) aunque había 3 grupos de 7 personas y 2 grupos de 5 personas. Cada grupo de trabajo debía proponer un proyecto a su elección y para el mismo responder a un cuestionario que se les suministraba con datos del mismo. A partir de la información aportada para cada proyecto en cada apartado y que suponían los criterios de selección se plantea una herramienta matemática de predicción del éxito de los proyectos. Las propuestas de proyecto se basan en soluciones de 
ingeniería como la lucha contra el cambio climático, nuevos combustibles para la movilidad sostenible, energía renovable, exploración y explotación de recursos minerales metálicos entre otros.

Para la elaboración de los equipos, se tomó en consideración la prueba de autopercepción inspirado en la metodología Belbin descrito en el apartado 3.1.4.

El objetivo de este estudio se centrará por tanto en la evaluación particular del criterio "equipo" y la relación de este con el éxito del proyecto. Para ello, se contará con una muestra de 21 propuestas de proyectos de ingeniería y su ponderación de éxito, junto con el análisis del equipo, mediante una encuesta de autopercepción inspirada en la metodología Belbin ya descrita en este trabajo anteriormente (Belbin, 1981) (Belbin, 1984) (Belbin, 2018).

\section{Los proyectos exitosos}

Es muy difícil seleccionar los proyectos más prometedores. Si estás trabajando además en proyectos innovadores, debido a su riesgo inherente, es todavía más difícil predecir cuáles serán los más exitosos. Basado en los procesos definidos por el Project Management Institute (PMI,2017), una metodología multicriterio es descrita en el estudio 1 presentado anteriormente y que dio lugar al artículo (M. Dolores Storch de Gracia et al., 2019).

\section{Los equipos de trabajo}

En cualquier tipo de proyectos, lo más importante son las personas. Sin ellas, no se podría llevar nada a cabo. La Gestión de los Recursos Humanos del Proyecto incluye los procesos que organizan, gestionan y conducen el equipo del proyecto. El equipo del proyecto está conformado por aquellas personas a las que se les han asignado roles y responsabilidades para completar el proyecto. El tipo y la cantidad de miembros del equipo del proyecto pueden variar con frecuencia, a medida que el proyecto avanza. Si bien se asignan roles y responsabilidades específicos a cada miembro del equipo del proyecto, la participación de todos los miembros en la toma de decisiones y en la planificación del proyecto puede resultar beneficiosa. La intervención y la participación tempranas de los miembros del equipo les aportan su experiencia profesional durante el proceso de planificación y fortalecen su compromiso con el proyecto.

En este estudio se propone el análisis de roles a partir de la Teoría de Belbin mediante la autoevaluación por cuestionario de los integrantes de cada grupo.

Así, Belbin propone 9 roles, divididos en 3 bloques según su función principal sea de reflexión, acción o social. 
Roles de reflexión: Cerebro, Monitor evaluador y especialista

Roles de acción: Impulsor, Implementador y Finalizador

Roles sociales: Cohesionador, Coordinador e Investigador de recursos

Cada rol se asocia a un comportamiento clave y el éxito del equipo dependerá de su composición. Las fortalezas y debilidades permitidas asociadas a cada rol definen las características de cada rol (Bernardo Llamas et al, 2019) (Key Issues for Management of Innovative Projects (2017)).

Dada la complementariedad de los roles y las 3 funciones principales, Belbin propone que en cada equipo haya al menos una persona de cada función para asegurar así un equilibrio que asegure que se cubran todas las necesidades.

En base a lo anterior se propone una categorización de los equipos en:

Absolutamente desequilibrados: Hay ausencia de uno de los 3 tipos de roles

Desequilibrados: hay presencia de los 3 roles, pero desbalanceada

Equilibrados: Hay presencia significativa y balanceada de los 3 roles

\section{El análisis estadístico}

En este estudio, se pretende analizar si existe una relación entre el valor asignado de "éxito" a los proyectos considerando la herramienta AHP (Valoración AHP) y su posible relación con diagnóstico de equilibrio de los equipos realizado en base a la autopercepción de roles inspirado en la teoría de Belbin.

El análisis estadístico propuesto en este estudio plantea estudiar si existe una relación entre los equipos de trabajo y los proyectos exitosos

En definitiva, se trata de confirmar si existe una correlación entre el valor asignado de "éxito" a los proyectos (valor asignado considerando la herramienta AHP) y su posible relación con diagnóstico de los equipos realizado en base a la autopercepción de roles inspirado en la teoría de Belbin (Equilibrio de los equipos de trabajo). 


$$
\begin{gathered}
\text { CAPÍTULO } 3 \\
\text { MATERIALES Y } \\
\text { MÉTODOS }
\end{gathered}
$$


A la hora de proponer una herramienta de selección de proyectos de innovación se escoge la metodología AHP.

La metodología AHP permite el desglose del problema, y de esta forma alcanzar una valoración cuantitativa. Para ello es necesario desglosar el problema/objetivo inicial, "financiar aquellos proyectos que vayan a aportar más valor a la compañía". Fruto de la investigación realizada sobre la aplicación de la metodología AHP y su vinculación con los proyectos innovadores y el Project Management Institute se publicó en 2019 el artículo siguiente:

M Dolores Storch de Gracia, David Moya Perrino and Bernardo Llamas (2019) "Multicriteria methodology and hierarchical innovation in the energy sector", Vol. 57 No. 5, pp. 12861303."

La revista Management Decision tuvo un factor de Impacto en 2019 de 2.723 siendo su categoría JCR la siguiente:

\begin{tabular}{|l|l|l|}
\hline Categoría de JCR® & Clasificación en la categoría & Cuartil en la categoría \\
\hline BUSINESS & 70 de 152 & $Q 2$ \\
\hline MANAGEMENT & 102 de 226 & $Q 2$ \\
\hline
\end{tabular}

Datos de la edición 2019 de Lournal Citation Reports

Por otro lado, es fundamental en los proyectos innovadores el valor del equipo y por este motivo en esta tesis se propone la teoría de Belbin y su aplicación en la metodología de selección de proyectos como uno de los factores decisivos.

En esta tesis también se presta especial atención, además de a "el trabajo en equipo", a otra competencia transversal que es la creatividad, como factor determinante a considerar en los proyectos innovadores. Fruto de esta investigación se publicó, en 2019, el siguiente artículo en el que se recoge la relación entre proyectos exitosos y la metodología de Belbin:

Bernardo Llamas, M. Dolores Storch de Gracia, Luis F. Mazadiego, Juan Pous, Julian Alonso. "Assessing transversal competences as decisive for Project management". Revista Thinking Skills \& Creativity. Estado: Publicado. (Thinking Skills and Creativity 31 (2019) 125-137)." 
La revista Thinking Skills \& Creativity tuvo un factor de Impacto en 2019 de 2.068 siendo su categoría JCR la siguiente:

\begin{tabular}{|l|l|l|}
\hline Categoría de JCR® & Clasificación en la categoría & Cuartil en la categoría \\
\hline EDUCATION \& EDUCATIONAL RESEARCH & 85 de 263 & Q2 \\
\hline
\end{tabular}

Datos de la edición 2019 de Journal Citation Reports

Por último, las conclusiones principales y resultados de este trabajo se proponen para publicar en un artículo que aglutine la investigación principal que vertebra este trabajo y que estudiará la relación entra la competencia de trabajo en equipo y los proyectos innovadores exitosos (estudio 3) que actualmente está en revisión por una revista JCR

M. Dolores Storch de Gracia, Bernardo Llamas, Luis F. Mazadiego, Noelia Cruz Pérez y Juan Carlos Santamarta "Studying the relationship between teamwork competition and successful innovative Projects" Revista Management Decision.

La revista Management Decision tuvo un factor de Impacto en 2019 de 2.723 siendo su categoría JCR la siguiente:

\begin{tabular}{|l|l|l|}
\hline Categoría de JCR® & Clasificación en la categoría & Cuartil en la categoría \\
\hline BUSINESS & 70 de 152 & $Q 2$ \\
\hline MANAGEMENT & 102 de 226 & $Q 2$ \\
\hline
\end{tabular}

Datos de la edición 2019 de Lournal Citation Reports 


\subsection{Habilidades transversales clave a considerar en los proyectos de innovación}

\subsubsection{Sobre el marco lógico de un proyecto.}

El creciente interés en la capacitación de jóvenes ingenieros en el campo de la gestión de proyectos se basa en diferentes factores (Ojiako, Ashleigh, Chipulu y Maguire, 2011), especialmente en el interés específico de las organizaciones en que los ingenieros desarrollen competencias transversales (Pollack, 2007) y competencias emocionales (Hartman, 2008) que son relevantes para la gestión de proyectos. En la capacitación en gestión de proyectos, es cada vez más importante desarrollar y considerar competencias transversales o humanas (Pant \& Baroudi, 2008): como se muestra en la Figura 11, comunicación, creatividad y trabajo en equipo son competencias que los ingenieros deben adquirir durante su capacitación para obtener un adecuado nivel en su desempeño.

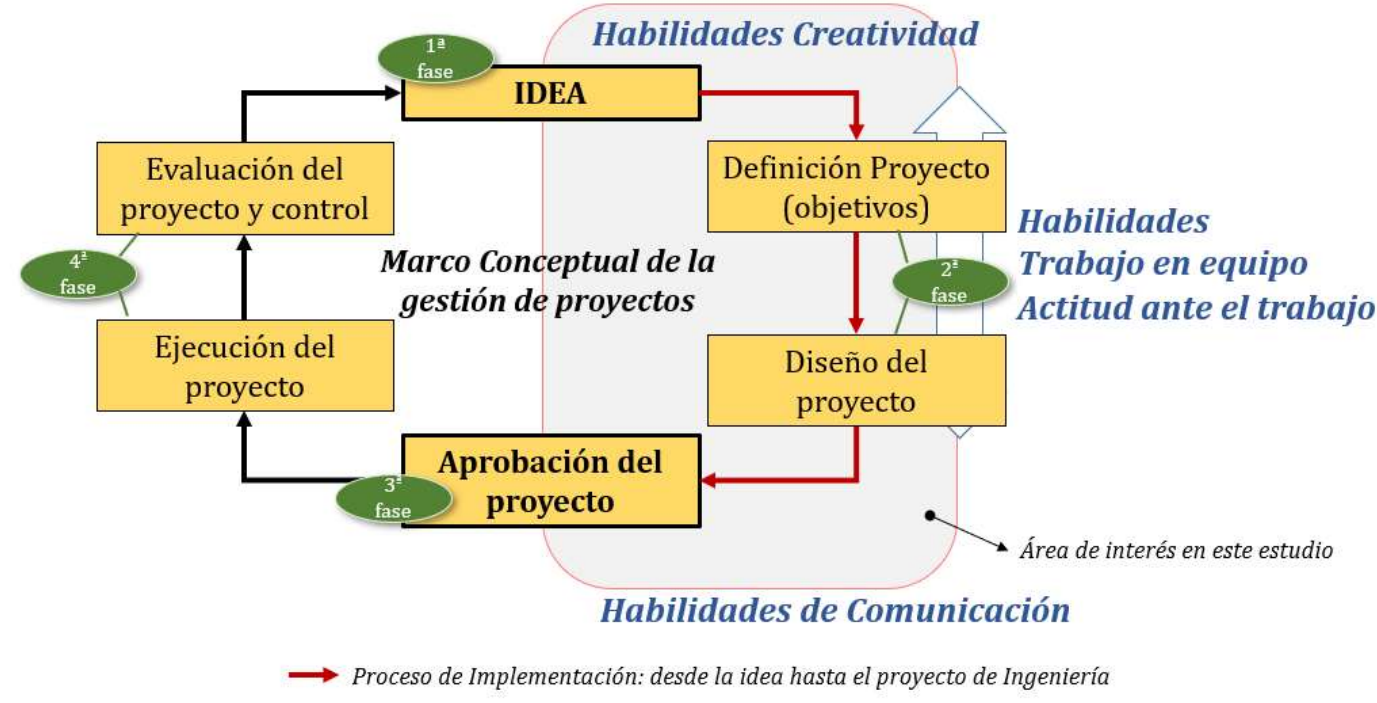

Figura 11. Marco conceptual y lógico de un proyecto.

La novedad del presente estudio se basa en un ejercicio eminentemente práctico, donde la interacción entre universidad y La empresa está presente. La evaluación del trabajo de los ingenieros se basó en las habilidades citadas anteriormente: creatividad, trabajo en equipo, actitud hacia el trabajo y comunicación. En el estudio, se considera el marco lógico de un proyecto (Figura 11) y se aborda la evaluación del proyecto desde una perspectiva práctica: los ingenieros forman pequeños grupos para proponer una idea (fase 1) y 
transformarla en una propuesta de proyecto (definición del objetivo) y diseño del proyecto, fase 2), que será evaluado por un grupo de expertos del sector público y privado para considerar la aprobación del proyecto (fase 3). Sectores como energía, minería, construcción y servicios, que normalmente contratan graduados de este programa, participaron en este ejercicio innovador. La Figura 11 muestra el marco lógico de un proyecto y es posible identificar dos problemas críticos: ideas o soluciones de innovación (fase 1 y 2) y la aprobación del proyecto a través de la financiación (fase 3); esas fases se considerarán en este estudio. Mientras que la ejecución y control del proyecto (fase 4) representan la ejecución / construcción y el control del proyecto. Para alcanzar cada una de las fases 1 y 2 , los equipos de trabajo tuvieron que generar una idea del proyecto de ingeniería y realizar un análisis DAFO (Fortalezas, Debilidades, Oportunidades y Amenazas) de su viabilidad.

A través de este ejercicio, se definió el propósito del proyecto. Para la siguiente fase de diseño, se utilizó el modelo de generación de puesta en marcha LEAN-CANVAS (Osterwalder, 2010). Finalmente, la fase de aprobación del proyecto (fase 3) se materializó a través del Ejercicio del Inversor (Llamas et al, 2019). En esta fase, se solicitó a los inversionistas que financiaran los proyectos en un escenario de recursos limitados. Una vez que se definieron las diferentes fases de conceptualización de un proyecto, se intentó alinear estas fases con las diferentes habilidades básicas requeridas: habilidades de creatividad e innovación para la fase 1 , habilidades de trabajo en equipo para la fase 2 y habilidades de comunicación para la fase 3 .

\section{Hipótesis de trabajo}

Estas competencias se midieron en una muestra del 100\% de los estudiantes de ingeniería de minas que participaron en este estudio1 (dieciocho participantes: 13 hombres y 5 mujeres), la mayoría de los cuales trabajaban y, por lo tanto, la metodología propuesta permite un análisis de la presencia de habilidades en el mercado laboral.

Se trata de un análisis de equipos de trabajo de alumnos de máster universitario de Ingeniería de Minas para estudiantes por evaluación continua. 


\subsubsection{Proyectos y equipos en evaluación.}

\section{Proyecto "Fly food"}

El proyecto consistió en implementar un servicio de entrega de alimentos a domicilio utilizando sistemas de aeronaves pilotadas a distancia (RPAS) como medio de transporte. La idea era básicamente proporcionar una flota de RPAS a una compañía de hospitalidad o una empresa de reparto a domicilio para reemplazar a sus distribuidores con tales drones. EI RPAS estaría equipado con un sistema de geolocalización y sería controlado con un software que transforma una coordenada GPS en comandos para mover el RPAS al consumidor y devolverlo. EI RPAS también tendría una caja incorporada para ingresar la orden equipada con un sensor de presión para activarse cuando el cliente extraiga el producto del RPAS para reanudar el vuelo de regreso al punto de partida.

Plazo de ejecución: 12 meses, presupuesto: $165.000 €$.

\section{Proyecto de sistemas EcoRun.}

Propuso un sistema de recuperación de energía a través de los pasos, como estrategia hacia las ciudades inteligentes. Mientras se investiga esta tecnología de recuperación de energía, el proyecto aumentó su interés potencial para ser utilizado en pistas urbanas y áreas deportivas, especialmente considerando el creciente interés del público por el jogging y la implementación de medidas respetuosas con el medio ambiente.

El principio técnico se basó en pistas de cualquier tamaño formadas por materiales piezoeléctricos para transformar la energía mecánica en energía eléctrica. Esta energía eléctrica se almacenaría en baterías para uso en alumbrado público cerca de la pista y / o área deportiva dentro de la ciudad, para lograr tanto un beneficio ambiental como una reducción en el costo del consumo de electricidad.

Plazo de ejecución: 21 meses, presupuesto: $338.000 €$.

\section{Proyecto GEO2COOL}

El proyecto consistió en la instalación de un sistema de intercambio de calor geotérmico de circuito cerrado. Se propuso colocar en la entrada de aire de la turbina de gas en plantas de ciclo combinado, para aumentar su eficiencia.

Mediante un sistema de bomba de calor de ciclo inverso, la energía se extraería del aire de entrada a la turbina, reduciendo así su temperatura. Para este propósito, se usaría un refrigerante apropiado para transportar el calor del aire al subsuelo a través de una sonda geotérmica de entalpía baja o media. 
Con una reducción estimada de la temperatura del aire de entrada de la turbina hasta $8^{\circ}$ C, el rendimiento general del ciclo sería

Aumentó significativamente, proporcionando así un impacto económico significativo para la empresa.

Plazo de ejecución: 18 meses, presupuesto: $418.500 €$.

\section{Proyecto iVibe}

El objetivo del proyecto era desarrollar un estuche para el teléfono móvil iPhone con vibración de voladura rigurosa y precisa Capacidades de detección, aprovechando la funcionalidad de este móvil para detectar vibraciones en los tres ejes. Este proyecto comprendería el desarrollo de hardware (selección de material y construcción de la funda) y software (aplicaciones). Plazo de ejecución: 12 meses, Presupuesto: $130.000 €$.

\subsubsection{Creatividad}

El Ejercicio del Inversor consiste en la evaluación práctica de las propuestas de proyectos por un grupo de seis profesionales externos, Sin relación con la dinámica del curso. Aunque dos de ellos son profesores de la misma institución, no han participado en la enseñanza de esta materia en particular. Otro criterio para la selección de los expertos fue maximizar la gama de sectores representados. En esta ocasión, los sectores representados incluyeron minería, construcción, energía, agua, economía e investigación. La amplia gama de sectores se consideraron sectores principales donde los ingenieros podían obtener su primer trabajo. Para que estos expertos evalúen las propuestas del proyecto, los equipos del proyecto deben presentar la idea junto con los objetivos y el diseño del proyecto con un límite de tiempo de 12 minutos. Se pidió a los expertos que completaran un cuestionario de escala Likert de cinco puntos que consistía en una evaluación de la competencia de la creatividad según estos tres indicadores principales: novedad, funcionalidad (desglosada en aspectos técnicos, económicos y sociales) e impacto de los proyectos. Además de este cuestionario, también se pidió a los expertos que distribuyeran 1.200.000€ entre los cuatro proyectos, basando su decisión de dónde invertir en dos requisitos: 1) deben invertir en al menos dos proyectos, y 2) la inversión mínima debe ser de $€ 40,000$. Tenga en cuenta que la cantidad de capital de inversión disponible cubre el volumen total de los presupuestos presentados para los cuatro proyectos. El propósito de esto fue lograr un alto grado de subjetividad en nuestro enfoque innovador para la evaluación de los proyectos, mientras 
que al mismo tiempo buscamos una mayor cercanía con las condiciones y operaciones reales del mercado.

Los expertos que formaron parte de este panel fueron los siguientes:

- Javier Carrillo de Albornoz; Ingeniero de Minas por la UPM, con más de 20 años de experiencia, actualmente es Business Development en Maxam.

- Elías Rodríguez: Ingeniero químico con más de 30 años de experiencia en proyectos de investigación relacionados con el medioambiente y energía

- Julian Alonso: Es Doctor Ingeniero de Minas por la UPM, con más de 30 años de experiencia, en la actualidad es profesor a tiempo completo y Director del Departamento de Ingeniería geológica y minera en la Escuela de Ingenieros de Minas y Energía de la UPM.

- Juan Pous: Es Ingeniero de Minas por la UPM, con más de 30 años de experiencia, Director de Innovación en Sacyr y profesor asociado en la UPM durante la participación en esta actividad. En la actualidad es profesor a tiempo completo en la Escuela de Ingenieros de Minas y Energía de la UPM.

- Bernardo Llamas: Es Ingeniero de Minas por la UPM, con más de 20 años de experiencia en la empresa privada en distintas posiciones, en la actualidad es profesor a tiempo completo en la Escuela de Ingenieros de Minas y Energía de la UPM.

- Lola Storch de Gracia: Es Ingeniero de Montes por la UPM, con más de 20 años de experiencia, Responsable de innovación en Redexis Gas y profesora asociado en la Escuela de Ingenieros Industriales de la UPM

\subsubsection{Trabajo en equipo}

La capacidad de trabajar en equipo es una competencia transversal e interpersonal claramente reconocida y de gran importancia en el marco de las competencias básicas que los ingenieros deben adquirir en las diferentes titulaciones universitarias (Comisión de acreditación de ingeniería, 2014). El enfoque estructural del aprendizaje cooperativo se basa en la creación de estructuras de manera libre (Kagan, 1989; Kuusisto \& Tirri, 2015). En este caso, los ingenieros tuvieron la libertad de crear sus equipos, recomendando homogeneidad en el tamaño del equipo.

Los ingenieros crearon cuatro grupos, tres con cinco miembros y un último grupo de tres miembros. El tema y el proyecto también fueron de libre elección, siendo una condición que los proyectos estaban relacionados con la ingeniería (Dillenbourg, 1999). 
El trabajo en equipo es una de las competencias más valoradas y se incluye en la mayoría de los indicadores al evaluar la capacitación proporcionada por un título universitario (Aritzeta, Swailes y Senior, 2007; Sancho-Thomas, Fuentes-Fernández y FernándezManjón, 2009). Para evaluar el comportamiento grupal (dinámica de grupo, comunicación, manejo de conflictos y otros), se realizó el cuestionario de Belbin, siendo esta teoría una de las más reconocidas para evaluar la dinámica y el éxito de un equipo (Meredith Belbin, 2010b).

Belbin proporciona la definición de hasta nueve roles de equipo diferentes que un individuo puede desempeñar. Un rol de equipo se define como el patrón de comportamiento que facilita el progreso de todo un equipo (Alberola, del Val, Sánchez-Anguix, Palomares y Dolores Teruel, 2016), o el comportamiento que un individuo muestra en los equipos de trabajo (Aritzeta et al, 2017). Un rol está definido por seis factores (Thomas y Mengel, 2008): personalidad, capacidad mental, valores y motivaciones actuales, limitaciones de campo, experiencia y aprendizaje de roles. Esta teoría establece que un equipo de trabajo será más fácil de motivar (Lupuleac, Lupuleac, y Rusu, 2012) y tendrá mejores resultados cuando exista un equilibrio entre todos los roles, en contraste con los equipos en los que faltan algunos de los roles o Presente en exceso (Belbin, 1981). Si inicialmente se definieron ocho roles, en actualizaciones recientes de la teoría, se agregó el rol de especialista para los equipos que requieren un conocimiento técnico detallado sobre un tema específico (Meredith Belbin, 2010b):

\subsubsection{Análisis de resultados de la metodología empleada (Belbin)}

A continuación, se muestran las preguntas realizadas en el cuestionario y sobre las respuestas el rol al que se está dando peso en la puntuación para un mejor entendimiento de la metodología. La asignación de roles está basada en la descripción de roles teoría Belbin descrita en el apartado 2.4.3.

\section{1.- ¿Qué es lo que yo creo que puedo aportar a un equipo?}

a) Creo que sé ver rápidamente nuevas oportunidades y sacar partido de ellas. (INVESTIGADOR RECURSOS)

b) Sé trabajar bien con una amplia variedad de gente. (COHESIONADOR)

c) Producir ideas es una de mis aptitudes personales. (CREATIVO) 
d) Mi habilidad reside en ser capaz de hacer que las personas hablen cuando detecto que tienen algo de valor con lo que contribuir a los objetivos del grupo. (COORDINADOR)

e) Mi efectividad personal tiene mucho que ver con mi capacidad para "seguir hacia delante". (DETALLISTA)

f) No me importa afrontar una impopularidad temporal si esta lleva a resultados que al final merezcan la pena. (MOTOR)

g) Normalmente soy capaz de saber que es realista y que es lo que tiene posibilidades de funcionar. (IMPLEMENTADOR)

h) Puedo argumentar razonadamente en favor de distintas alternativas de acción excluyentes sin que estén presentes los prejuicios. (EVALUADOR)

i) Mis comentarios sobre los puntos generales y específicos son siempre bien recibidos. (ESPECIALISTA)

\section{2.- Si tuviera algún problemilla trabajando en equipo, podría ser debido a:}

a) No estoy a gusto a menos que las reuniones estén bien estructuradas, controladas y generalmente bien conducidas. (IMPLEMENTADOR)

b) Tengo inclinación a ser demasiado generoso hacia otros que tienen un punto de vista válido al que no se le ha prestado suficiente atención. (COORDINADOR)

c) Cuando en el equipo nos ponemos a buscar nuevas ideas, yo tiendo a hablar demasiado. (INVESTIGADOR DE RECURSOS)

d) Mi punto de vista, más objetivo, hace que me resulte difícil el reunirme cómodamente con colegas. (EVALUADOR)

e) Algunas veces soy visto como enérgico y dominante si se tiene que hacer una cosa. (MOTOR)

f) Encuentro difícil el dirigir estando al frente, quizá porque me puedo dejar llevar demasiado por el ambiente del grupo. (COHESIONADOR)

g) Tengo tendencia a ensimismarme en ideas que se me ocurren a mí; y por ello perder el contacto con lo que estamos haciendo. (CREATIVO)

h) Mis colegas ven que suelo estar preocupado innecesariamente por los detalles y por la posibilidad de que las cosas vayan mal. (DETALLISTA)

i) Me cuesta contribuir salvo que el tema tenga algo ver con algo que conozca bien. (ESPECIALISTA)

\section{3.- Cuando estoy metido en un proyecto con otras personas:}

a) Tengo capacidad para influir sobre las personas sin presionarlas. (COORDINADOR) 
b) Mi nivel de atención continua me evita el cometer tanto omisiones como errores por descuido. (DETALLISTA)

c) No dudo en tomar medidas para asegurar que en la reunión no se pierde el tiempo ni se pierden de vista los objetivos. (MOTOR)

d) Se puede contar conmigo para contribuir con algo original. (CREATIVO)

e) Estoy siempre dispuesto a respaldar una buena sugerencia de interés para todos. (COHESIONADOR)

f) Me gusta buscar lo último en ideas y desarrollos. (INVESTIGADOR DE RECURSOS)

g) Creo que mi capacidad de juicio puede ayudar a tomar la decisión adecuada. (EVALUADOR)

h) Se puede confiar en mí para contar con que todo el trato esencial esté organizado. (IMPLEMENTADOR)

i) Se puede tener la seguridad de que seré yo mismo. (ESPECIALISTA)

\section{4.- Mi forma de abordar el trabajo en equipo es:}

a) Tengo bastante interés en conocer mejor a los colegas. (COHESIONADOR)

b) Soy reacio a dar una oportunidad a los puntos de vista de otros o a apoyar el punto de vista de una minoría. (MOTOR)

c) Generalmente encuentro un argumento con el que refutar proposiciones poco firmes.

(EVALUADOR)

d) Creo que tengo talento para hacer que funcionen las cosas una vez tiene que ponerse en práctica un plan. (IMPLEMENTADOR)

e) Tengo tendencia a evitar lo obvio y salir con lo inesperado. (CREATIVO)

f) Aporto un toque de perfección a todo el trabajo que dirijo. (DETALLISTA)

g) Hago uso de contactos ajenos al grupo en sí mismo. (INVESTIGADOR DE RECURSOS)

h) Al mismo tiempo que estoy interesado en todos los puntos de vista, no tengo ningún problema cuando la decisión ha de ser tomada. (COORDINADOR)

i) Contribuyo cuando realmente sé del tema. (ESPECIALISTA)

\section{5.- Obtengo satisfacción de un trabajo porque...}

a) Disfruto analizando situaciones y sopesando las posibles alternativas. (EVALUADOR)

b) Me intereso por encontrar soluciones prácticas a los problemas. (IMPLEMENTADOR)

c) Me gusta ver que estoy fomentando buenas relaciones de trabajo. (COHESIONADOR)

d) Sé influir fuertemente en la toma de decisiones. (MOTOR)

e) Sé contactar con gente que podría tener algo nuevo que ofrecer. (INVESTIGADOR DE RECURSOS) 
f) Sé poner a la gente de acuerdo en un camino a seguir, si es necesario. (COORDINADOR)

g) Me siento en mi elemento cuando puedo dedicar toda mi atención a una tarea. (DETALLISTA)

h) Me gusta encontrar un área que ensanche mi imaginación. (CREATIVO)

i) Siento que estoy utilizando mi formación y mis especiales aptitudes para sacar partido de las situaciones. (ESPECIALISTA)

\section{6.- Si de repente me dan la responsabilidad de una tarea difícil, con un tiempo limitado y gente desconocida:}

a) Me apetecería retirarme a un rincón para idear una salida al problema antes que aplicar una línea de acciones. (CREATIVO)

b) Estaría dispuesto a trabajar con la persona que me mostrara la propuesta más positiva.

\section{(COHESIONADOR)}

c) Encontraría la manera de reducir el tamaño de la tarea discerniendo a qué aspecto contribuirán mejor los diferentes individuos. (COORDINADOR)

d) Mi sentido natural de la urgencia ayudaría a asegurar que no sobrepasáramos el plazo previsto. (DETALLISTA)

e) Creo que no me alteraría y mantendría mi capacidad de pensar intacta. (EVALUADOR)

f) Mantendría invariables los objetivos a pesar de las presiones. (IMPLEMENTADOR)

g) Llevaría de la mano al grupo si viera que no está haciendo ningún progreso. (MOTOR)

h) Fomentaría discusiones de cara a estimular nuevas ideas y hacer que algo empezara a moverse. (INVESTIGADOR DE RECURSOS)

i) Enfocaría todo el problema desde el punto de vista del conocimiento que tuviera sobre el tema. (ESPECIALISTA)

\section{7.- Haciendo referencia a los problemas que tengo trabajando en equipo:}

a) Suelo mostrar mi impaciencia con aquellos que están impidiendo el progresar. (MOTOR)

b) Los demás podrían criticarme por ser demasiado analítico e insuficientemente intuitivo.

(EVALUADOR)

c) Mi deseo de asegurar que el trabajo se hace de manera adecuada puede suponer un freno.

(DETALLISTA)

d) Tiendo a aburrirme bastante fácilmente y a confiar en uno o dos miembros del grupo interesantes para sacarme del aburrimiento. (INVESTIGADOR DE RECURSOS)

e) Encuentro difícil empezar algo a no ser que las metas estén claras. (IMPLEMENTADOR)

f) A veces soy pobre en la explicación y clarificación de ideas complejas que se me ocurren a mí. (CREATIVO) 
g) Soy consciente de que pido a los otros las cosas que no puedo hacer por mí mismo.

\section{(COORIDINADOR)}

h) Dudo en exponer mis puntos de vista si me encuentro con una buena oposición.

\section{(COHESIONADOR)}

i) Me inclino a pensar que estoy perdiendo el tiempo y podría hacerlo mejor yo solo.

(ESPECIALISTA)

\subsubsection{Actitud hacia el trabajo.}

Elegir un gerente de proyecto con un perfil de personalidad que coincida con el proyecto es una de las decisiones más influyentes para el éxito de un proyecto (Cohen, Ornoy, \& Keren, 2013; Müller \& Rodney Turner, 2006). Esto es crítico en proyectos de I + D en los que el comportamiento de liderazgo puede fomentar y apoyar la creatividad de los empleados (Jaskyte y Kisieliene, 2006). Existen varios estudios para definir los perfiles psicológicos como una herramienta para conocer y definir los estilos de pensamiento de los individuos (Jung, 1921, 1990; Myers-Briggs, 1962). Este perfil se superpone al resto del desempeño normal del individuo y, por lo tanto, marca el comportamiento en su interacción con el medio y con los demás individuos.

Para comprender mejor el perfil de cada individuo y su perfil dominante hacia el trabajo, se diseñó un cuestionario para evaluar el estilo de cada ingeniero frente al trabajo, considerando los cuatro perfiles definidos según Jung (1921). Los resultados para cada equipo se compilan en la Figura 18, en la que diferentes líneas de color representan los cuatro tipos principales de pensamiento. El pensamiento analítico se distingue por la mentalidad lógica y analítica, apreciando el rigor y la claridad para trabajar. Es comúnmente asociado con la abstracción, las matemáticas y las habilidades de resolución de problemas. El pensamiento secuencial corresponde a individuos organizados y planificadores, con una forma de trabajo muy estructurada y metódica: asumen habilidades de organización y un trabajo meticuloso. El pensamiento interpersonal se corresponde con personas más enfocadas en el cuidado de los miembros del equipo de trabajo, con una Implicación afectiva en su trabajo.

El pensamiento imaginativo corresponde a personas más intuitivas y originales, que trabajan más por conceptos y con mayor competencia para la creatividad. 
El comportamiento personal evalúa las fortalezas y debilidades de cada miembro de un equipo (Figura 12). Existe una conexión entre el comportamiento personal y la actitud hacia el trabajo, como se puede ver en la siguiente figura, que también analiza para cada perfil la contribución máxima que cada individuo hará en términos de Retorno de la Inversión (Rol) de acuerdo con la combinación de variables anteriores.

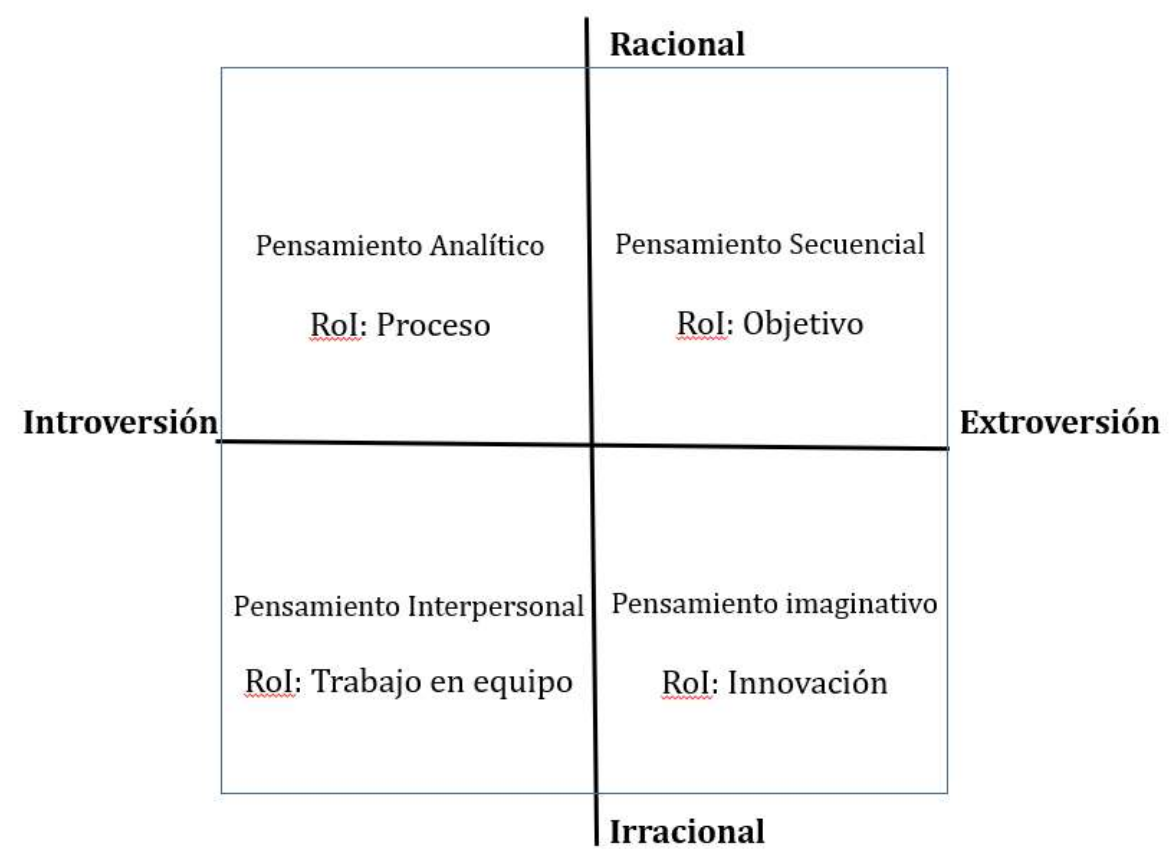

RoI: Return of Investment

Figura 12. Comportamiento personal versus actitud hacia el trabajo.

\subsubsection{Comunicación}

Considerada como una importancia relevante para los gerentes (Ramazani y Jergeas, 2015; Thornberry y Weintraub, 1983), se considera comunicación tanto interna (trabajo en equipo) como externa (cliente y partes interesadas). Abarca el trabajo en equipo basado en la confianza y la cooperación, en lugar de centrarse en acciones y procesos.

Este estudio evalúa las habilidades de comunicación de los equipos de trabajo y se evalúa mediante las habilidades orales y escritas (Figura 18). Esta evaluación comienza, al igual que las competencias anteriores, a través del juicio experto, que obtuvo de 1 a 5 las siguientes habilidades: 
- Las habilidades escritas consideradas fueron estructura de la comunicación, estilo, recursos necesarios, extensión y reglas gramaticales.

- Las habilidades orales consideradas fueron la estructura de la comunicación, el estilo, los recursos necesarios, la gestión del tiempo, las técnicas de comunicación oral, escuchar al interlocutor y responder.

En la siguiente figura se muestra la rúbrica utilizada por los expertos para la valoración de creatividad y comunicación.

\begin{tabular}{|c|c|c|c|c|c|c|c|}
\hline & & & & & & & Descripción \\
\hline CREATIVIDAD & & 1 & 2 & 3 & 4 & 5 & \\
\hline Novedad & & & & & & & $\begin{array}{l}\text { Avance con respecto al Estado del Arte correspondiente } \\
\text { con el área de conocimiento: Relevancia de los enfoques y } \\
\text { soluciones para la situación planteada }\end{array}$ \\
\hline \multirow{3}{*}{ Utilidad } & Técnica & & & & & & \multirow{3}{*}{$\begin{array}{l}\text { Grado de aplicación de la solución propuesta; viabilidad } \\
\text { técnica y económica de la solución propuesta }\end{array}$} \\
\hline & Económica & & & & & & \\
\hline & Social, ambiental, otros & & & & & & \\
\hline Impacto & & & & & & & $\begin{array}{l}\text { Capacidad de llegar al mercado: capacidad de modificar el } \\
\text { Estado del Arte actual y de modificar el modo de } \\
\text { desarrollar un proceso/forma de proceder }\end{array}$ \\
\hline COMUNICACION & & 1 & 2 & 3 & 4 & 5 & \\
\hline Estructura de la comunicación & Escrito & & & & & & $\begin{array}{l}\text { Organiza la información para facilitar la comprensión y } \\
\text { teniendo en cuenta el propósito de la comunicación. }\end{array}$ \\
\hline Estilo & E & & & & & & $\begin{array}{l}\text { Utiliza el estilo adecuado teniendo en cuenta las } \\
\text { expectativas y conocimientos previos de los destinatarios. }\end{array}$ \\
\hline Recursos necesarios & E & & & & & & $\begin{array}{l}\text { Utiliza los recursos gráficos y los medios necesarios para } \\
\text { comunicar de forma efectiva la información. }\end{array}$ \\
\hline Extensión & E & & & & & & $\begin{array}{l}\text { Se ajusta a la extensión indicada o prevista para el } \\
\text { documento }\end{array}$ \\
\hline Normas gramaticales & E & & & & & & Utiliza correctamente las normas gramaticales. \\
\hline Estructura de la comunicación & Oral & & & & & & $\begin{array}{l}\text { Organiza la información para facilitar la comprensión y } \\
\text { teniendo en cuenta el propósito de la comunicación. }\end{array}$ \\
\hline Estilo & 0 & & & & & & $\begin{array}{l}\text { Utiliza el estilo adecuado teniendo en cuenta las } \\
\text { expectativas y conocimientos previos de los destinatarios. }\end{array}$ \\
\hline Recursos necesarios & 0 & & & & & & $\begin{array}{l}\text { Utiliza los recursos gráficos y los medios necesarios para } \\
\text { comunicar de forma efectiva la información. }\end{array}$ \\
\hline Gestión del tiempo & 0 & & & & & & $\begin{array}{l}\text { Se ajusta al tiempo indicado o previsto para la } \\
\text { comunicación }\end{array}$ \\
\hline Técnicas de comunicación oral & 0 & & & & & & Utiliza correctamente técnicas de comunicación oral \\
\hline Escucha al interlocutor y responde & 0 & & & & & & $\begin{array}{l}\text { lesponde de forma clara y precisa a sus preguntas o } \\
\text { comentarios }\end{array}$ \\
\hline
\end{tabular}

Figura 13. Rúbrica de creatividad y comunicación. 


\subsection{Presentación del método AHP y aplicación a las alternativas propuestas}

\subsubsection{Jerarquización matemática}

El proceso de toma de decisiones fue apoyado por algoritmos basados en múltiples criterios que se utilizaron para seleccionar la mejor alternativa entre los proyectos evaluados. Un numero de algoritmos matemáticos se han desarrollado para este propósito (Ho, 2008). La metodología AHP es uno de los algoritmos más utilizados (Zheng et al., 2018), siendo aplicado a diferentes soluciones: planificación, selección de alternativas, identificación de recursos, resolución de conflictos, optimización y otros (Thomas et al., 2013; Yazdi y Zarei, 2018; Multicriterio metodología Descargado por la Sra. Lola Storch de Gracia a las 00:57 25 de octubre de 2018 (PT) Randelovic et al., 2018). Entre las ventajas que aporta esta metodología se encuentran: simplicidad, facilidad de uso y gran flexibilidad (Vaidya y Kumar, 2006; Patari et al., 2018).

El método de AHP propuesto para evaluar las propuestas de proyectos en un entorno de Ol está estructurado en las siguientes fases:

- Descripción de los criterios considerados: de acuerdo con los procesos descritos por el Metodología PMI, se describen y evalúan los criterios considerados.

- Organizar los criterios en una estructura de árbol: los criterios están estructurados por niveles, hasta Alcanzando el medible.

- Asignación de ponderaciones a cada criterio: la asignación de ponderaciones a cada criterio. Es constante para la evaluación de las alternativas. La asignación de peso será realizada por matrices de comparación por pares, y la normalización de pesos, Según la estructura jerárquica construida para este fin.

- Asignación de valores a criterios medibles: los criterios finales de cada rama deben ser medible Con el objetivo de establecer comparaciones entre más de siete alternativas, el método propone en este estudio el uso del método AHP en modo absoluto En este caso, las alternativas se comparan con un estándar o modelo de referencia. 
Cada una de las alternativas en estudio será evaluada considerando el modelo que será construido explícitamente para este objetivo, considerando la siguiente ecuación, que es la ecuación de AHP para la evaluación de las alternativas en estudio:

$$
A_{1}=\sum_{i=1}^{n} W_{i} \cdot V_{i},
$$

\section{Ecuación 1. Ecuación AHP para evaluar alternativas en estudio}

\subsubsection{Selección de criterios}

\section{Criterios técnicos.}

Para la definición de los criterios dependientes de este bloque, han sido considerados cuatro criterios y procesos descritos por el PMP (PMI, 2017).

Alcance: define todos los procesos y trabajos necesarios para llevar a cabo el proyecto. Entre los subcriterios más críticos, es importante resaltar los siguientes: gestión (cómo se llevarán a cabo otros procesos y requisitos (necesidades de los interesados); definición; y Estructura de desglose del trabajo (EDT)a través de una descomposición de criterios.

Tiempo: es un criterio clave en la planificación de proyectos. Los siguientes subcriterios deben ser considerados: definición de tareas e hitos (descripción basada en la EDT descrita en el criterio técnico anterior); estimación del tiempo y recursos necesarios; y Restricciones impuestas por los recursos o por el tiempo.

Coste: hay una limitación en el proceso de toma de decisiones, aún más en un ambiente de Innovación Abierta (OI). Para estudiar esto, se han considerado los siguientes subprocesos: planificación de costes - o cómo estimar costes, desarrollo de presupuesto o control de desviaciones; estimación de costes, calculando los costes de cada recurso utilizado para completar las actividades del proyecto; y herramientas económicas considerando la tasa interna de retorno, el valor en riesgo y el período de Recuperación de la inversión (PRI).

Calidad: cuando el objetivo alcanzado en el proyecto satisface las necesidades para las cuales fue emprendido. Esto incluye actividades reguladas como la planificación de la 
calidad; manual de calidad de acuerdo con ISO9000; y otros subcriterios como el cumplimiento del cliente.

\section{Criterios organizacionales.}

De acuerdo con los procesos de PMP, otros cuatro criterios fueron definidos en este bloque:

Recursos humanos: en cualquier tipo de proyectos, las personas tienen un papel fundamental. Sin ellas, nada se puede lograr. Por lo tanto, es importante considerar al personal para desarrollar el proyecto. Además, los diferentes proyectos a evaluar tendrán diversos requisitos relativos a la estructura del personal y la formación. Los subprocesos considerados en este capítulo serán el director del proyecto como líder del equipo, el equipo debido a la motivación del equipo y el estilo de liderazgo que es clave para el éxito del proyecto. En este caso, hay tres aspectos clave: identificación de roles dentro de un equipo (por ejemplo, utilizando la teoría de Belbin), un estilo de liderazgo apropiado (por ejemplo, a través de la teoría situacional del liderazgo) y la adquisición y desarrollo del equipo, y el plan de manejo de conflictos, definido como la herramienta que asegurará una mayor productividad y mejor toma de decisiones.

Comunicación: esta es la habilidad principal que debe tener un coordinador de proyecto. Para la efectividad de la comunicación, es necesario contar con un plan de comunicaciones. Según la necesidad del proyecto, y la correcta gestión de la información y su flujo.

Riesgos: la innovación inherente en cada proyecto implica riesgo, que aumenta con la cantidad de innovación involucrada. Para proteger la inversión, una serie de subcriterios se establecen que tienen como objetivo evaluar este parámetro: identificación de riesgos, análisis, respuesta y monitoreando. Los riesgos considerados deben ser económicos, tecnológicos y temporales, y la evaluación de estos se basará en la probabilidad y el impacto (matriz de riesgo).

Partes interesadas: lograr y mantener el interés en el proyecto es una de las tareas más delicadas: contar con soporte interno y externo es una de las principales obligaciones de los coordinadores del proyecto. Según el PMI, este proceso se describe mediante la planificación, gestión y control de la participación de los grupos de interés. 


\subsubsection{Descripción de las alternativas}

La Escuela Técnica Superior de Ingenieros de Minas y Energía de la Universidad Politécnica de Madrid (UPM) ofrece una formación holística, donde los aspectos técnicos se complementan con competencias transversales como la creatividad y la innovación.

En consecuencia, se anima a los ingenieros a presentar un proyecto innovador en el último año del Máster en Ingeniería de Minas. Algunas de las propuestas de proyectos han sido incluidas en esta sección; Por otro lado, otros proyectos han sido seleccionados porque tienen recientemente aprobado por instituciones financieras y empresas dentro del laboratorio de ingeniería de proyectos.

Proyecto A. Basado en el principio de tecnología CAES, se propone aplicar en estructuras geológicas de áreas poco profundas e hibridación de energía térmica y tecnología de almacenamiento geotérmico. La idea es premiada por el concurso de ideas actas de la UPM. El principio consiste en desarrollar una cavidad, en una estructura geológica óptima, con el propósito de acumular energía en los períodos de baja demanda de energía eléctrica y generar electricidad a través del aire comprimido en los puntos de demanda. El proyecto propone relacionar la energía de almacenamiento con energía renovable no predecible (principalmente energía eólica).

Plazo de ejecución: 36 meses; presupuesto: $553.000 €$.

Proyecto B. Consiste en un sistema de recuperación de energía a través de los pasos, como estrategia hacia las ciudades inteligentes. El proyecto propone su uso en pistas y área deportiva en ciudades. La tendencia del running está aumentando, al igual que la aplicación de medidas que son amigables con el medio ambiente.

El principio técnico se basa en pistas de cualquier tamaño formadas por materiales piezoeléctricos para transformar la energía mecánica en electricidad. Esta energía será almacenada en baterías para ser utilizada en alumbrado público cerca de la pista y / o área deportiva dentro de la ciudad, con beneficio ambiental significativo y reducción del costo del consumo eléctrico.

Plazo de ejecución: 21 meses; presupuesto: $338.000 €$.

Proyecto C. El proyecto se basa en la transformación de la energía eléctrica en hidrógeno en periodos de exceso de producción. Para optimizar el almacenamiento de hidrógeno, se utilizarán los gasoductos convencionales. Las propiedades de combustión y la disminución 
de la contaminación (liberación de CO2 y NOX principalmente), facilitando así la hibridación de las redes de energía actualmente desconectadas. Esta propuesta ganó una subvención en el concurso de licitación de una empresa (UP4 Solutions Grant).

Plazo de ejecución: 32 meses, con un presupuesto de $254.000 €$.

Proyecto D. Aplicación de un sistema de intercambio de calor geotérmico de circuito cerrado ubicado en una turbina de gas de entrada de aire en ciclo combinado.

Mediante un sistema de bomba de calor de ciclo inverso, la energía se extrae del aire de entrada a la turbina, reduciendo así su temperatura. Para este procedimiento, se utiliza un refrigerante, capaz de transportar el calor del aire al subsuelo a través de una sonda geotérmica de baja o entalpia media.

Con esta reducción de la temperatura del aire de entrada (hasta $8^{\circ} \mathrm{C}$ ) a la turbina, la eficiencia global del ciclo se incrementa considerablemente, lo que proporciona un importante ahorro económico.

Plazo de ejecución:18 meses; presupuesto: $418.500 €$.

Proyecto E. Servicio de entrega a domicilio utilizando vehículos aéreos no tripulados (UAV) como medio de transporte. La idea es básicamente proporcionar una flota de vehículos aéreos no tripulados (UAV) a una empresa de hostelería o empresa de reparto a domicilio. EI UAV estará equipado con un sistema de geolocalización y será controlado con software que transforma las coordenadas GPS en comandos para mover el UAV al consumidor y devolución. EI UAV también tendrá un cuadro incorporado para ingresar la orden y un sensor de presión para que cuando el cliente extraiga el producto que el UAV transporta se reanude el vuelo hasta el punto de partida.

Plazo de ejecución: 12 meses; presupuesto de $165.000 €$. 


\subsection{Desarrollo del modelo matemático y su aplicación a los proyectos innovadores}

La elección del proyecto era libre y los aspectos a desarrollar en el cuestionario comprendían 8 apartados que recogían los 8 criterios que se exponen detalladamente a continuación y que se describen en la Figura 14 :

Se trata así de preparar un árbol de toma de decisiones considerando 8 criterios, 4 de carácter técnico y 4 de carácter organizativo.

Estos 8 apartados se corresponden con los aspectos principales que definen a cada proyecto según la metodología del Project Management Institute (PMI) que es una organización estadounidense sin fines de lucro que asocia a profesionales relacionados con la Gestión de Proyectos.

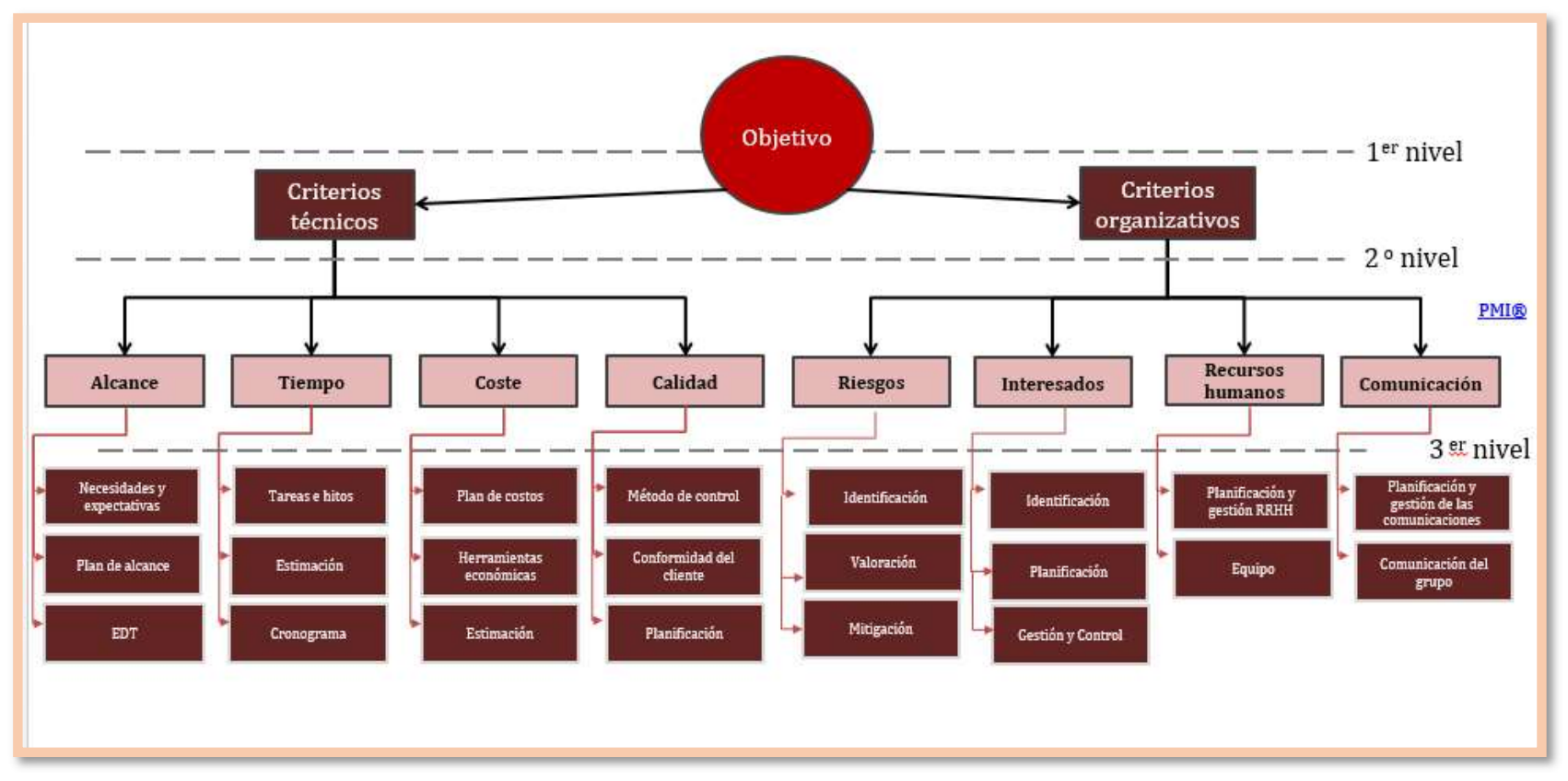

Figura 24: Criterios de selección de proyectos. Árbol de toma de decisiones

La Guía del PMBOK (del inglés Project Management Body of Knowledge), desarrollada por el Project Management Institute, contiene una descripción general de los fundamentos de la Gestión de Proyectos reconocidos como buenas prácticas para lograr un gerenciamiento eficaz y eficiente del proyecto. La guía del PMBOK describe 49 procesos de dirección de 
proyectos que clasifica en 10 áreas de conocimiento (Integración, Alcance, Tiempo, Costes, Calidad, Recursos, Comunicación, Riesgos, Adquisiciones e Interesados).

Para este estudio se han escogido las 8 áreas de conocimiento principales (sin considerar la integración que supone la validación de todas y las adquisiciones que son un área menor).

Además, se han dividido entre Criterios técnicos y organizativos. Se han analizado los siguientes criterios y subcriterios de acuerdo a la metodología propuesta por el PMI:

\section{BLOQUE CRITERIOS TÉCNICOS}

1. Alcance (Procesos y trabajo necesario para que el proyecto se lleve a cabo. Se pueden definir: el objetivo, entregables, criterios de aceptación, exclusiones, supuestos, restricciones, riesgos identificados y otros). Los subcriterios considerados fueron Necesidades y expectativas, Plan de alcance y EDT (Estructura de Desglose del Trabajo).

2. Tiempo (Plantear el cronograma con el grado de desarrollo que se considere). Los subcriterios a desarrolla fueron Tareas e Hitos, Estimación y Cronograma.

3. Costes (proponer la estructura de costes del proyecto con el grado de desarrollo que considere). Los subcriterios a considerar fueron el plan de Costes, Estimación y Herramientas económicas.

4. Calidad (La gestión de la calidad implica que el proyecto satisfaga las necesidades por las cuales se emprendió. Se solicitó planificar la gestión de la calidad del proyecto y posibles acciones de control que pueda considerar). Subcriterios a desarrollar se plantearon Planificación Método de control y Conformidad del cliente

\section{BLOQUE CRITERIOS ORGANIZATIVOS}

1. Riesgos (plantear cómo se planificarán y ejecutarán las actividades de identificación, análisis (probabilidad e impacto), respuesta y monitoreo de riesgos). Los subcriterios considerados fueron Identificación, Valoración y Respuesta y control a riesgos. 
2. Interesados (Plantear la gestión de los interesados (identificar, analizar y desarrollar relaciones con todas aquellas personas u organizaciones que se verán afectadas por el proyecto o afectarán de alguna forma al proyecto). Subcriterios considerados fueros Identificación, Planificación y Gestión y Control.

3. Recursos humanos: En cualquier tipo de proyectos, lo más importante son las personas. Sin ellas, no se podría llevar nada a cabo. La Gestión de los Recursos Humanos del Proyecto incluye los procesos que organizan, gestionan y conducen el equipo del proyecto. El equipo del proyecto está conformado por aquellas personas a las que se les han asignado roles y responsabilidades para completar el proyecto. El tipo y la cantidad de miembros del equipo del proyecto pueden variar con frecuencia, a medida que el proyecto avanza. Los miembros del equipo del proyecto también pueden denominarse personal del proyecto. Si bien se asignan roles y responsabilidades específicos a cada miembro del equipo del proyecto, la participación de todos los miembros en la toma de decisiones y en la planificación del proyecto puede resultar beneficiosa. La intervención y la participación tempranas de los miembros del equipo les aportan su experiencia profesional durante el proceso de planificación y fortalecen su compromiso con el proyecto. Los subcriterios a considerar en este apartado fueron Planificación y gestión de RRHH y Equipo de trabajo. El subcriterio de Equipo de trabajo se consideró desde el análisis de roles de la Teoría de Belbin mediante la autoevaluación por cuestionario de los integrantes de cada grupo. El análisis de la presencia de roles se propone en el apartado siguiente.

4. Comunicación: La Gestión de las Comunicaciones del Proyecto incluye los procesos requeridos para asegurar que la planificación, recopilación, creación, distribución, almacenamiento, recuperación, gestión, control, monitoreo y disposición final de la información del proyecto sean oportunos y adecuados. Los directores de proyecto emplean la mayor parte de su tiempo comunicándose con los miembros del equipo y otros interesados en el proyecto, tanto si son internos (en todos los niveles de la organización) como externos a la misma. Este apartado también se valoró mediante presentaciones orales de cada equipo. Los subcriterios a considerar en este apartado fueron Planificación y gestión de comunicaciones y Comunicación del grupo. Este último subcriterio (Comunicación del grupo) se valoró a partir del juicio de expertos formado por los autores del trabajo según el procedimiento que se destaca más adelante. 


\subsubsection{Desarrollo del modelo matemático}

\subsubsection{Introducción}

La toma de decisiones es un proceso de selección y evaluación entre diferentes alternativas, basado en un conjunto de criterios, para alcanzar uno o más objetivos, seleccionando la mejor opción posible. No todos los criterios anteriormente mencionados contarán con el mismo peso para la valoración del mejor proyecto. Además, todos los criterios principales se han desglosado en subcriterios (o criterios de segundo nivel) con lo que el manejo y valoración de cada alternativa se hace más complejo.

La aplicación de un modelo matemático para la toma de decisión en la selección del mejor proyecto ayudará a encontrar la mejor solución, facilitando además el manejo de información generada por las diferentes disciplinas del conocimiento que confluyen en el problema planteado.

\subsubsection{Métodos de evaluación y decisión con múltiples criterios}

Los métodos de evaluación y decisión multicriterio comprenden la selección entre un conjunto de alternativas factibles, la optimización con varias funciones objetivo simultáneas y un agente decisor y procedimientos de evaluación racionales y consistentes (Eduardo Martínez, 1998). Sus principios derivan de la teoría de matrices, teoría de las organizaciones, teoría de grafos, teoría de la medida, teoría de las decisiones colectivas, investigación de operaciones y de economía.

Aquellos problemas en los que las alternativas de decisión son finitas se denominan problemas de Decisión Multicriterio Discreta. Este tipo de problemas son los más comunes en la realidad y es el tipo que se desarrollará en el presente trabajo.

Los principales métodos de evaluación y decisión multicriterio discretos son: ponderación lineal (scoring), utilidad multiatributo (MAUT), relaciones de superación y análisis jerárquico (AHP, del inglés "Analytic Hierarchy Process)". En este caso se ha escogido el análisis jerárquico (AHP) ya que presenta las ventajas frente a otros métodos de decisión multicriterio de presentar una base matemática, desglosar y analizar el problema por partes, medir criterios cuantitativos y cualitativos mediante una escala común, la participación de diferentes personas o grupos de interés y generar un consenso, verificar el índice de consistencia y hacer las correcciones, si es del caso. 


\subsubsection{Análisis jerárquico (AHP) y generación de la estructura jerárquica}

Este método fue desarrollado por el matemático Thomas Saaty y consiste en formalizar la comprensión intuitiva de problemas complejos mediante la construcción de un modelo jerárquico.

El propósito del método es permitir que el agente decisor pueda estructurar un problema multicriterio en forma visual, mediante la construcción de un modelo que básicamente contiene tres niveles: meta u objetivo, criterios y alternativas.

Una vez construido el modelo, se realizan comparaciones uno a uno entre dichos elementos (criterios-subcriterios y alternativas) y se atribuyen valores numéricos a las preferencias señaladas por las personas, entregando una síntesis de las mismas mediante la agregación de esos juicios parciales.

El fundamento del proceso del Dr. Saaty descansa en el hecho de que permite dar valores numéricos a los juicios dados por las personas, logrando medir cómo contribuye cada elemento de la jerarquía al nivel inmediatamente superior del cual se desprende.

Para estas comparaciones se utilizan escalas de razón en términos de preferencia, importancia o probabilidad, sobre la base de una escala numérica propuesta por el mismo Saaty, que va desde 1 hasta 9 . Una vez obtenido el resultado final, el AHP permite llevar a cabo el análisis de sensibilidad.

Para el desarrollo del problema se ha procedido a la generación del modelo jerárquico y valoración de los criterios, de forma que se les asigne un peso en función de su importancia en la determinación del mejor proyecto. En esta fase se utilizará el método del proceso de análisis jerárquico (AHP).

En este caso el peso ( $\mathrm{Pi}$ ) es el número positivo que indica la importancia concedida a un criterio frente al total (tanto por uno).

El término criterio (Ci) se aplicará tanto a los criterios principales, como a los dependientes, y serán aspectos o propiedades técnicos u organizativos que deben cuantificarse para el estudio de idoneidad del mejor proyecto.

El método AHP permite desglosar un problema según los diferentes aspectos que son necesarios abordar para su resolución. Estos criterios (criterios de $1^{\circ}$ nivel) pueden desglosarse en sucesivos criterios ( $2^{\circ}$ y 3 er nivel, etc.) de forma que finalmente el problema 
quede simplificado a la obtención de una serie de valores (ensayos, estudios, etc.) para conseguir el análisis global y por tanto la solución del problema complejo inicial.

En este caso que ocupa, la selección de proyectos de innovación se ha desdoblado en: (1) aspectos técnicos y (2) aspectos organizativos.

El primero de ellos engloba aquellos criterios técnicos que son necesarios abordar para la definición inicial del proyecto (alcance, tiempo, costes, calidad)

El segundo criterio de primer nivel aborda aspectos organizativos (riesgos, interesados, recursos humanos y comunicación).

En la Figura 14 anteriormente expuesta se muestra la estructura jerárquica propuesta. Es necesario remarcar que los últimos criterios de cada ramificación, y dado que el método se aplica como medida absoluta, terminan con una escala (o tabulación) del valor científico, obtenido mediante valoraciones de expertos que son los autores del estudio (escala cualitativa). Dicha escala científica se traduce, mediante juicios de valor, en la escala matemática propuesta por T.L. Saaty para la aplicación del método AHP. Una vez clasificados cualitativamente los criterios (ver apartado anterior), se procede a asignar valores cuantitativos, siguiendo el proceso de análisis jerárquico, lo que da lugar a los pesos.

A modo de resumen, el resultado final de la aplicación del método AHP será la obtención de una matriz en la que se resuman la valoración de los criterios y el peso que aplica a cada uno de ellos tal y como se expone en la siguiente tabla.

Tabla VI: Explicación de la matriz de ponderación y valoración de un proyecto

\begin{tabular}{|c|c|c|c|c|c|}
\hline & $\begin{array}{l}\text { VALOR (Saaty) } \\
\text { CRITERIO }\end{array}$ & $\begin{array}{l}I \\
(1)\end{array}$ & $\begin{array}{l}\text { II } \\
(\mathbf{5})\end{array}$ & $\begin{array}{l}\text { III } \\
\text { (9) }\end{array}$ & PESO \\
\hline \multirow[t]{4}{*}{ PROYECTO A } & C1 & $\mathrm{V} 1(0)$ & $\mathrm{V} 1(1)$ & $\mathrm{V} 1(2)$ & P1 \\
\hline & $\ldots$. & & & & $\ldots$ \\
\hline & C1 & & & & $\mathrm{Pn}$ \\
\hline & TOTAL & & & & 1 \\
\hline
\end{tabular}

Finalmente, para la obtención del valor que caracteriza la idoneidad de un Proyecto se utilizará la siguiente ecuación: 


$$
E_{A}=\sum_{i=1}^{i=n} P_{i} \cdot V_{i}
$$

\section{Ecuación 2: Fórmula para la obtención del valor de clasificación de un proyecto}

Donde $E_{A}$ es el valor obtenido una vez aplicado el método al Proyecto $A ; n$ el número de criterios, $\mathrm{P}$ el peso asignado a cada criterio y $\mathrm{V}$ el valor matemático asignado a cada criterio; finalmente i es el número de criterios cuantificables considerados. A continuación se muestran los valores asignados a los criterios técnicos y organizativos:

\section{Tabla VII. Aplicación criterios a metodología PMP}

\begin{tabular}{|c|c|c|c|c|}
\hline \multirow{2}{*}{$\begin{array}{l}\text { CRITERIOS } \\
\text { TÉCNICOS }\end{array}$} & \multirow{2}{*}{$\begin{array}{l}\text { CRITERIOS } \\
\text { SECUNDARIOS } \\
\end{array}$} & \multicolumn{3}{|c|}{ VALORES } \\
\hline & & 1 & 5 & 9 \\
\hline \multirow{3}{*}{ 1. Alcance } & $\begin{array}{l}\text { Necesidades y } \\
\text { expectativas }\end{array}$ & $\begin{array}{l}\text { La matriz de rastreabilidad no es clara o no está bien } \\
\text { definida o no existe. Los requisitos no están justificados }\end{array}$ & $\begin{array}{l}\text { La matriz de rastreabilidad es clara y está bien } \\
\text { definida, pero faltan documentos }\end{array}$ & $\begin{array}{l}\text { La matriz de rastreabilidad es clara y está bien } \\
\text { definida. Todos los requisitos están justificados } \\
\text { con la pertinente documentación }\end{array}$ \\
\hline & Plan de alcance & $\begin{array}{l}\text { No hay un plan de gestión de alcance ni un plan de } \\
\text { gestión de requisitos }\end{array}$ & $\begin{array}{l}\text { Hay un plan de gestión de alcance y un plan de } \\
\text { gestión de requisitos; pero alguno de ellos no está } \\
\text { bien definido }\end{array}$ & $\begin{array}{l}\text { Hay un plan de gestión de alcance y un plan de } \\
\text { gestión de requisitos; ambos están bien definidos }\end{array}$ \\
\hline & EDT & No hay una EDT & Hay una EDT, pero no está completada & $\begin{array}{l}\text { Hay una EDT con todos sus paquetes de trabajo } \\
\text { definidos }\end{array}$ \\
\hline \multirow{3}{*}{ 2. Tiempo } & Tareas e hitos & No hay una lista ni de tareas ni de hitos & $\begin{array}{l}\text { Hay una lista de tareas e hitos, pero no están } \\
\text { incluido en su totalidad todos los puntos. }\end{array}$ & $\begin{array}{l}\text { Hay una lista de tareas e hitos con todos los puntos } \\
\text { incluidos }\end{array}$ \\
\hline & Estimación & $\begin{array}{l}\text { No se ha seguido un proceso de estimación preciso y es } \\
\text { muy probable que haya desviaciones importantes }\end{array}$ & $\begin{array}{l}\text { Se ha realizado un proceso de estimación } \\
\text { adecuado, pero podría haber sido más preciso }\end{array}$ & $\begin{array}{l}\text { El método de estimación de tiempos ha sido } \\
\text { consistente y preciso. No se esperan variaciones } \\
\text { significativas }\end{array}$ \\
\hline & Cronograma & No hay cronograma o no está detallado & $\begin{array}{l}\text { Existe un grado de detalle conforme a un } \\
\text { Diagrama de bloques. No hay un método de } \\
\text { control }\end{array}$ & $\begin{array}{l}\text { Existe un grado de detalle conforme a un Diagrama } \\
\text { de Gantt. Además, hay un método de control del } \\
\text { mismo }\end{array}$ \\
\hline \multirow{3}{*}{ 3. Coste } & Plan de costos & No hay un plan de costes & $\begin{array}{l}\text { Hay un plan de costes, pero no están definidos } \\
\text { todos los puntos }\end{array}$ & Hay un plan de costes perfectamente definido \\
\hline & Estimación & $\begin{array}{l}\text { No se ha seguido un proceso de estimación de costos } \\
\text { preciso y es muy probable que haya desviaciones } \\
\text { importantes }\end{array}$ & $\begin{array}{l}\text { Se ha realizado un proceso de estimación de } \\
\text { costos adecuado, pero podría haber sido más } \\
\text { preciso }\end{array}$ & $\begin{array}{l}\text { El método de estimación de costos ha sido } \\
\text { consistente y preciso. No se esperan variaciones } \\
\text { significativas }\end{array}$ \\
\hline & $\begin{array}{l}\text { Herramientas } \\
\text { económicas }\end{array}$ & No se usa ninguna herramienta & $\begin{array}{l}\text { Se utiliza al menos dos de las herramientas } \\
\text { económicas principales [TIR, VAR, PRI] }\end{array}$ & Se utilizan todas las herramientas [TIR, VAR, PRI] \\
\hline \multirow[b]{2}{*}{ 4. Calidad } & Planificación & $\begin{array}{l}\text { Las normas que se van a utilizar no están definidas, ni } \\
\text { tampoco su método de satisfacción }\end{array}$ & $\begin{array}{l}\text { Las normas que se van a utilizar no están } \\
\text { totalmente definidas, hay entregables que no } \\
\text { tienen un plan de control de calidad }\end{array}$ & $\begin{array}{l}\text { Las normas que se van a utilizar están totalmente } \\
\text { definidas, asi como su método de satisfacción }\end{array}$ \\
\hline & $\begin{array}{l}\text { Método de } \\
\text { control }\end{array}$ & No hay ningún método de control de la calidad & $\begin{array}{l}\text { Hay un método de control, pero algunos puntos } \\
\text { no están definidos o no son lo suficientemente } \\
\text { claros }\end{array}$ & $\begin{array}{l}\text { Hay un método de control perfectamente claro y } \\
\text { definido }\end{array}$ \\
\hline
\end{tabular}

\begin{tabular}{|c|c|c|c|c|}
\hline \multirow{2}{*}{$\begin{array}{l}\text { CRITERIOS } \\
\text { ORGANIZATIVOS }\end{array}$} & \multirow{2}{*}{$\begin{array}{l}\text { CRITERIOS } \\
\text { SECUNDARIOS }\end{array}$} & \multicolumn{3}{|c|}{ VALORES } \\
\hline & & 1 & 5 & 9 \\
\hline \multirow{3}{*}{ 5. Riesgos } & Identificación & $\begin{array}{l}\text { No existe un procedimiento ni un plan para saber cuáles } \\
\text { son los riesgos que afectan al proyecto }\end{array}$ & $\begin{array}{l}\text { Existe un procedimiento y un plan, pero no está } \\
\text { definido para todos los factores que afectan al } \\
\text { proyecto }\end{array}$ & $\begin{array}{l}\text { Existe un procedimiento y un plan, ambos } \\
\text { totalmente claros y definidos, para saber cuáles son } \\
\text { los riesgos que afectan al proyecto }\end{array}$ \\
\hline & Valoración & No se valoran los riesgos identificados & $\begin{array}{l}\text { Los riesgos están valorados por impacto y } \\
\text { probabilidad. No se sabe el nivel de riesgo asociado } \\
\text { a estos valores }\end{array}$ & $\begin{array}{l}\text { Los riesgos están valorados por impacto y } \\
\text { probabilidad. Se sabe el nivel de riesgo gracias a la } \\
\text { matriz de riesgo asociada }\end{array}$ \\
\hline & Mitigación & $\begin{array}{l}\text { No hay acciones de mitigación definidas para los riesgos } \\
\text { asociados }\end{array}$ & $\begin{array}{l}\text { Hay acciones de mitigación definidas para alguno de } \\
\text { los riesgos asociados }\end{array}$ & $\begin{array}{l}\text { Todos los riesgos asociados tienen una acción de } \\
\text { mitigación definida }\end{array}$ \\
\hline \multirow{3}{*}{ 6. Interesados } & Identificación & No está ningún o casi ningún interesado identificado & $\begin{array}{l}\text { Un número significativo de los interesados está } \\
\text { identificado }\end{array}$ & Todos los interesados están identificados \\
\hline & Planificación & $\begin{array}{l}\text { No hay un plan de gestión de los interesados ni un plan } \\
\text { de comunicación }\end{array}$ & $\begin{array}{l}\text { Hay un plan de gestión de gestión de los } \\
\text { interesados, pero no hay un plan de comunicación }\end{array}$ & $\begin{array}{l}\text { Hay un plan de gestión de los interesados y un plan } \\
\text { de comunicación completamente definidos }\end{array}$ \\
\hline & $\begin{array}{l}\text { Gestión } \quad y \\
\text { control }\end{array}$ & $\begin{array}{l}\text { No existe un plan de gestión de los requisitos exigidos por } \\
\text { los interesados }\end{array}$ & $\begin{array}{l}\text { Existe un plan de gestión de los requisitos exigidos } \\
\text { por los interesados, pero no todos los interesados } \\
\text { tienen un plan definido }\end{array}$ & $\begin{array}{l}\text { Existe un plan de gestión de los requisitos exigidos } \\
\text { por los interesados completamente definido }\end{array}$ \\
\hline \multirow{2}{*}{$\begin{array}{l}\text { 7. Recursos } \\
\text { humanos }\end{array}$} & $\begin{array}{l}\text { Plan y gestión } \\
\text { de RRHH }\end{array}$ & No existe un plan de gestión de RRHH & $\begin{array}{l}\text { Existe un plan de gestión de RRHH, pero no se sabe } \\
\text { cómo se comunicará al personal }\end{array}$ & $\begin{array}{l}\text { Existe un plan de gestión de RRHH y está planificada } \\
\text { la forma en la cual se comunicará al equipo }\end{array}$ \\
\hline & $\begin{array}{l}\text { Equipo } \\
\text { trabajo }\end{array}$ & Equipo absolutamente desequilibrado & Equipo desequilibrado & Equipo equilibrado \\
\hline \multirow[t]{2}{*}{ 8. Comunicación } & $\begin{array}{l}\text { Planificación y } \\
\text { gestión del flujo } \\
\text { de información }\end{array}$ & No hay un plan de gestión de información & $\begin{array}{l}\text { Hay un plan de gestión de información, pero falta } \\
\text { alguna parte (canal de comunicación, formato y } \\
\text { contenidos del tipo de información, personas } \\
\text { responsables de comunicar, personas que recibirán } \\
\text { la información, tecnologías de la información a } \\
\text { utilizar, frecuencia de la comunicación, glosario de } \\
\text { términos comunes) }\end{array}$ & $\begin{array}{l}\text { Hay un plan de gestión de información } \\
\text { completamente definido }\end{array}$ \\
\hline & $\begin{array}{l}\text { Comunicación } \\
\text { del grupo }\end{array}$ & $\begin{array}{l}\text { La media de las calificaciones individuales de los } \\
\text { miembros del equipo }(0-3) \text { está comprendida entre } 0 \text { y } 1,5\end{array}$ & $\begin{array}{l}\text { La media de las calificaciones individuales de los } \\
\text { miembros del equipo (0-3) está comprendida entre } \\
1,5 \text { y } 2,25\end{array}$ & $\begin{array}{l}\text { La media de las calificaciones individuales de los } \\
\text { miembros del equipo (0-3) está comprendida entre } \\
2,25 \text { y } 3\end{array}$ \\
\hline
\end{tabular}


Para aplicar la metodología AHP, diferentes pesos son asignados a cada uno de los criterios de manera que se puede otorgar a cada propuesta un valor indicativo de su éxito. Según M Dolores Storch et al, 2019, este algoritmo se ha aplicado en la valoración de propuestas de proyecto innovadores según los criterios descritos por PMI (M Dolores Storch et al, 2019). La asignación de pesos se ha realizado en base a un juicio de expertos. Para cada una de estas propuestas se han calculado los valores que resultan de aplicar los criterios de la metodología AHP expuesta anteriormente obteniendo, así como punto de partida la valoración de cada grupo según la probabilidad de éxito de sus proyectos.

A continuación es necesario asignar los pesos a cada uno de los criterios. En la siguiente tabla se muestra los pesos otorgados a cada criterio en los 3 niveles, incluyendo en el nivel 3 el peso ponderado que será el que se utilice para analizar los resultados.

Tabla VIII: Asignación de pesos a los criterios de selección de proyectos

\begin{tabular}{|c|c|}
\hline NIVEL 1 & W \\
\hline Criterios técnicos & 0,5 \\
\hline $\begin{array}{c}\text { Criterios } \\
\text { organizativos }\end{array}$ & 0,5 \\
\hline & \\
\hline NIVEL 2 & \\
\hline Criterios técnicos & W \\
\hline Alcance & 0,3 \\
\hline Tiempo & 0,3 \\
\hline Coste & 0,3 \\
\hline Calidad & 0,1 \\
\hline Criterios organizativos & W \\
\hline RRHH & 0,5600 \\
\hline Comunicación & 0,1325 \\
\hline Riesgos & 0,2125 \\
\hline Interesados & 0,0950 \\
\hline
\end{tabular}

Tal y como se expuso al comienzo, para los criterios de RRHH y de Comunicación se desarrolló una metodología específica en el caso de los subcriterios de Equipo (RRHH) y Comunicación del grupo (Comunicación). Por este motivo se tratan de manera específica en los siguientes apartados.

\subsubsection{Equipo de trabajo}

Como se ha indicado anteriormente, en cada grupo se realizó un test de autopercepción de roles de Belbin por cada integrante. Después se calculó para cada grupo el peso relativo de los roles Sociales (Coordinador, Investigador de Recursos y Cohesionador), de 
Reflexión (Cerebro, Monitor y Especialista) y de Acción (Impulsor, Implementador y Finalizador).

Para el análisis de los datos se ha considerado que hay presencia de roles significativa cuando la suma de las aportaciones de todos los miembros del grupo suma más de 25 puntos, y en caso de destacar en 2 clases de roles se ha considerado como principal el mayor de ambos.

Los equipos se clasificaron en:

- Absolutamente desequilibrados: tras analizar a los miembros del equipo se observa que en conjunto hay ausencia de uno de los 3 tipos de roles (reflexión, acción, social) ya que ninguno de los miembros posee una contribución significativa de alguno de los mismos.

- Desequilibrados: tras el análisis de los miembros del equipo se puede concluir que en conjunto hay presencia de los 3 tipos de roles (reflexión, acción, social) ya que al menos alguno de los miembros posee una contribución significativa de alguno de los mismos pero se considera desbalanceada la participación de cada rol.

- Equilibrados: Hay presencia significativa y balanceada de los 3 roles

\subsubsection{Comunicación del grupo}

Se evaluó a partir de la valoración de la competencia comunicativa de cada miembro de los grupos. Para ello se pidió a cada grupo que defendieran su propuesta ante el equipo investigador de este estudio (Bernardo Llamas y $\mathrm{M}^{\mathrm{a}}$ Dolores Storch de Gracia), quienes dieron un valor a cada integrante del equipo en función de sus habilidades de comunicación entre 0 y 3. Posteriormente se calculó la media del equipo y se asignó un peso total al equipo en función del valor obtenido final:

- Media entre 0 a 1,5 : se asigna un valor ponderado final de 1

- Media entre 1,5 a 2 : se asigna un valor ponderado final de 5

- Media entre 2 a 3 : se asigna un valor ponderado final de 9

\subsubsection{Análisis estadístico}

Se trata de confirmar si existe una correlación entre el valor asignado de "éxito" a los proyectos, el valor asignado considerando la herramienta AHP y su posible relación con diagnóstico de los equipos realizado en base a la autopercepción de roles inspirado en la 
teoría de Belbin. Se ha utilizado para este propósito el software estadístico líder mundial IBM SPSS Statistics ${ }^{\circledR}$, programa informático utilizado para las ciencias sociales y aplicadas, así como en empresas de investigación de mercado. El nombre originario correspondía al acrónimo de Statistical Package for the Social Sciences (SPSS), reflejando la orientación a su mercado original, aunque este programa era también muy utilizado en otros campos como las ciencias sociales y la mercadotecnia. Este software es utilizado para resolver problemas de negocio e investigación mediante análisis ad hoc, pruebas de hipótesis, análisis geoespacial y analítica predictiva. Las organizaciones utilizan IBM SPSS Statistics para comprender los datos, analizar tendencias, prever y planificar para validar las hipótesis y sacar conclusiones precisas. (Field, A.P.,2009).

El análisis estadístico se ha realizado para las siguientes variables:

Variable AHP: se llama así al resultado que se obtiene de la aplicación de la metodología AHP descrita anteriormente para los 21 grupos de trabajo. Este resultado nos informa del "valor" del proyecto defendido por cada grupo en función de la puntuación obtenida para los Subcriterios técnicos y organizativos definidos, una vez considerados los pesos y valores indicados anteriormente. Es una variable cuantitativa

Variable Equilibrio Roles equipos: se llama así al valor que se obtiene del diagnóstico de equipos de trabajo según la presencia de roles, siendo el resultado Absolutamente desequilibrado, desequilibrado o equilibrado como se describe posteriormente. Se trata de una variable cualitativa.

Tal y como se ha mencionado anteriormente, lo primero que se realizó fueron pruebas de bondad de ajuste. Las pruebas de bondad de ajuste se utilizan para contrastar si los datos de la muestra pueden considerarse que proceden de una determinada distribución o modelo de probabilidad. En consecuencia, las pruebas de bondad de ajuste permiten verificar qué tipo de distribución siguen los datos disponibles y, por tanto, qué pruebas (paramétricas o no) podemos llevar a cabo en el contraste estadístico posterior.

A continuación, y tras verificar que ambas variables siguen una distribución Normal, se realiza un test de análisis de la varianza (Test Anova). En estadística, este análisis de la varianza (más conocido como ANOVA por sus siglas en inglés ANalysis Of VAriance) es un conjunto de modelos estadísticos en los que la varianza está particionada en ciertos componentes debidos a diferentes variables explicativas. Se utiliza de forma intensiva en el análisis y diseño de experimentos con el objetivo de evaluar el efecto de tratamientos en la variabilidad de la variable respuesta. El análisis de la varianza se fundamenta en el concepto de regresión lineal, pero ampliando sus funcionalidades. Con un análisis de 
varianza permitiría determinar, por ejemplo, si diferentes tratamientos muestran diferencias en sus resultados o si, por el contrario, podemos suponer que sus medias poblacionales no difieren.

La prueba ANOVA es una prueba paramétrica y como tal requiere una serie de supuestos para poder ser aplicada correctamente. Este análisis de la varianza, en realidad sirve no solo para estudiar las dispersiones o varianzas de los grupos, sino para estudiar sus medias y la posibilidad de crear subconjuntos de grupos con medias iguales.

El objetivo en este análisis estadístico será evaluar si existen diferencias que no se deben al azar y si se puede confirmar que existe una relación entre la variable AHP y la variable Equilibro Roles Equipo.

Prueba de bondad de ajuste a la distribución Normal (Kolmogorov - Smirnov) para la variable AHP

En primer lugar, en el caso que nos ocupa, se ha hecho el test de Kolmogorov-Smirnov que es una prueba de bondad de ajuste a la distribución Normal, para ver si la variable cuantitativa (Valoración AHP) sigue la distribución Normal. Se emplea para variables cuantitativas continuas cuando el tamaño muestral es superior a 50 . El objetivo final es confirmar si los datos provienen de una población que tiene la distribución teórica especificada.

Si $p<0,05$, la distribución de la variable no es Normal, mientras que valores superiores a 0,05 aseguran que la distribución es Normal

\section{Prueba de Shapiro-Wilk para la variable Equipos de trabajo}

El test de Shapiro-Wilk se usa para contrastar si un conjunto de datos sigue una distribución Normal o no. Este hecho es de vital importancia porque otros muchos análisis estadísticos requieren de la normalidad de los datos para poder llevarlos a cabo. ShapiroWilk estima la fuerza del ajuste con una recta. Se usa para contrastar la normalidad de un conjunto de datos. Cuanto mayor sea el valor de este estadístico mayor desacuerdo habrá en la recta de normalidad, por lo que se rechaza la hipótesis nula.

Cuando la muestra es como máximo de tamaño 50 se puede contrastar la normalidad con la prueba de Shapiro-Wilk. Para efectuarla se calcula la media y la varianza muestral, S2, y se ordenan las observaciones de menor a mayor. A continuación, se calculan las diferencias entre: el primero y el último; el segundo y el penúltimo; el tercero y el antepenúltimo, etc. y se corrigen con unos coeficientes tabulados por Shapiro y Wilk. 
El estadístico de prueba es:

$$
W=\frac{D^{2}}{n S^{2}}
$$

donde $\mathrm{D}$ es la suma de las diferencias corregidas.

Se rechazará la hipótesis nula de normalidad si el estadístico W es menor que el valor crítico proporcionado por la tabla elaborada por los autores para el tamaño muestral y el nivel de significación dado.

\section{Prueba de comparación de medias de 3 o más variables (ANOVA)}

A continuación se realizará un test de contraste de hipótesis entre las 3 categorías (Equilibrados, Desequilibrados y Absolutamente Desequilibrados).

El test ANOVA se debe aplicar a variables cuantitativas, luego se han asignado valores numéricos (1,2 y 3$)$ a las categorías anteriores y se ha evaluado si existen diferencias que no se deben al azar. (Moder, K.,2010)

Para poder hacer el test ANOVA debemos cumplir (Kutnervet al., 2005):

- que las variables sean independientes (demostrado anteriormente)

- que las variables sigan una distribución normal (demostrado con el test de Kolmogorov-Smirnov)

- que las varianzas sean homogéneas

La última condición es que sean homogéneas las varianzas para lo cual se realizará una prueba de homogeneidad de varianzas (Estadístico de Levene).

Por último, se realizará el test ANOVA para la variable AHP, con el objetivo de poder determinar si existen diferencias que no se deben al azar y si se puede confirmar que existe una relación entre el Valor AHP (éxito de los proyectos) y el Equilibrio de los roles de equipo 


\section{CAPÍTULO 4 \\ RESULTADOS}


En este capítulo se muestran los principales resultados de esta tesis. En el anexo I se incluye el detalle de los resultados fruto de la investigación realizada así como su vinculación con la misma.

\subsection{Discusión y Resultados sobre el papel de las habilidades transversales a través del marco lógico del proyecto}

Se describen los resultados logrados en la evaluación de cuatro habilidades: creatividad, trabajo en equipo, actitudes hacia el trabajo y comunicación. Los resultados del Ejercicio del inversionista permiten establecer una herramienta real para la toma de decisiones de evaluación de proyectos, como lo demuestra la configuración de un panel de expertos en proyectos de investigación y desarrollo, tanto en el sector privado como en el público. Este ejercicio nos permite evaluar proyectos teniendo en cuenta aspectos subjetivos, que a veces son responsables de una mayor predisposición a financiar proyectos frente a otros. La hipótesis de trabajo definida era para alumnos de evaluación continua y se podrá concluir que se favorece el aprendizaje con esta metodología, lo cual está alineado con los resultados mucho más favorables para los alumnos mediante este tipo de evaluación tal y como la comunidad docente defiende de manera generalizada.

\subsubsection{Creatividad}

Esta sección describe los resultados obtenidos al evaluar la habilidad de creatividad de los cuatro equipos y sus propuestas de proyectos. Para este objetivo, como se describe en la sección anterior, los evaluadores externos cumplieron con la novedad, la funcionalidad y el impacto de los proyectos utilizando un cuestionario de técnica de evaluación consensual (CAT).

De manera general, el cuestionario sobre creatividad CAT permite establecer que la creatividad en los ingenieros presenta una baja funcionalidad, siendo este efecto más evidente en el aspecto económico, sopesando así la evaluación del impacto de los resultados esperados. Sin embargo, la evaluación de los expertos representa una percepción de creatividad media-alta en cada equipo. 
La competencia en creatividad de los ingenieros se midió de acuerdo con la evaluación de seis expertos no relacionados con la dinámica del sujeto, considerando el CAT, y un ejercicio innovador, donde los expertos propusieron una inversión en cada propuesta de proyecto.

Los resultados muestran que el conocimiento de los ingenieros en problemas científicos y de ingeniería actuales fue significativo. Sin embargo, los conceptos económicos y de impacto no estaban suficientemente desarrollados en las propuestas de proyectos.

La Figura 15 muestra los resultados cuantitativos de cada proyecto, como promedio de cada uno de los indicadores en los que se ha desglosado el concepto de creatividad: novedad, funcionalidad (técnica, económica y social) y, finalmente, impacto. Los puntos negros representan valores medios para cada criterio medible. La valoración promedio en términos de novedad para los cuatro proyectos fue favorable, con una valoración significativa en términos de novedad $(3.70 / 5)$ y se destacó el proyecto iVibe. De esta manera, se verificó que los ingenieros son conocedores de las nuevas tecnologías aplicadas a la ingeniería.

El concepto de funcionalidad, valorado desde tres prismas diferentes: técnico, económico y social, plantea algunas dudas sobre la viabilidad de las soluciones propuestas. Técnicamente, los proyectos presentan valores razonables, destacando los proyectos Geo2Cool e iVibe, ambos con una exposición basada en conceptos técnicos, en detrimento de los proyectos FlyFood y EcoRun donde las presentaciones tenían más componentes comerciales y económicos.

Existe una falta de funcionalidad en el aspecto económico, donde solo el proyecto Geo2Cool alcanzó un valor por encima del valor intermedio en la escala de Likert de 5 puntos. En esta sección se destaca el proyecto EcoRun Systems, con una baja valoración; Aunque su explicación se basó en conceptos económicos, solo destacó los valores tangibles y no los intangibles, que en este proyecto son mucho más altos que los tangibles. 


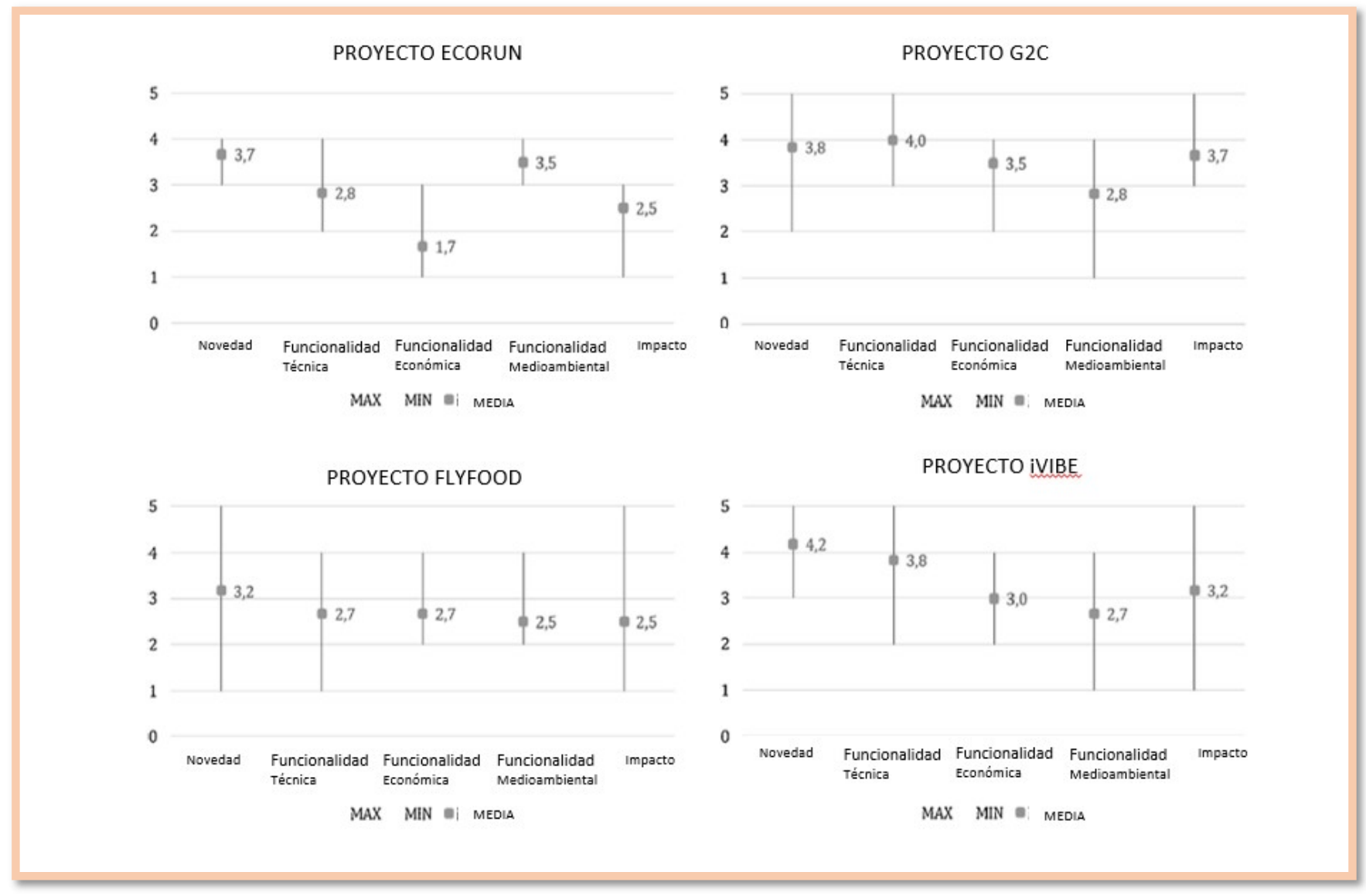

Figura 15. Evaluación de la creatividad considerando valores específicos. El gráfico se basa en la escala de cinco puntos de Likert.

En términos de funcionalidad social, donde se valoran los conceptos relacionados con el medio ambiente y los beneficios para la sociedad (intangibles), destaca el proyecto EcoRun Systems, mientras que el resto de los proyectos no alcanzan el valor promedio de la escala. Finalmente, en términos del impacto del proyecto, los proyectos Geo2Cool e iVibe se destacaron particularmente y fueron calificados positivamente por el panel de expertos. Si bien ambos proyectos reconocieron el mayor impacto en mercados individuales, el proyecto Geo2Cool se podría estandarizar y aplicar en plantas de energía térmica de gas natural. Por otro lado, el proyecto iVibe se evaluó favorablemente después de la discusión posterior, donde los expertos analizaron y enumeraron nuevos nichos de mercado potenciales además de su aplicación en voladuras técnicas en minería, la aplicación propuesta originalmente por el equipo del proyecto. Finalmente, el proyecto EcoRun Systems presentó la debilidad de ser una aplicación local: los ingenieros propusieron una ubicación concreta de difícil replicación, mientras que el proyecto FlyFood resintió la incertidumbre en la legislación relacionada con los RPAS. 
La segunda parte del análisis de la creatividad se realizó considerando el Ejercicio del Inversor, en el que se pueden analizar los siguientes resultados. La Figura 16 representa la cantidad de inversión para cada inversor (diferentes colores en cada barra). Los puntos de color azul claro (y la línea de guion) indican la cantidad de inversión requerida para cada proyecto. Si bien los proyectos FlyFood e iVibe lograron obtener los fondos necesarios, el proyecto Geo2Cool también se consideró financiado, alcanzando más del $99 \%$ del capital solicitado.

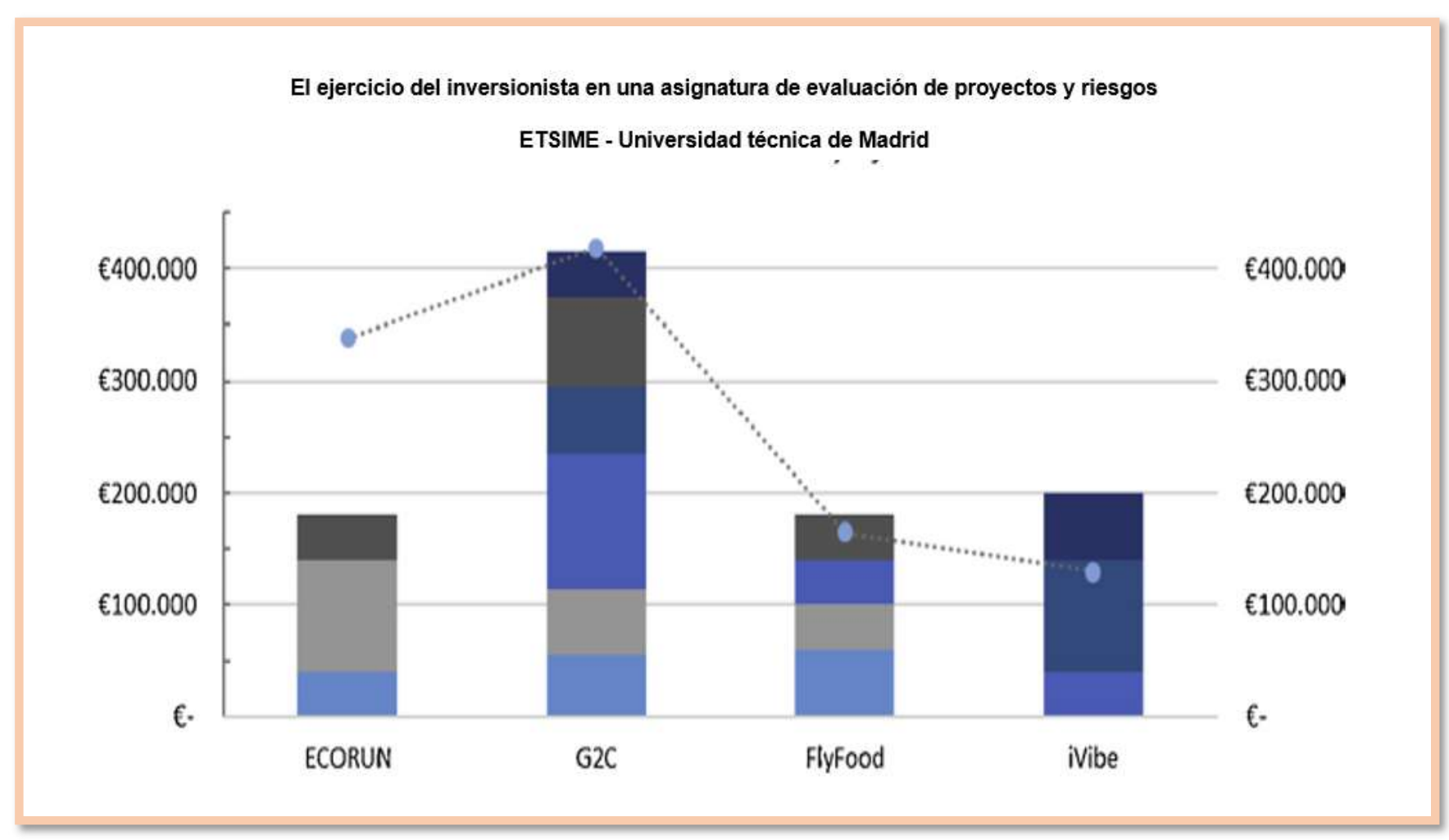

Figura 16. Resultados del ejercicio de inversión.

Nota: Las barras del gráfico indican la suma de los seis inversores, mientras que la línea de puntos indica el presupuesto de cada propuesta de proyecto.

En este caso, es posible observar un sesgo en la inversión total requerida en un proyecto en particular, favoreciendo proyectos de presupuesto más pequeños en comparación con proyectos con mayores necesidades de inversión. Mientras que los proyectos FlyFood e iVibe requerían inversiones por debajo del capital asignado a cada uno de los expertos, EcoRun y Geo2Cool de los resultados obtenidos en los proyectos financiados. El proyecto iVibe recibió más de un $54 \%$ de inversión adicional de la requerida inicialmente, con solo la contribución de tres expertos, mientras que el proyecto Geo2Cool tuvo la contribución de todos los inversionistas para lograr financiamiento. 


\subsubsection{Trabajo en equipo}

Los resultados del cuestionario de Belbin para los cuatro grupos estudiados en este artículo se muestran en la Figura 17 el equipo de ingeniería se representa con un tono de color diferente, y la suma de ellos representa las habilidades o roles generales de un equipo. EI rol del Implementador se destacó en los cuatro equipos bajo evaluación y, en menor medida, en los roles de Especialista y Evaluador.

Por el contrario, los resultados muestran valores muy bajos del rol de la creatividad, siendo este uno de los roles más pequeños en cada equipo. En este aspecto, el proyecto EcoRun Systems se destaca positivamente, al ser un rol creativo no solo superior al de los otros equipos, sino también una contribución de cuatro de sus cinco miembros. Por otro lado, el proyecto iVibe muestra una baja contribución del rol de Creativo con un solo miembro que presenta un valor modesto en este rol.

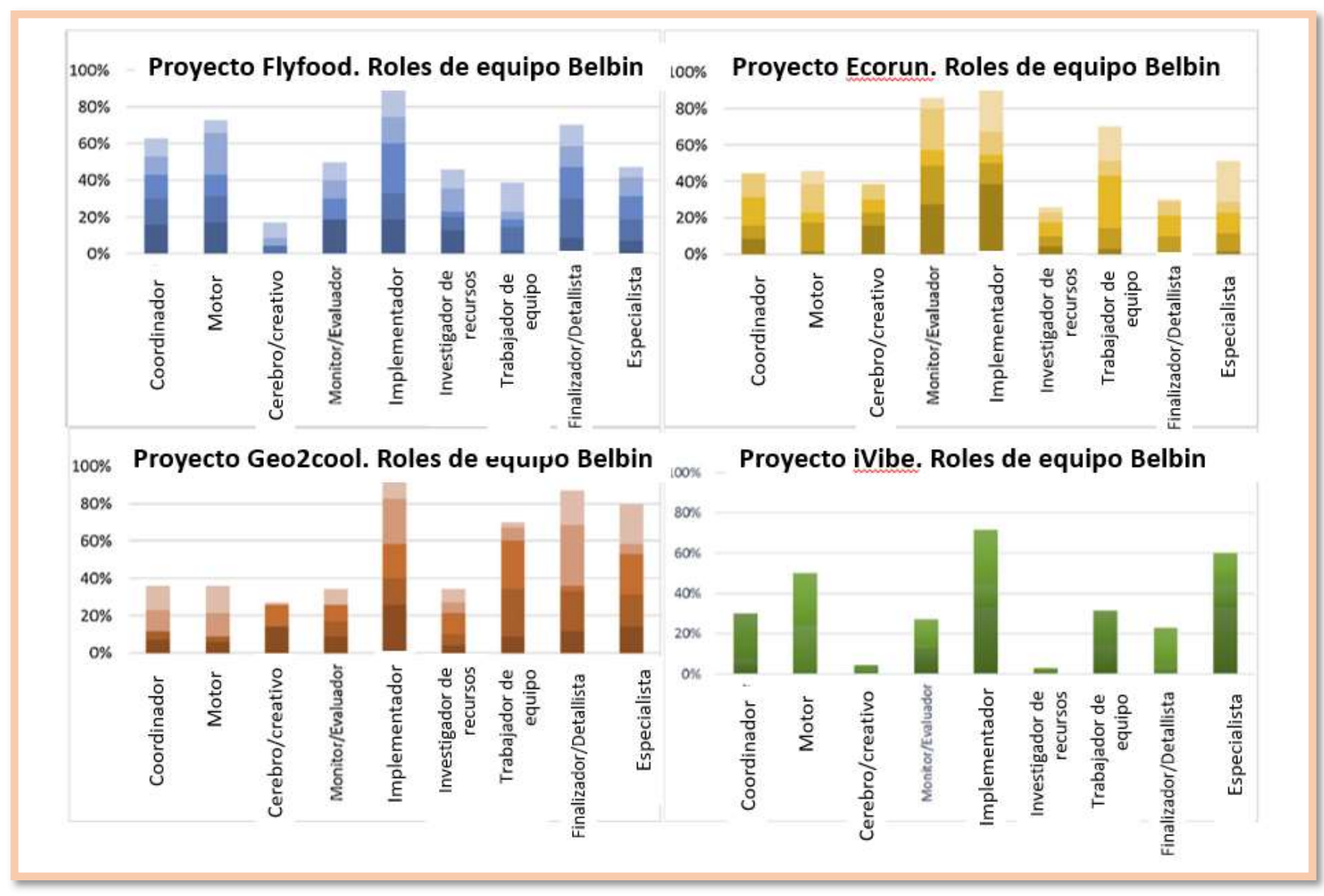

Figura 17. Roles del equipo según la teoría de Belbin. Identificación para los cuatro equipos. 
Teniendo en cuenta las diferentes etapas a través de las cuales pasa un equipo (identificación de necesidades, búsqueda de ideas, formulación de planes, generación de ideas, establecimiento de la organización y desarrollo del equipo), los equipos que tienen perfiles de Coordinador y Formador pueden tener mayor éxito en las primeras etapas de un proyecto, mientras que Los implementadores y finalistas serán fundamentales para las últimas etapas. Tenga en cuenta que, para el ejercicio propuesto, el rol de Investigador de recursos será igualmente necesario e importante. Finalmente, el rol de Especialista está presente en todos los equipos de proyecto, lo que denota un perfil eminentemente técnico de los individuos en estos equipos.

El rol de autopercepción de Belbin de los equipos (considerado como el cuestionario del rol individual dentro del equipo) y Jung. La teoría (predisposición del individuo hacia el trabajo), proporciona una visión profunda del rendimiento y la predisposición de los sujetos hacia el trabajo. Es importante enfatizar que estos cuestionarios se basan en una autopercepción, mientras que CAT se basa en una evaluación externa de la competencia de creatividad.

Al analizar los perfiles encontrados en los equipos, todos ellos muestran una fuerte inclinación hacia el Implementador y, en algunos casos, el Finalizador, el Evaluador y otros perfiles. Sin embargo, el perfil de la creatividad, que fue uno de los focos de este estudio, muestra valores bajos en todos los equipos. El equipo de EcoRun Systems fue el único con un alto perfil de creatividad, contribuyendo en este perfil hasta cuatro de los cinco miembros. Este resultado es consistente con el obtenido en la prueba de actitud hacia el trabajo (Figura 18).

El estudio muestra que los equipos tenían una baja predisposición a la imaginación y la creatividad (Fig. 17), aunque vale la pena señalar que esta evaluación se realiza para la creatividad disruptiva, donde se aplican nuevos conceptos al mercado.

Partiendo de la teoría del equipo de Belbin sobre la necesidad de un equipo equilibrado, este estudio enfatiza la falta de un recurso (Perfil del investigador en el lanzamiento del proyecto). 


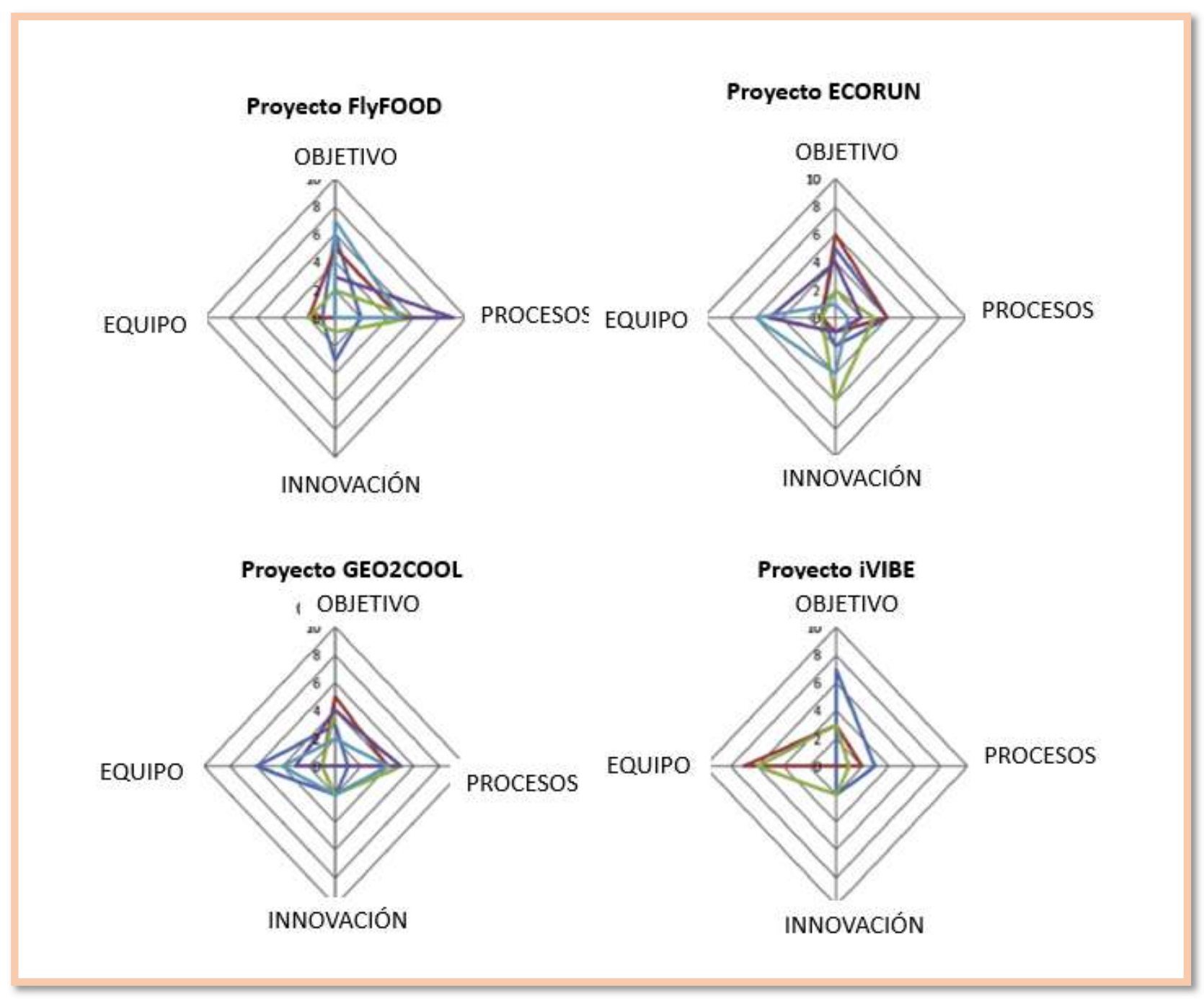

Figura 18. Perfil de cada ingeniero frente al trabajo, según C.G. Teoría de Jung.

Este perfil permite conectar el equipo y el proyecto con el exterior, para obtener el apoyo necesario para el desarrollo del proyecto. Este hecho se refleja en el bajo valor obtenido en términos de funcionalidad del proyecto EcoRun: a pesar de una valoración razonable en términos de novedad e impacto, la falta de este perfil se reflejó en la comunicación y exposición del proyecto.

\subsubsection{Actitud hacia el trabajo}

El análisis de los perfiles de Jung demuestra la predisposición de los individuos hacia roles mayormente objetivos y, en algunos casos, hacia perfiles y procesos de equipos. 
El análisis de los resultados proporcionó las siguientes observaciones interesantes: en primer lugar, vale la pena señalar que para muchos individuos no existe un perfil único dominante, pero presentan una doble dominación, donde sus preferencias se definen mediante una imagen izquierda-derecha o cortical-límbica. Hemisferio, o incluso dominancia triple o cuádruple. Una conclusión que puede derivarse de los datos que se muestran en la Figura 18 es que la mayoría de los individuos involucrados en este estudio de caso presentan una tendencia clara hacia perfiles basados en objetivos (pensamiento analítico), seguidos de perfiles orientados a procesos (pensamiento secuencial), perfiles de equipo (pensamiento interpersonal) y, por último, perfiles de innovación (pensamiento imaginativo).

Centrándose en el concepto de creatividad, el grupo EcoRun se destaca por ser el único equipo que tiene una gran inclinación por este perfil entre sus miembros, ya que dos de los cinco miembros presentan este perfil como dominante. Por el contrario, ningún otro individuo presenta el perfil creativo como dominante en ninguno de los otros equipos. Finalmente, vale la pena mencionar el fuerte perfil orientado al equipo, presentado como el primer o segundo perfil en seis de las dieciocho muestras.

Es importante notar que los equipos Geo2Cool y EcoRun presentan el valor más bajo en el eje "Objetivo", y es otra razón para entender los bajos valores obtenidos en el ejercicio de inversión. Es importante destacar la falta de habilidades de innovación en todos los ingenieros: solo uno de ellos presenta un resultado significativo en este eje (incluido en el proyecto EcoRun). Finalmente, tres de los equipos incluyen ingenieros con un alto valor en el eje del equipo, lo que significa un equipo cohesionado y comprometido; se correlaciona con los resultados a largo plazo; incluso si el proyecto FlyFood obtuvo un resultado positivo en el ejercicio, el equipo decidió no pasar a la idea en la competencia global de ideas / proyectos actúaupm. 


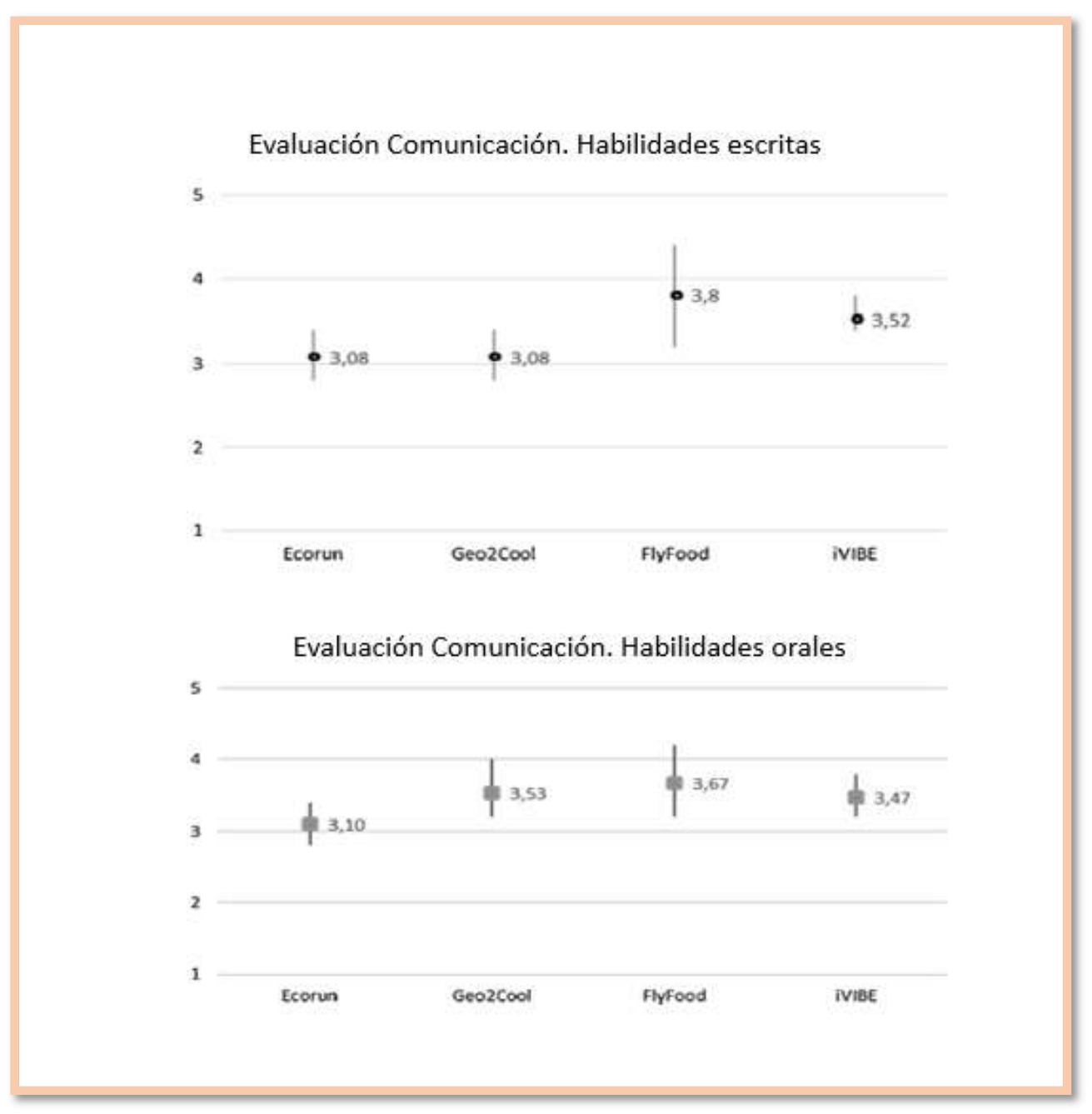

Figura 19. Evaluación de la comunicación. Habilidades escritas y orales de cada equipo.

Nota: El gráfico se basa en la escala de cinco puntos de Likert.

\subsubsection{Comunicación}

Como se muestra en los resultados (Figura 17), el proyecto EcoRun adolece de una falta de esta competencia, siendo el equipo el que obtiene los resultados más bajos en comunicación oral y escrita; más evidente en la puntuación de los evaluadores / inversores a la pregunta "escuchar al interlocutor y responder". En comparación con el proyecto Geo2Cool, otro proyecto que requiere una gran inversión se ha demostrado que esta habilidad es fundamental en proyectos de alto nivel o multidisciplinarios.

Por otro lado, los proyectos iVibe y Flyfood obtienen una buena puntuación en esta competencia, y esto contribuye a obtener los mejores resultados en el ejercicio del inversor. 
Incluso si el proyecto iVibe obtuvo una puntuación más baja en las habilidades orales que en el proyecto Geo2Cool, podría explicarse porque el primero está formado por ingenieros nativos no españoles.

Según la Figura 16, iVIBE y FlyFood obtuvieron la inversión requerida para el proyecto, mientras que el resto de la propuesta fracasó en el resultado final. Es consistente con los resultados presentados en las habilidades de comunicación: FlyFood Project obtuvo la mejor puntuación en estas habilidades, seguido por el proyecto iVIBE. Por otro lado, el Proyecto EcoRun mostró los valores más bajos en habilidades de comunicación en comparación con el Proyecto FlyFood: $-18 \%$ en habilidades orales y $-19 \%$ en habilidades escritas. Por lo tanto, las habilidades de comunicación son las competencias más importantes que se necesitan en la tercera etapa del marco lógico del proyecto. 


\subsection{Discusión y Resultados del método AHP y su aplicación a las alternativas propuestas}

De acuerdo con el objetivo de seleccionar los proyectos innovadores más viables entre las alternativas en evaluación, el modelo de cálculo basado en el algoritmo AHP multi-criterio establece los siguientes pasos en su resolución:

- asignación de valores para cada criterio medible

- construcción del modelo y estructura de los criterios de AHP

- asignación de pesos para cada criterio.

Para resolver este modelo, el equipo de investigación refleja la experiencia combinada de más de 15 años de trabajo en innovación y selección de ideas que podrían implementarse en proyectos exitosos. Los resultados presentados cuentan con una estructuración de valores, asignación de pesos y estructuración y cuantificación de los valores medibles.

La definición de criterios realizada en las secciones anteriores de este documento ha supuesto la construcción de una estructura de toma de decisiones basada en un árbol de decisiones (Figura 20) específico en este caso por el objetivo perseguido. Este modelo permite evaluar analíticamente las diferentes alternativas en estudio y apoya el agente de decisión a través de un algoritmo matemático consistente.

El modelo debe ser detallado y estructurado, de modo que al final de cada nodo, se describen criterios cuantificables. 


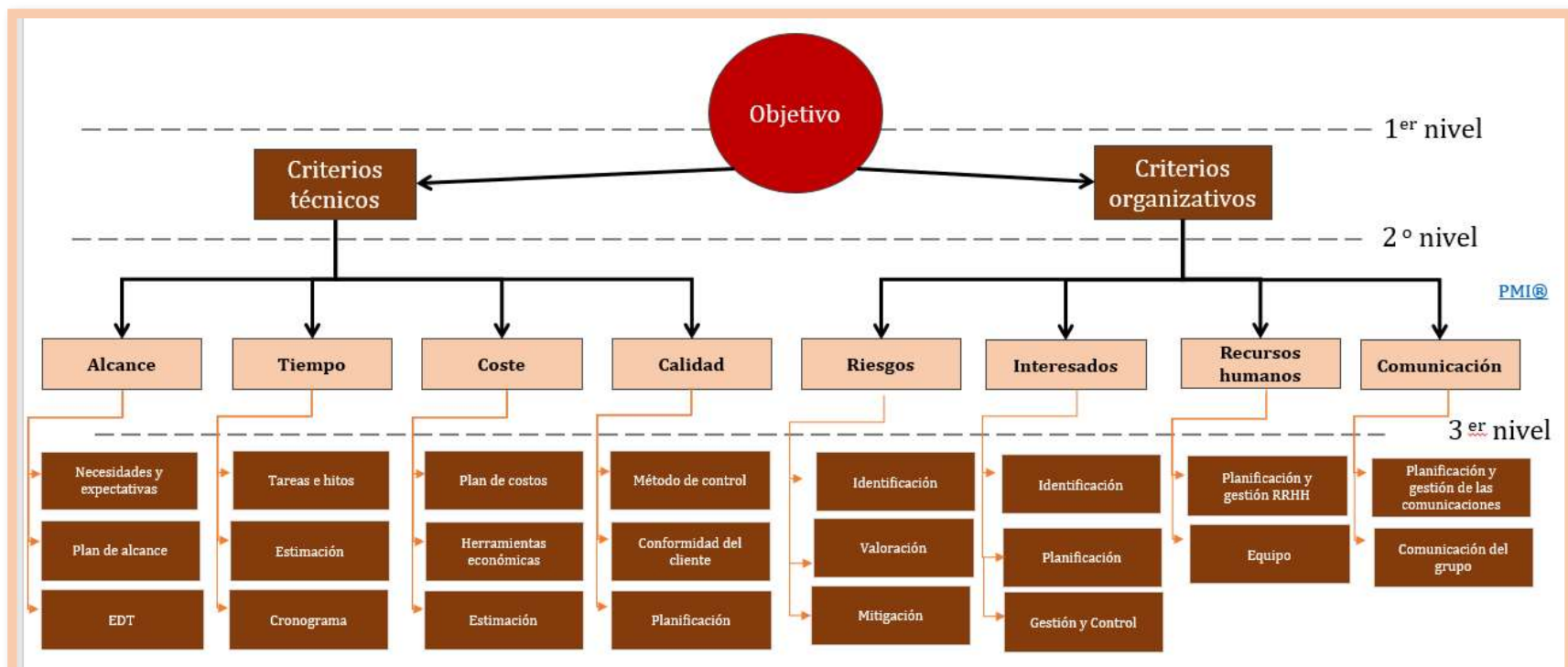

Figura 20. Estructura jerárquica y selección de estructuras propuestas para la selección de proyectos innovadores bajo enfoque de innovación abierta

Nota: Los bloques del 3er nivel son criterios medibles.

\section{EVALUACIÓN DEL PESO (WI)}

En este caso, el método AHP se considera en cada modo para establecer una comparación amplia de alternativas. En este caso, se evita una de las limitaciones de este algoritmo: esto establece que la comparación de alternativas en modo relativo (comparación de las alternativas con entre sí) deben limitarse a no más de siete. Esta restricción es conocida como consistencia (límite matemático) y límite neural (establecido por el impedimento del cerebro humano para ser capaz de comparar elementos simultáneamente).

La aplicación del modelo AHP en modo absoluto es establecer un patrón de comparación. Aquí el patrón se ha definido estableciendo los valores óptimos de cada criterio medible para mantener la consistencia en niveles aceptables, el método AHP propone considerar los principios de reciprocidad y transitividad a través de la siguiente ecuación (Saaty, 2006), que muestra el principio para mantener la consistencia de los juicios, la consistencia: transitividad y reciprocidad.

$$
\begin{aligned}
& \text { aij = aik. ajk } \\
& \text { aij = } 1 \text { / aji; }
\end{aligned}
$$

Ecuación 3. Ecuación de reciprocidad y transitividad de criterios AHP 
Se deben usar matrices de comparación (Ecuación 4) para establecer el peso de cada criterio estas matrices se construyen de manera secuencial, donde se establece una comparación de nivel a nivel, descendiendo de nivel y relacionando los criterios y ponderaciones de acuerdo con la relación de nodos establecida en el árbol de decisión (Figura 20):

$$
A=\left[\begin{array}{ccc}
1 & a_{12} & \ldots a_{1 n} \\
\frac{1}{a_{12}} & 1 & \ldots a_{2 n} \\
\frac{1}{a_{13}} & \frac{1}{a_{23}} & \ldots 1
\end{array}\right]
$$

\section{Ecuación 4. Matrices de comparación por pares (AHP)}

El peso de cada criterio se calculará utilizando la siguiente ecuación, donde el juicio experto se establece utilizando el valor propio máximo de la matriz de comparación.

(Ecuación 4):

$$
W_{i}=\sqrt[n]{\prod_{j=1}^{n} a_{i j}},
$$

\section{Ecuación 5. Cálculo del peso utilizando metodología AHP}

Utilizando esta metodología, se han establecido ponderaciones para cada criterio medible, representados en la Figura 21. Estas ponderaciones se aplicarán por igual en la evaluación de las alternativas para que se obtenga una evaluación objetiva de cada alternativa.

Finalmente, y a modo de verificación, la suma de pesos establecida para cada el criterio debe ser 1 , con el peso siempre siendo un valor mayor que 0 , que se muestra por la siguiente ecuación:

$$
\sum_{j=1}^{n} W_{j}=1
$$

Ecuación 6. Suma de pesos normalizados 


\section{EVALUACIÓN DEL VALOR (Vi)}

Teniendo en cuenta el modelo AHP absoluto, es necesario establecer un óptimo o valor máximo para cada uno de los criterios medibles. Para ello se ha establecido una estructura de criterios, considerando en el segundo nivel los procesos descritos en la metodología $\mathrm{PMI}$. Al final de cada nodo, se recogen los criterios medibles.

De acuerdo con las tablas descritas (Tablas IX y X), no solo la descripción científica de cada criterio ha sido recogida, pero una evaluación o escala matemática ha sido atribuida, siendo el juicio de valor del agente de decisión transferido en un valor numérico.

\section{APLICACIÓN DEL MODELO AHP, EVALUACIÓN DE ALTERNATIVAS (Ai).}

La prioridad es una unidad abstracta válida para cualquier escala en la que las preferencias del individuo son integradas con aspectos tangibles e intangibles comparables.

Los proyectos descritos en la sección anterior incluyen el trabajo desarrollado en el laboratorio de Ingeniería de proyectos durante los años académicos 2016-2017 y 2017 2018. Muchos de los proyectos recopilados forman parte de la cartera de trabajo, mientras que otros son el resultado de trabajar junto a ingenieros del Máster de Ingeniería de Minas.

El ejercicio de evaluación se centra en el proceso de toma de decisiones sobre la financiación de ideas y su desarrollo hasta la presentación final para quien toma las decisiones (ver Figura 8).

La Tabla XI muestra la evaluación de los proyectos considerados. A medida que se recopila, la valoración final de la alternativa se presenta de forma desagregada considerando los dos criterios del primer nivel y el total de cada alternativa. 


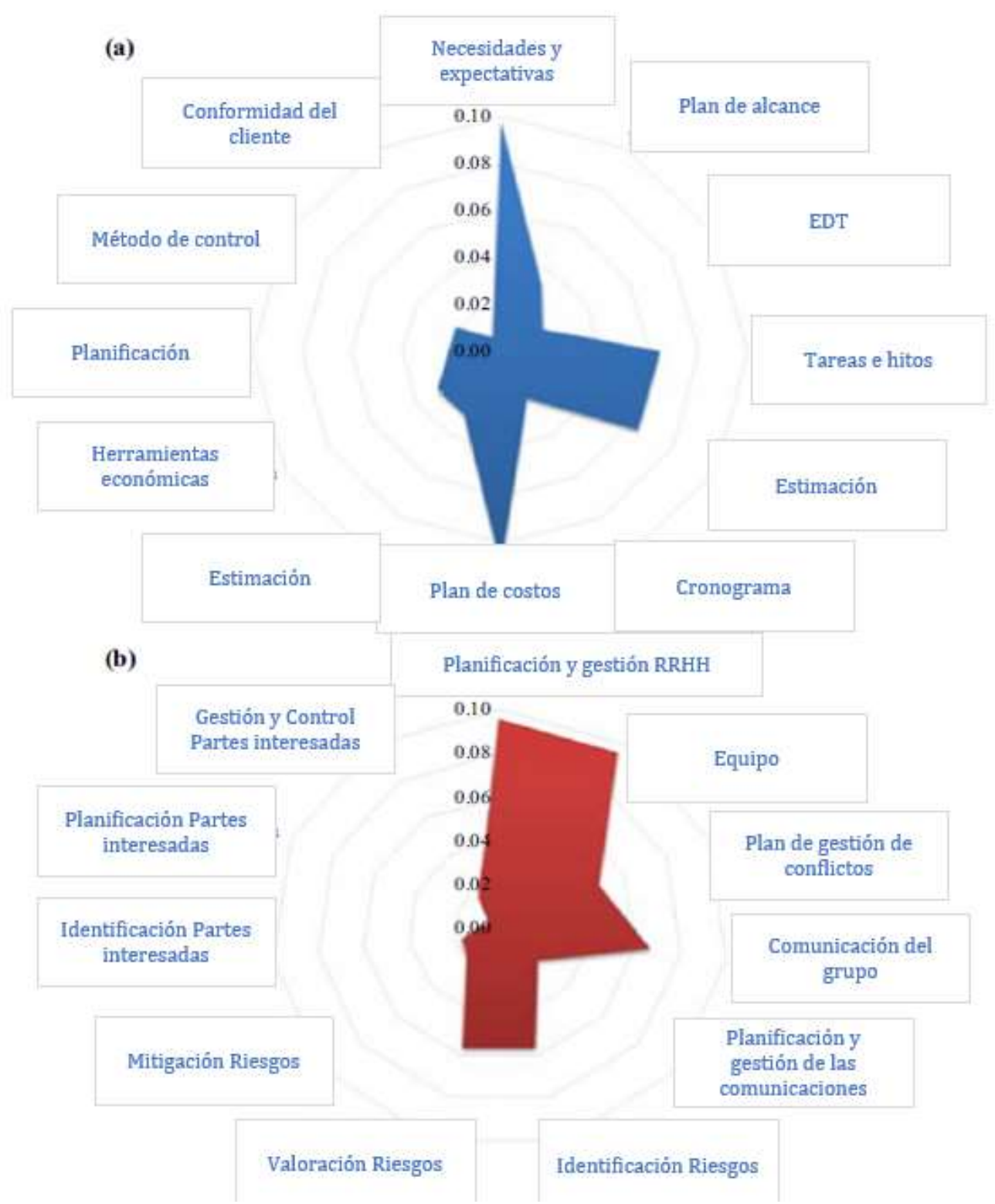

Notas: (a) Criterios técnicos; (b) criterios organizacionales

Figura 21. Evaluación de pesos.

Gracias a este estudio, es posible seleccionar el proyecto más viable, y, además, es posible identificar las fortalezas y debilidades de la propuesta para gestionar la fase de consulta y I o aclaraciones en el proceso de toma de decisiones. En este caso, el proyecto A tiene la valoración más alta entre las alternativas consideradas.

Este proyecto ha definido claramente la participación y la estructura del trabajo y un alcance técnico detallado, lo que lo convierte en un excelente proyecto para ser financiado. Por el contrario, el criterio de riesgo tiene una valoración media o baja, evidente en el criterio de 
"mitigación del riesgo", que hace que este criterio, uno de los puntos débiles que deben corregirse en la actualización de los informes consultados.

Tabla IX. Subcriterios de selección cuantificables dentro de cada criterio técnico.

\begin{tabular}{|c|c|c|c|c|}
\hline \multirow{2}{*}{$\begin{array}{l}\text { CRITERIOS } \\
\text { TÉCNICOS }\end{array}$} & \multirow{2}{*}{$\begin{array}{c}\text { CRITERIOS } \\
\text { SECUNDARIOS }\end{array}$} & \multicolumn{3}{|c|}{ CRITERIOS CUANTIFICABLES } \\
\hline & & 1 & 5 & 9 \\
\hline \multirow{3}{*}{ Alcance } & $\begin{array}{c}\text { Necesidades y } \\
\text { expectativas }\end{array}$ & $\begin{array}{l}\text { La matriz de rastreabilidad no es clara o } \\
\text { no está bien definida o no existe. Los } \\
\text { requisitos no están justificados }\end{array}$ & $\begin{array}{l}\text { La matriz de rastreabilidad es clara y está } \\
\text { bien definida, pero faltan documentos }\end{array}$ & $\begin{array}{l}\text { La matriz de rastreabilidad es clara y está } \\
\text { bien definida. Todos los requisitos están } \\
\text { justificados con la pertinente documentación }\end{array}$ \\
\hline & Plan de alcance & $\begin{array}{l}\text { No hay un plan de gestión de alcance ni } \\
\text { un plan de gestión de requisitos }\end{array}$ & $\begin{array}{l}\text { Hay un plan de gestión de alcance y un plan } \\
\text { de gestión de requisitos; pero alguno de ellos } \\
\text { no está bien definido }\end{array}$ & $\begin{array}{l}\text { Hay un plan de gestión de alcance y un plan } \\
\text { de gestión de requisitos; ambos están bien } \\
\text { definidos }\end{array}$ \\
\hline & EDT & No hay una EDT & Hay una EDT, pero no está completada & $\begin{array}{l}\text { Hay una EDT con todos sus paquetes de } \\
\text { trabajo definidos }\end{array}$ \\
\hline \multirow{3}{*}{ Tiempo } & Tareas e hitos & No hay una lista ni de tareas ni de hitos & $\begin{array}{l}\text { Hay una lista de tareas e hitos, pero no están } \\
\text { incluido en su totalidad todos los puntos. }\end{array}$ & $\begin{array}{l}\text { Hay una lista de tareas e hitos con todos los } \\
\text { puntos incluidos }\end{array}$ \\
\hline & Estimación & $\begin{array}{l}\text { No se ha seguido un proceso de } \\
\text { estimación preciso y es muy probable } \\
\text { que haya desviaciones importantes }\end{array}$ & $\begin{array}{l}\text { Se ha realizado un proceso de estimación } \\
\text { adecuado, pero podria haber sido más } \\
\text { preciso }\end{array}$ & $\begin{array}{l}\text { El método de estimación de tiempos ha sido } \\
\text { consistente y preciso. No se esperan } \\
\text { variaciones significativas }\end{array}$ \\
\hline & Cronograma & No hay cronograma o no está detallado & $\begin{array}{l}\text { Existe un grado de detalle conforme a un } \\
\text { Diagrama de bloques. No hay un método de } \\
\text { control }\end{array}$ & $\begin{array}{l}\text { Existe un grado de detalle conforme a un } \\
\text { Diagrama de Gantt. Además, hay un método } \\
\text { de control del mismo }\end{array}$ \\
\hline \multirow{3}{*}{ Costo } & Plan de costos & No hay un plan de costos & $\begin{array}{l}\text { Hay un plan de costos, pero no están } \\
\text { definidos todos los puntos }\end{array}$ & Hay un plan de costos perfectamente definido \\
\hline & Estimación & $\begin{array}{l}\text { No se ha seguido un proceso de } \\
\text { estimación de costos preciso y es muy } \\
\text { probable que haya desviaciones } \\
\text { importantes }\end{array}$ & $\begin{array}{l}\text { Se ha realizado un proceso de estimación de } \\
\text { costos adecuado, pero podria haber sido más } \\
\text { preciso }\end{array}$ & $\begin{array}{l}\text { El método de estimación de costos ha sido } \\
\text { consistente y preciso. No se esperan } \\
\text { variaciones significativas }\end{array}$ \\
\hline & $\begin{array}{l}\text { Herramientas } \\
\text { económicas }\end{array}$ & No se usa ninguna herramienta & $\begin{array}{l}\text { Se utiliza al menos dos de las herramientas } \\
\text { económicas principales [TIR, VAR, PRI] }\end{array}$ & $\begin{array}{l}\text { Se utilizan todas las herramientas [TIR, } \\
\text { VAR, PRI] }\end{array}$ \\
\hline \multirow{3}{*}{ Calidad } & Planificación & $\begin{array}{l}\text { Las normas que se van a utilizar no } \\
\text { están definidas, ni tampoco su método } \\
\text { de satisfacción }\end{array}$ & $\begin{array}{l}\text { Las normas que se van a utilizar no están } \\
\text { totalmente definidas, hay entregables que no } \\
\text { tienen un plan de control de calidad }\end{array}$ & $\begin{array}{l}\text { Las normas que se van a utilizar están } \\
\text { totalmente definidas, asi como su método de } \\
\text { satisfacción }\end{array}$ \\
\hline & Método de control & $\begin{array}{l}\text { No hay ningún método de control de la } \\
\text { calidad }\end{array}$ & $\begin{array}{l}\text { Hay un método de control, pero algunos } \\
\text { puntos no están definidos o no son lo } \\
\text { suficientemente claros }\end{array}$ & $\begin{array}{l}\text { Hay un método de control perfectamente } \\
\text { claro y definido }\end{array}$ \\
\hline & $\begin{array}{l}\text { Conformidad del } \\
\text { cliente }\end{array}$ & $\begin{array}{l}\text { No existe ningún método para saber la } \\
\text { conformidad del cliente }\end{array}$ & $\begin{array}{l}\text { Existe un método para la conformidad del } \\
\text { cliente, pero se prevén posibles problemas } \\
\text { de implantación o de procedimiento }\end{array}$ & $\begin{array}{l}\text { Existe un método de conformidad del cliente; } \\
\text { este es claro y eficaz }\end{array}$ \\
\hline
\end{tabular}

Nota: El plan de costes contiene la planificación, estructuración y control de los costos del proyecto, así como los procesos de gestión de costes (herramientas y técnicas asociadas), detalles de financiamiento del proyecto o recursos del proyecto 
Tabla X. Subcriterios de selección cuantificables dentro de cada criterio organizativo

\begin{tabular}{|c|c|c|c|c|}
\hline \multirow{2}{*}{$\begin{array}{c}\text { CRITERIOS } \\
\text { ORGANIZATIVOS }\end{array}$} & \multirow{2}{*}{$\begin{array}{c}\text { CRITERIOS } \\
\text { SECUNDARIOS }\end{array}$} & \multicolumn{3}{|c|}{ CRITERIOS CUANTIFICABLES } \\
\hline & & 1 & 5 & 9 \\
\hline \multirow{3}{*}{ Recursos humanos } & $\begin{array}{l}\text { Director de } \\
\text { proyectos }\end{array}$ & $\begin{array}{l}\text { El DP dirige por primera vez proyectos } \\
\text { de estas caracteristicas o de } \\
\text { caracteristicas similares } \\
\end{array}$ & $\begin{array}{l}\text { El DP ha dirigido proyectos caracteristicas } \\
\text { similares, pero no de estas características }\end{array}$ & $\begin{array}{l}\text { El DP ya ha dirigido proyectos de estas } \\
\text { caracteristicas }\end{array}$ \\
\hline & Equipo & $\begin{array}{l}\text { No existe una planificación para la } \\
\text { adquisición y formación del equipo }\end{array}$ & $\begin{array}{l}\text { Existe una planificación para la adquisición } \\
\text { del equipo, pero no existe una planificación de } \\
\text { la formación }\end{array}$ & $\begin{array}{l}\text { Existe tanto uma planificación para la } \\
\text { adquivición y formación del equipo }\end{array}$ \\
\hline & $\begin{array}{l}\text { Plan de gestión de } \\
\text { conflictos }\end{array}$ & $\begin{array}{l}\text { No existe un plan de gestión de } \\
\text { conflietos }\end{array}$ & $\begin{array}{l}\text { Existe un plan de gestión de conflictos, pero } \\
\text { no se sabe cómo se comunicará al personal }\end{array}$ & $\begin{array}{l}\text { Existe un plan de geatión de conflictos y está } \\
\text { planificado la forma en la cual se comumicará } \\
\text { al equipo }\end{array}$ \\
\hline \multirow[t]{2}{*}{ Comunicación } & Planificación & $\begin{array}{l}\text { No hay un plan de gestión de } \\
\text { información }\end{array}$ & $\begin{array}{l}\text { Hay un plan de gestión de información, pero } \\
\text { falta algrma parte (canal de comunicación, } \\
\text { formato y contenidos del tipo de información, } \\
\text { personas responsables de comunicar, personas } \\
\text { que recibirán la información, tecnologias de la } \\
\text { información a utilizar, frecuencia de la } \\
\text { comunicación, glosario de téminos comunes) }\end{array}$ & $\begin{array}{l}\text { Hay un plan de gestión de información } \\
\text { completamente definido }\end{array}$ \\
\hline & $\begin{array}{l}\text { Flujo de } \\
\text { información }\end{array}$ & No hay un plan elaborado & $\begin{array}{l}\text { Hay un plan elaborado, pero no es lo } \\
\text { suficientemente claro y preciso como para } \\
\text { informar en tiempo y forma a los interesados }\end{array}$ & $\begin{array}{l}\text { Hay un plan elaborado; claro y preciso de } \\
\text { como informar en tiempo y forma a los } \\
\text { interesados }\end{array}$ \\
\hline \multirow{3}{*}{ Riesgo } & Identificación & $\begin{array}{l}\text { No existe un procedimiento ni un plan } \\
\text { para saber cuiles son los rieszos que } \\
\text { afectan al proyecto }\end{array}$ & $\begin{array}{l}\text { Existe un procedimiento y un plan, pero no } \\
\text { enti definido para todos los factores que } \\
\text { afectan al proyecto }\end{array}$ & $\begin{array}{l}\text { Existe un procedimiento y un plan, ambos } \\
\text { totalmente claros } y \text { definidos, para saber } \\
\text { cuáles son los riesgos que afectan al proyecto }\end{array}$ \\
\hline & Valoración & No se valoran los riesgos identificados & $\begin{array}{l}\text { Los riesgos están valorados por impacto y } \\
\text { probabilidad. No se sabe el nivel de riesgo } \\
\text { arociado a ertos valores }\end{array}$ & $\begin{array}{l}\text { Los riesgos están valorados por impacto y } \\
\text { probabilidad. Se sabe el nivel de riesgo } \\
\text { gracias a la matriz de rienro asociada }\end{array}$ \\
\hline & Mitigación & $\begin{array}{l}\text { No hay acciones de mitigación definidas } \\
\text { para los riesgos asociados }\end{array}$ & $\begin{array}{l}\text { Hay acciones de mitigación definidas para } \\
\text { alguno de los riesgos asociados }\end{array}$ & $\begin{array}{l}\text { Todos los riesgos asociados tienen una acción } \\
\text { de mitigación definida }\end{array}$ \\
\hline \multirow{3}{*}{ Interesados } & Identificación & $\begin{array}{l}\text { No está ningún o casi ningún interesado } \\
\text { identificado }\end{array}$ & $\begin{array}{l}\text { Un número significativo de los interesados } \\
\text { está identificado }\end{array}$ & Todos los interesados están identificados \\
\hline & Planificación & $\begin{array}{l}\text { No hay un plan de gestión de los } \\
\text { interesados ni un plan de comunicación }\end{array}$ & $\begin{array}{l}\text { Hay un plan de gestión de gestión de los } \\
\text { interesados, pero no hay un plan de } \\
\text { comunicación }\end{array}$ & $\begin{array}{l}\text { Hay un plan de gestión de los interesados y um } \\
\text { plan de comunicación completamente } \\
\text { definidos }\end{array}$ \\
\hline & Gestión y control & $\begin{array}{l}\text { No existe un plan de gestión de los } \\
\text { requisitos exigidos por los interesados }\end{array}$ & $\begin{array}{l}\text { Existe un plan de gestión de los requisitos } \\
\text { exigidos por los interesados, pero no todos los } \\
\text { interesados tienen un plan definido }\end{array}$ & $\begin{array}{l}\text { Existe un plan de gestión de los requisitos } \\
\text { exigidos por los interesados completamente } \\
\text { definido }\end{array}$ \\
\hline
\end{tabular}


Tabla XI. Evaluación de las alternativas (propuestas de proyectos).

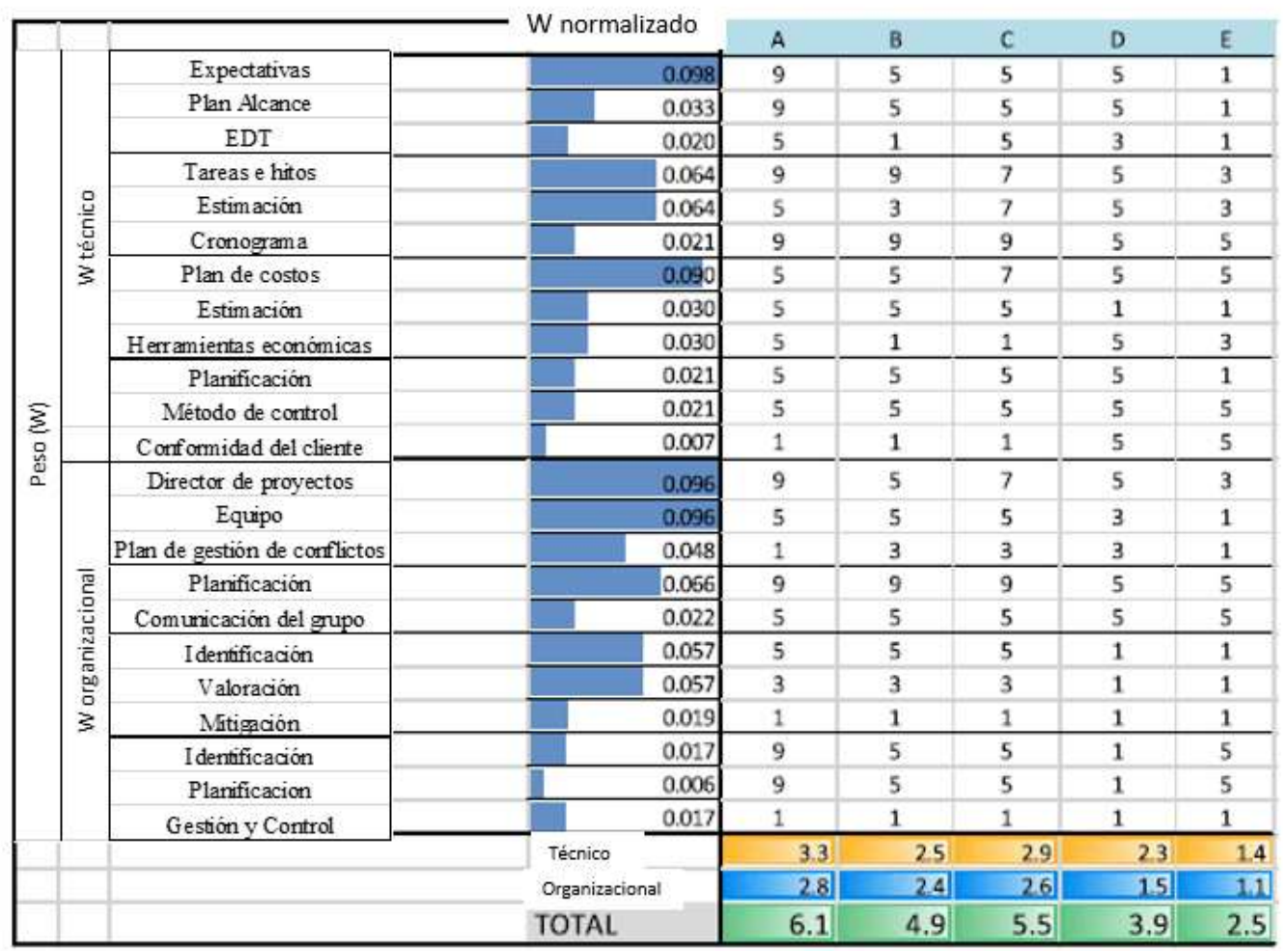

Entre los proyectos consultados, destacan los proyectos C y B porque presentan valores razonables tanto desde el punto de vista técnico y organizativo: ambos proyectos tienen una evaluación desde un punto de vista técnico.

Los resultados obtenidos por el algoritmo propuesto en este estudio fueron validados gracias a una evaluación profesional y externa: se aprobaron dos de los proyectos más valiosos y financiado por empresas (propuesta de proyecto A y C). De ahí, el proceso de aprobación y validación del algoritmo considerado como la evaluación más robusta y difícil: la industria. 


\subsection{Discusión y Resultados del modelo matemático y su aplicación a los proyectos innovadores}

Recordemos que el objetivo buscado es estudiar la posible correlación entre la valoración AHP y los equipos de trabajo. De esta manera, podremos:

a) confirmar si existe una correlación entre el valor asignado de "éxito" a los proyectos, el valor asignado considerando la herramienta AHP y su posible relación con diagnóstico de los equipos realizado en base a la autopercepción de roles inspirado en la teoría de Belbin.

b) reforzar el análisis anterior con una línea de investigación futura que permita profundizar en la relación anterior utilizando métodos estadísticos adicionales como el análisis Clúster (o Análisis de Conglomerados), que es una técnica estadística multivariante de clasificación automática de datos que permite agrupar elementos (o variables) para así lograr la máxima homogeneidad en cada grupo y la mayor diferencia entre los grupos.

c) proponer futuras líneas de trabajo relacionadas con la correspondencia entre las dos variables anteriores, tanto en la formación de nuevos equipos de trabajo como en una posible herramienta de predicción de éxito asociado a los proyectos que permita así decidir la priorización de recursos en una organización.

En primer lugar, se han calculado los valores de éxito asociado a los proyectos mediante la aplicación de la metodología AHP a los proyectos según lo descrito en la publicación:

M Dolores Storch de Gracia, David Moya Perrino y Bernardo Llamas (2019) "Multicriteria methodology and hierarchical innovation in the energy sector", Management Decision, Vol. 57 No. 5, pp. 1286-1303."

Los resultados se muestran en la tabla siguiente: 


\section{Tabla XII: Resultados de la aplicación metodología AHP a proyectos}

\begin{tabular}{|c|c|c|c|}
\hline GRUPO & Detalle proyecto & $\begin{array}{l}\text { Valor Total } \\
\text { criterios }\end{array}$ & $\begin{array}{l}\text { Valor Total aplicando } \\
\text { la metodología AHP }\end{array}$ \\
\hline Grupo 1 & Proyecto de exploración geológica, exploración de cobre u otros minerales metólicos & 43,33 & 3,37 \\
\hline Grupo 2 & $\begin{array}{l}\text { Proyecto de reapertura de minería metálico en España según la lista de } 14 \text { materias primas } \\
\text { críticas en la Unión Europea. }\end{array}$ & 25,33 & 1,92 \\
\hline Grupo 3 & Desarrollo de un proyecto de coracterización y exploración para el campo del Oil\&Gas & 23,33 & 1,72 \\
\hline Grupo 4 & Energia undimotriz: tecnologías, desorrollos y costes & 51,33 & 3,09 \\
\hline Grupo 5 & Regulación de la red eléctrico mediante cargadores de baterías de coches eléctricos & 38,67 & 2,74 \\
\hline Grupo 6 & $\begin{array}{l}\text { Energía solar: selección de tecnología (fotovoltaica, guiada o no, de concentración y otros), } \\
\text { costes y ubicación }\end{array}$ & 40,00 & 2,76 \\
\hline Grupo 7 & $\begin{array}{l}\text { Edificoción sostenible, generación de energía en entornos urbanos, desde un edificio hasto un } \\
\text { jardin }\end{array}$ & 22,00 & 1,85 \\
\hline Grupo 8 & Desarrollo de un parque eólico off-shore: Trafalgar ubicación, tecnología y costes & 34,33 & 2,73 \\
\hline Grupo 9 & $\begin{array}{l}\text { Sistema eléctrico, hacia un modelo de sostenibilidad: selección de tecnologia por beneficios } \\
\text { ambientales, costes y seguridad de suministro }\end{array}$ & 45,33 & 3,22 \\
\hline Grupo 10 & Edificación sostenible: sistemas de recuperación y generación de energía en entornos urbanos & 33,33 & 2,74 \\
\hline Grupo 11 & Implementación y operación de red undimotriz en las aguos de Santoña & 36,00 & 2,74 \\
\hline Grupo 12 & Coche eléctrico y movilidad: despliegue de los puntos de conexión en una urbe e interurbono & 34,00 & 2,36 \\
\hline Grupo 13 & $\begin{array}{l}\text { Geotermia: Climatización de un edificio de viviendas en la Comunidad de Madrid (Ecothermal } \\
\text { S.A.) }\end{array}$ & 33,33 & 2,71 \\
\hline Grupo 14 & Proyecto de búsqueda de inversión inicial para la Mina Platreef & 33,67 & 2,27 \\
\hline Grupo 15 & $\begin{array}{l}\text { Edificación sostenible: sistemas de recuperación, generación de energía en entornos urbanos, } \\
\text { desde un edificio hasta un jardín }\end{array}$ & 29,33 & 2,00 \\
\hline Grupo 16 & Almacenamiento de energía: caracterización y estudio de la tecnologia CAES & 42,00 & 2,64 \\
\hline Grupo 17 & Captura y Almacenamiento de CO2: tecnologías propuestas, costes y beneficios esperados & 37,33 & 2,98 \\
\hline Grupo 18 & Almacenamiento de energía: caracterización y estudio de la tecnología CAES & 56,00 & 4,11 \\
\hline Grupo 19 & Movilidad sostenible: Tecnologías y opciones paro el parque móvil del servicio público & 46,67 & 2,95 \\
\hline Grupo 20 & Producción de bioetanol a partir de materiales lignocelulósicos/ & 49,33 & 3,16 \\
\hline Grupo 21 & $\begin{array}{l}\text { Energía solar: selección de tecnología (fotovoltaica, guiada o no, de concentración y otros), } \\
\text { costes y ubicación }\end{array}$ & 24,67 & 2,38 \\
\hline
\end{tabular}

Se obtiene un valor total para cada uno de los grupos (valor total criterios) que posteriormente se corrige aplicando la metodología AHP descrita anteriormente. Con este valor se puede así trabajar para confirmar si existe una relación entre la composición de estos grupos y la robustez de sus propuestas.

Para ello, y tal y como se describió en el 3.3.1.3 se evalúa para cada uno de los grupos los 4 criterios técnicos y organizativos, dando un valor de 1,5 o 9 en función del desarrollo alcanzado según la Tabla VII. Aplicación criterios a metodología PMP para obtener la columna "Valor Total criterios" en la tabla XII y se corrige este valor según la asignación de pasos a los criterios de selección de proyectos descritos en la Tabla VIII, para obtener así el "Valor Total aplicando la metodología AHP".

En segundo lugar, se han clasificado los grupos identificando los roles de sus componentes y a continuación considerando las categorías propuestas anteriormente (Absolutamente 
desequilibrados, Desequilibrados o Equilibrados) obteniendo los resultados que se muestran en la tabla XIII. Tal y como se describió en el apartado 3.3.1.4 los equipos se considera que hay una presencia de roles significativa cuando la suma de las aportaciones de los miembros del grupo en esa categoría (Social, Reflexión o Acción) es mayor de 25 puntos y se clasifican a continuación en una de las categorías siguientes:

- Absolutamente desequilibrados: si tras analizar a los miembros del equipo se observa que en conjunto hay ausencia de uno de los 3 tipos de roles (reflexión, acción, social) ya que ninguno de los miembros posee una contribución significativa de alguno de los mismos.

- Desequilibrados: si tras el análisis de los miembros del equipo se puede concluir que en conjunto hay presencia de los 3 tipos de roles (reflexión, acción, social) ya que al menos alguno de los miembros posee una contribución significativa de alguno de los mismos pero se considera desbalanceada.

- Equilibrados: si hay presencia significativa de los 3 roles

A modo de ejemplo, y para una mejor comprensión del Diagnóstico propuesto y de la propuesta de clasificación se muestran a continuación varios ejemplos:

Grupo 1: Hay 2 miembros con una aportación en Roles Sociales significativa, 2 miembros con aportación en Roles de Reflexión significativa y 2 miembros con aportación en Roles de Acción significativa. Hay por tanto presencia significativa de los 3 roles y podemos concluir que es un Grupo EQUILIBRADO.

Grupo 5: Hay 2 miembros con una aportación en Roles Sociales significativa y 5 miembros con aportación en Roles de Acción significativa pero ningún miembro tiene una aportación en Roles de Reflexión significativa. No hay por tanto presencia significativa de los 3 roles y podemos concluir que es un Grupo ABSOLUTAMENTE DESEQUILIBRADO.

Grupo 17: Hay 1 miembro con una aportación en Roles Sociales significativa, 1 miembro con aportación en Roles de Reflexión significativa y 4 miembros con aportación en Roles de Acción significativa. Hay por tanto presencia significativa de los 3 roles pero muy desbalanceada, siendo mucho mayor la presencia de Roles de Acción por lo que se clasifica el diagnóstico como Grupo DESEQUILIBRADO. 
Tabla XIII: Diagnóstico de equipos de trabajo según la presencia de roles

\begin{tabular}{|c|c|c|c|c|}
\hline Grupo & $\begin{array}{l}\text { Valor Roles } \\
\text { Sociales }>25\end{array}$ & $\begin{array}{l}\text { Valor Roles } \\
\text { Reflexión }>25\end{array}$ & $\begin{array}{l}\text { Valor Roles } \\
\text { Acción }>25\end{array}$ & Diagnóstico \\
\hline Grupo 1 & 2 & 2 & 2 & Equilibrado \\
\hline Grupo 2 & 0 & 1 & 6 & Absolutamente desequilibrado \\
\hline Grupo 3 & 0 & 1 & 4 & Absolutamente desequilibrado \\
\hline Grupo 4 & 2 & 2 & 3 & Equilibrado \\
\hline Grupo 5 & 2 & 0 & 5 & Absolutamente desequilibrado \\
\hline Grupo 6 & 2 & 4 & 1 & Desequilibrado \\
\hline Grupo 7 & 5 & 1 & 0 & Absolutamente desequilibrado \\
\hline Grupo 8 & 0 & 0 & 6 & Absolutamente desequilibrado \\
\hline Grupo 9 & 3 & 1 & 2 & Equilibrado \\
\hline Grupo 10 & 1 & 1 & 4 & Desequilibrado \\
\hline Grupo 11 & 4 & 1 & 1 & Absolutamente desequilibrado \\
\hline Grupo 12 & 2 & 0 & 4 & Absolutamente desequilibrado \\
\hline Grupo 13 & 1 & 3 & 1 & Desequilibrado \\
\hline Grupo 14 & 3 & 2 & 1 & Equilibrado \\
\hline Grupo 15 & 1 & 1 & 4 & Desequilibrado \\
\hline Grupo 16 & 3 & 0 & 3 & Absolutamente desequilibrado \\
\hline Grupo 17 & 1 & 1 & 4 & Desequilibrado \\
\hline Grupo 18 & 2 & 1 & 2 & Equilibrado \\
\hline Grupo 19 & 1 & 2 & 3 & Equilibrado \\
\hline Grupo 20 & 3 & 2 & 2 & Equilibrado \\
\hline Grupo 21 & 1 & 0 & 3 & Absolutamente desequilibrado \\
\hline
\end{tabular}

Para cada uno de los grupos se asigna 1 punto por cada miembro que obtenga una puntuación superior a 25 en los atributos correspondientes a los Roles Sociales, Reflexión y Acción, según el cuestionario planteado en el apartado 3.1.4.1 de esta tesis. A continuación, como se planteó en la metodología del estudio descrita anteriormente se asigna un valor de diagnóstico para los 21 grupos, de los cuales 7 son equilibrados, 5 son desequilibrados y 9 son absolutamente desequilibrados tal y como se muestra en la siguiente figura. 


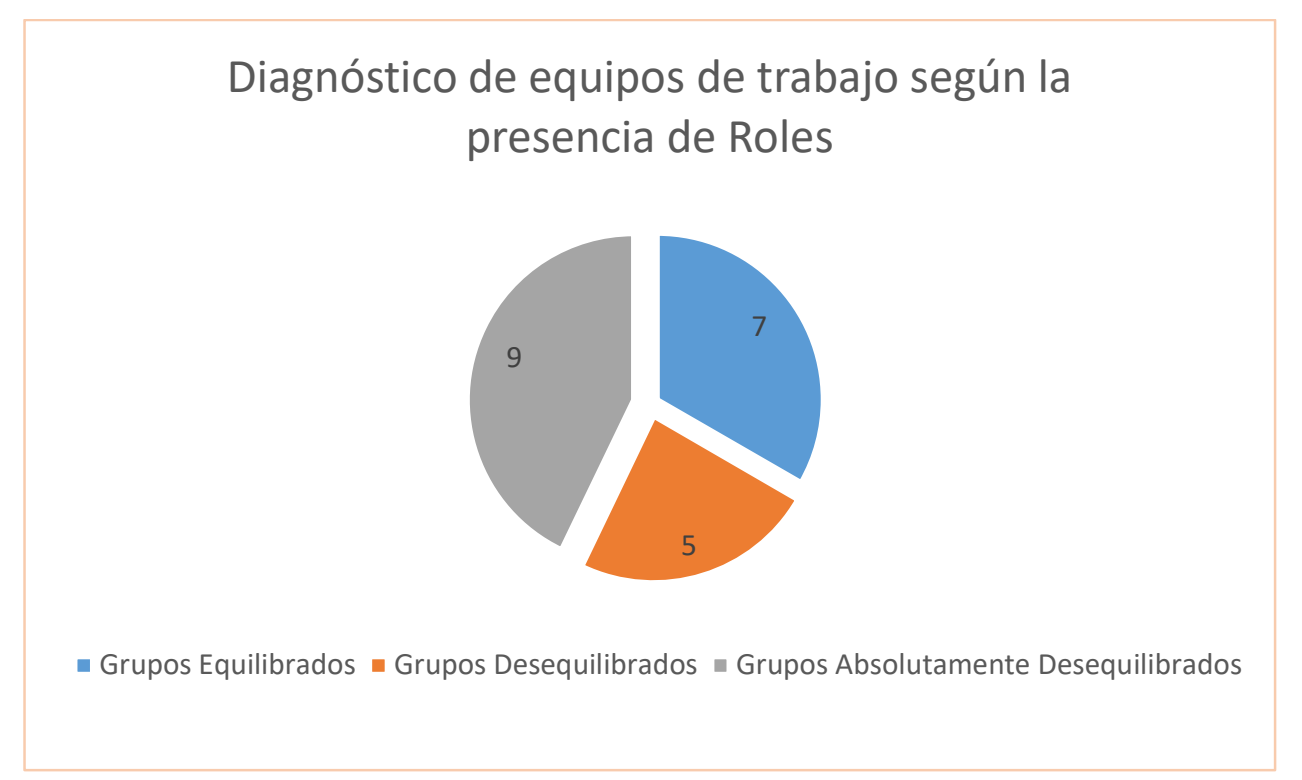

Figura 22. Diagnóstico de equipos de trabajo según la presencia de Roles

Tal y como se ha descrito anteriormente se trata de confirmar si existe una correlación entre el valor asignado de "éxito" a los proyectos, el valor asignado considerando la herramienta AHP y su posible relación con diagnóstico de los equipos realizado en base a la autopercepción de roles inspirado en la teoría de Belbin.

Con este objetivo, se va a realizar el análisis estadístico de los resultados para poder estudiar la posible relación entre los valores de éxito asociados a los proyectos (tabla XII) y la composición de los equipos de trabajo (tabla XIII)

Para ello se realizará en primer lugar la prueba de bondad de ajuste a la distribución Normal (Kolmogorov - Smirnov) para la variable AHP y la prueba de Shapiro-Wilk para la variable Equipos de trabajo, para concluir con la prueba de comparación de medias de 3 o más variables (ANOVA) para la variable AHP, con el objetivo de poder determinar si existen diferencias que no se deben al azar y si se puede confirmar que existe una relación entre el Valor AHP (éxito de los proyectos) y el Equilibrio de los roles de equipo.

En la prueba de bondad de ajuste a la distribución Normal (Kolmogorov - Smirnov) para la variable AHP, si el nivel de significación $p<0,05$, la distribución de la variable no es Normal, mientras que valores superiores a 0,05 aseguran que la distribución es Normal.

En la prueba de Shapiro-Wilk para la variable Equipos de trabajo, si el nivel de significación $p<0,05$, la distribución de la variable no es Normal 
Por último, la prueba de comparación de medias de 3 o más variables (ANOVA) se debe aplicar a variables cuantitativas, luego se han asignado valores numéricos (1,2 y 3 ) a las categorías anteriores y se ha evaluado si existen diferencias que no se deben al azar. (Moder, K.,2010). Además es requisito para esta prueba que las variables sean independientes (demostrado anteriormente), que las variables sigan una distribución normal (demostrado con el test de Kolmogorov-Smirnov) y que las varianzas sean homogéneas (para confirmar esto último se realizará una prueba de homogeneidad de varianzas (Estadístico de Levene)).

\section{Prueba de bondad de ajuste a la Distribución Normal (Saphiro Wilk)}

Si $p<0,05$, la distribución de la variable no es Normal. Se muestra a continuación la salida del programa SPSS:

\begin{tabular}{|c|c|c|c|c|c|c|}
\hline \multicolumn{7}{|c|}{ Resumen de procesamiento de casos } \\
\hline & \multicolumn{6}{|c|}{ Casos } \\
\hline & \multicolumn{2}{|c|}{ Válido } & \multicolumn{2}{|c|}{ Perdidos } & \multicolumn{2}{|c|}{ Total } \\
\hline & $\mathrm{N}$ & Porcentaje & $\mathrm{N}$ & Porcentaje & $\mathrm{N}$ & Porcentaje \\
\hline AHP & 21 & $100,0 \%$ & 0 & $0,0 \%$ & 21 & $100,0 \%$ \\
\hline
\end{tabular}

Pruebas de normalidad

\begin{tabular}{rrr|r|r|r|r} 
& \multicolumn{4}{c}{ Kolmogorov-Smirnova } & \multicolumn{3}{c}{ Shapiro-Wilk } \\
& Estadístico & gl & \multicolumn{1}{c}{ Sig. } & Estadístico & gl & \multicolumn{1}{c}{ Sig. } \\
\hline AHP &, 135 & 21 &, $200^{*}$ &, 958 & 21 &, 485 \\
\hline
\end{tabular}

*. Esto es un límite inferior de la significación verdadera.

a. Corrección de significación de Lilliefors 


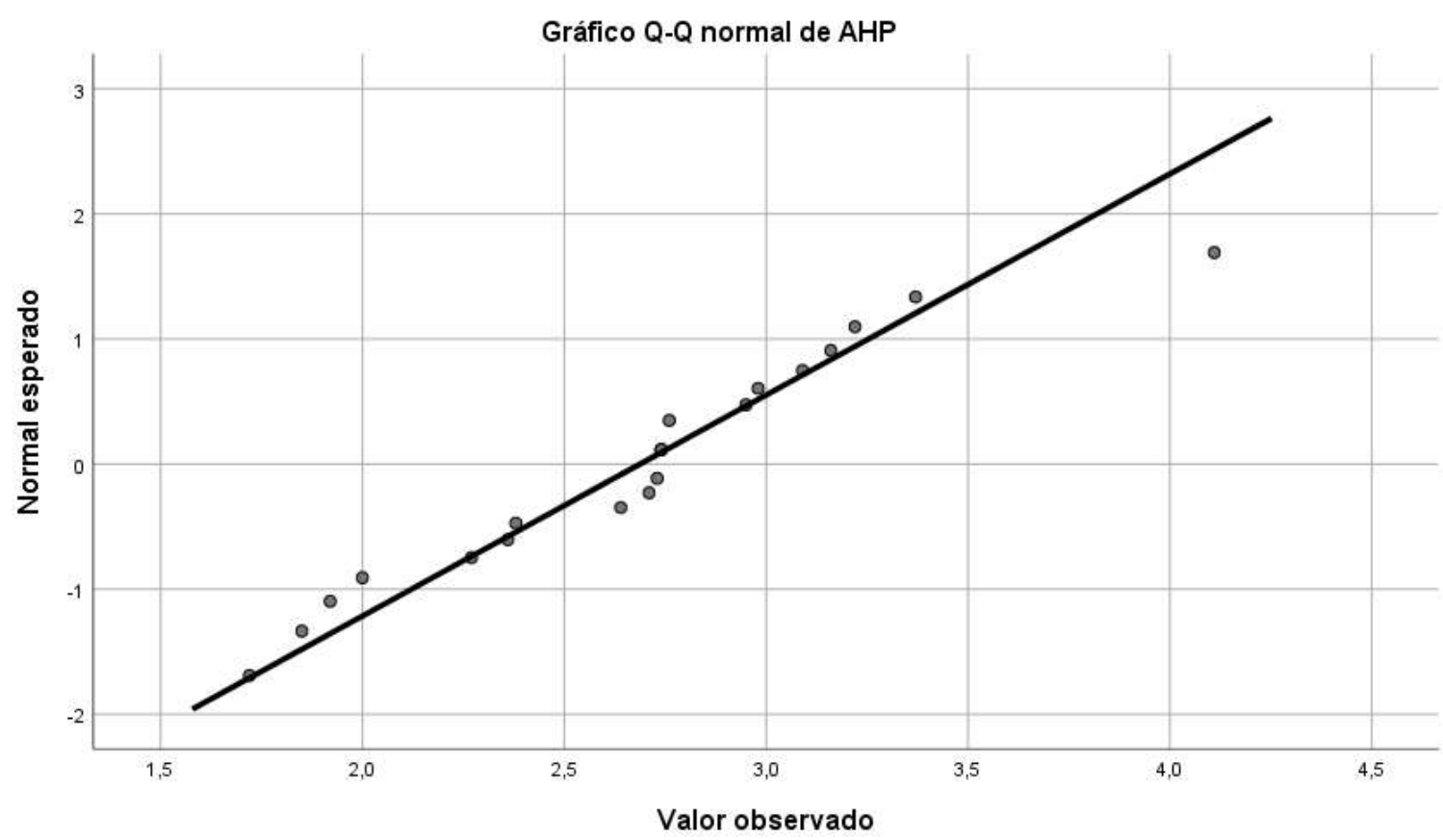

Figura 23. Resultados Prueba de bondad de ajuste a la distribución normal (Saphiro Wilk) para la variable AHP

El valor de $p$ (nivel de significación) es 0,485 en la prueba de Saphiro Wilk luego la variable AHP sigue una distribución normal.

Se describe a continuación la variable en los diferentes grupos (media y desviación estándar)

Descriptivos

AHP

\begin{tabular}{|c|c|c|c|c|c|c|c|c|}
\hline & \multirow[b]{2}{*}{$\mathrm{N}$} & \multirow[b]{2}{*}{ Media } & \multirow[b]{2}{*}{$\begin{array}{l}\text { Desviación } \\
\text { estándar }\end{array}$} & \multirow[b]{2}{*}{$\begin{array}{l}\text { Error } \\
\text { estándar }\end{array}$} & \multicolumn{2}{|c|}{$\begin{array}{c}\text { 95\% del intervalo de confianza } \\
\text { para la media }\end{array}$} & \multirow[b]{2}{*}{ Mínimo } & \multirow[b]{2}{*}{ Máximo } \\
\hline & & & & & Limite inferior & $\begin{array}{l}\text { Límite } \\
\text { superior }\end{array}$ & & \\
\hline $\begin{array}{l}\text { absolutamente } \\
\text { desequilibrado }\end{array}$ & 9 & 2,34222 & , 413061 & 137687 & 2,02472 & 2,65973 & 1,720 & 2,740 \\
\hline Desequilibrado & 6 & 2,57667 & ,365331 & 149146 & 2,19328 & 2,96006 & 2,000 & 2,980 \\
\hline Equilibrado & 6 & 3,31667 & , 412779 & 168516 & 2,88348 & 3,74985 & 2,950 & 4,110 \\
\hline Total & 21 & 2,68762 &, 565950 & 123500 & 2,43000 & 2,94524 & 1,720 & 4,110 \\
\hline
\end{tabular}

Figura 24. Resultados del análisis de la variable AHP en las distintas categorías de equipos de trabajo 


\section{Prueba de comparación de medias de 3 o más variables (ANOVA)}

A continuación se realizó un test de contraste de hipótesis entre las 3 categorías (Equilibrados, Desequilibrados y Absolutamente Desequilibrados).

El test ANOVA se debe aplicar a variables cuantitativas, luego se han asignado valores numéricos $(1,2$ y 3$)$ a las categorías anteriores y se ha evaluado si existen diferencias que no se deben al azar. (Moder, K.,2010)

Para poder hacer el test ANOVA debemos cumplir (Kutnervet al., 2005):

- que las variables sean independientes (demostrado anteriormente)

- que las variables sigan una distribución normal (demostrado con el test de Kolmogorov-Smirnov)

- que las varianzas sean homogéneas

La última condición es que sean homogéneas las varianzas para lo cual se ha realizado una prueba de homogeneidad de varianzas (Estadístico de Levene):

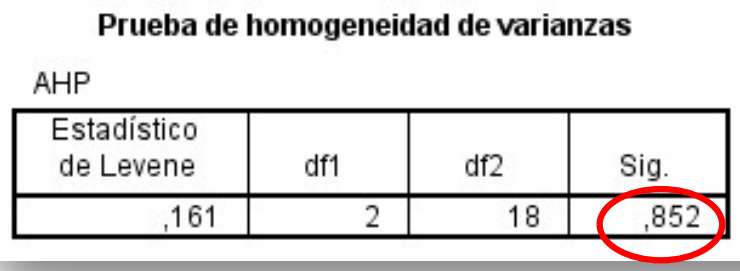

Figura 25. Prueba de homogeneidad de varianzas

Al obtenerse 0,0852, por encima 0,05, se puede realizar el test ANOVA y no es necesario Welch ANOVA o Kruskall Wallis que es la alternativa en caso de heterogeneidad de varianzas (Hangcheng Liu, 2015) (Kruskal, Wallis,1952)

Por último, se ha realizado el test ANOVA, obteniendo una significación (Sig.) de 0,001 para la variable AHP lo cual significa que sí existen diferencias que no se deben al azar. Wuensch, K. (2009). 


\section{ANOVA}

AHP
\begin{tabular}{|l|r|r|r|r|r|}
\hline & \multicolumn{1}{|c|}{$\begin{array}{c}\text { Suma de } \\
\text { cuadrados }\end{array}$} & gl & \multicolumn{1}{c|}{$\begin{array}{c}\text { Media } \\
\text { cuadrática }\end{array}$} & \multicolumn{1}{c|}{ F } & Sig. \\
\hline Entre grupos & 3,522 & 2 & 1,761 & 10,989 &, 001 \\
Dentro de grupos & 2,884 & 18 &, 160 & & \\
Total & 6,406 & 20 & & & \\
\hline
\end{tabular}

Figura 26. Resultados Test ANOVA para la variable AHP en las 3 categorías de equipos de trabajo

Al hacer el test ANOVA entonces sale una significación de 0,001 para la variable AHP luego si existen diferencias que no se deben al azar. Se confirma así que existe una relación entre el Valor AHP (éxito de los proyectos) y el Equilibrio de los roles de equipo. (Moder, K.,2007). 


$$
\begin{gathered}
\text { CAPÍTULO } 5 \\
\text { CONCLUSIONES Y } \\
\text { LÍNEAS FUTURAS } \\
\text { DE } \\
\text { INVESTIGACIÓN }
\end{gathered}
$$




\subsection{Conclusiones}

Las principales conclusiones extraídas de la presente investigación son las que se enumeran a continuación:

- El conocimiento asociado con la gestión de proyectos está en continua evolución y las competencias transversales descritas en este estudio se consideran críticas para la gestión innovadora de proyectos. Para lograr una mayor integración e interpenetración de temas en un equipo, se deben buscar ejercicios innovadores en los que los individuos se sientan comprometidos. La incorporación de elementos en el mundo de los negocios durante las primeras etapas de la vida profesional se considera un estímulo para los ingenieros, y la oportunidad de enfrentar desafíos cercanos al mercado es una experiencia de aprendizaje única. Los investigadores proponen una evaluación bienal de la creatividad y la innovación asociadas a la gestión de proyectos y una extensión de la metodología propuesta a otras maestrías.

- El marco lógico de un proyecto ofrece la posibilidad de trabajar diferentes competencias transversales, entre las que se encuentran la creatividad (generación de ideas que pueden implementarse en proyectos), la identificación, formulación y resolución de problemas de ingeniería a través del trabajo en equipo (análisis de factibilidad y factibilidad). y, por último, la comunicación (fase de aprobación del proyecto).

- La competencia en creatividad asociada a la gestión de proyectos se puede definir como una idea novedosa o una nueva solución de ingeniería que es valiosa (la propuesta del proyecto es aprobada por el cliente). Por lo tanto, el marco lógico de un proyecto apoya el proceso para generar proyectos innovadores exitosos.

- El Ejercicio del inversor se ha demostrado como un ejercicio que aglutina el análisis de las competencias indicadas anteriormente, siendo un ejercicio innovador de aprendizaje experiencial, diferente de la capacitación tradicional en gestión de proyectos. 
- Al evaluar la creatividad, el investigador concluye que los ingenieros son capaces de identificar y formular nuevos problemas de ingeniería, pero existe una falta de funcionalidad. Este hecho se hace más evidente en aquellos aspectos relacionados con la funcionalidad económica, un aspecto crítico en la fase de aprobación de un proyecto. Otro aspecto en el que la creatividad se ve afectada es el impacto esperado del proyecto.

- El análisis de Belbin hizo posible identificar la importancia de tener equipos equilibrados, en los que se necesita un perfil de Investigador de Recursos, para poder relacionarse con el mundo exterior y facilitar así el logro de financiamiento (fase 3, Figura 11 y fase significativa para el éxito del proyecto).

- El análisis del individuo hacia el trabajo (Jung) permitió definir el perfil orientado al objetivo (pensamiento analítico) como el perfil dominante en los cuatro grupos, seguido de los perfiles de proceso (pensamiento secuencial) y orientado al equipo (pensamiento interpersonal) y, por último, la innovación (Perfil de pensamiento imaginativo).

- Los proyectos innovadores o de I + D deben considerar a los equipos e individuos como el activo más valioso en un proyecto / empresa: son responsables del desarrollo de ideas y soluciones para cumplir con las tareas y actividades en este tipo de proyectos. Se recomienda al gerente de proyecto que utilice las técnicas descritas en este estudio para mantener la motivación del equipo lo más alta posible.

- Finalmente, se ha demostrado que la competencia en comunicación es clave en la etapa de aprobación del proyecto (en este caso, el ejercicio del inversor). Aquellos equipos con alto puntaje en esta competencia completaron la inversión requerida en el ejercicio del inversor; por ejemplo, los ingenieros deben tener en cuenta que esta competencia para la aprobación de la inversión en proyectos innovadores es la etapa más crítica. Esta habilidad es más valiosa en proyectos superiores o multidisciplinarios, en los que es necesaria una alta inversión.

- Los resultados del estudio nos permiten identificar puntos en los que trabajar en el futuro, como las funcionalidades y la resolución de problemas de ingeniería, teniendo en cuenta aspectos económicos y beneficiosos para varias partes 
interesadas o la sociedad en general. Otro aspecto a trabajar en el concepto de creatividad será el impacto, buscando soluciones de ingeniería que permitan una mayor replicabilidad.

- Por último, cabe destacar que dos de los proyectos considerados en el presente estudio fueron seleccionados en la primera fase de la Competición actúaupm (competencia de creación de negocios (14 ${ }^{a}$ edición). Se presentaron más de quinientas ideas de negocios, y algunas de ellas se consideraron para la siguiente fase.

Adicionalmente, el estudio 2, "Assessing transversal competences as decisive for Project management", arroja las siguientes conclusiones:

- Por un lado, en un entorno externo del mercado del sector energético, donde el cambio es un proceso acelerado, derivado de los acuerdos políticos por la lucha contra el cambio climático, un aumento del consumo y la necesidad de garantizar el suministro a un coste competitivo se convierte en necesario establecer procesos de innovación. Esto genera un caso de estudio muy interesante sobre el que poder trabajar para analizar la propuesta de esta tesis, sobre la importancia de la creación de equipos de trabajo asociados a proyectos innovadores de éxito.

- No solo la Innovación abierta permite aprovechar los recursos internos de una empresa, sino también se extiende a todos los sectores e instituciones relacionadas con la innovación en todo el mundo - el resultado de la globalización derivada de la hiperconectividad. Este hecho produce una dificultad para tomar decisiones, derivadas de la gran respuesta que se puede recibir. El uso de estándares que apoyan el proceso de toma de decisiones se convierte en una herramienta para aumentar la competitividad en la gestión de proyectos innovadores: la selección de ideas y su desarrollo mediante financiación es un proceso de alto riesgo y que consume mucho tiempo.

- El uso de algoritmos matemáticos que apoyan esta toma de decisiones, y especialmente el uso del modelo AHP se demuestra en este estudio como una herramienta útil para evaluar proyectos innovadores. No solo la toma de decisiones, sino que también permite establecer puntos fuertes y débiles siguiendo una de las 
metodologías de gestión de proyectos más reconocidas a nivel mundial que es la desarrollada por el PMI.

- La aplicación de esta herramienta a un caso de estudio real y concreto, basado en cinco ejemplos, demuestra su viabilidad. Los casos estudiados no solo han sido desarrollados por estudiantes, sino que algunos de ellos están financiados y forman parte de la cartera de proyectos del Laboratorio de Ingeniería de Proyectos ETSIME-UPM.

Respecto al estudio 3, "Studying the relationship between teamwork competition and successful innovative Projects", del modelo matemático y su aplicación a los proyectos innovadores, puedo concluir que :

- Los resultados obtenidos demuestran que existe una relación entre el éxito de los proyectos y el equilibrio de los equipos que impulsan estos proyectos. En realidad, de manera inconsciente se asume por lo general que esto ocurre, pero la posibilidad de "categorizar" los equipos en función del equilibro de roles presentes en los mismos es una potente herramienta para poder trabajar en la composición de estos equipos.

- La metodología propuesta, según la cual en primer lugar se asigna una puntuación a los grupos en función de los criterios definidos (metodología AHP) para pronosticar el posible éxito de las distintas propuestas en función de la madurez de los criterios considerados (Alcance, tiempo, coste, calidad, riesgos, interesados, recursos humanos y comunicación)

- A continuación se procede a clasificar los equipos en función del equilibrio de los mismos según la presencia complementaria de roles (Diagnóstico de equipos de trabajo), lo cual permite obtener un diagnóstico sobre el equilibrio de cada grupo (Absolutamente desequilibrado, desequilibrado, equilibrado)

A partir del análisis estadístico de los resultados anteriores se pueden establecer las conclusiones siguientes:

- Por un lado se consigue demostrar que existe una relación entre la madurez de las propuestas (Valor AHP) y el equilibro de los grupos que no se debe al azar. 
- La conclusión anterior abre la posibilidad de analizar la composición de los equipos para asegurar el equilibrio de roles como aspecto clave para garantizar el éxito de los proyectos de innovación, en los que la limitación de recursos obliga a tener que seleccionar a menudo entre los mismos. Además, se podría pensar en proponer una composición de equipos que asegurara el éxito de los proyectos que emprendieran, como herramienta predictiva que ayudara a establecer el mejor equipo para cada proyecto 


\subsection{Líneas futuras de investigación}

El primer estudio, "Multicriteria methodology and hierarchical innovation in the energy sector", permite evaluar ideas, que podrían materializarse en proyectos, como un primer paso en un proceso de innovación o innovación abierta. Además, también evalúa la capacidad de cada equipo para tener éxito en la implementación de un proyecto. Por lo tanto, la metodología evalúa las ideas innovadoras y los equipos de antemano, y podría considerarse una herramienta adicional y objetiva para los tomadores de decisiones o los inversores (entorno interno o externo). Las investigaciones futuras se centrarán en el proceso para generar ideas y cómo un equipo puede tratarlas. Se prestará especial atención al proceso de formación del equipo, ya que el equipo de investigación lo considera un tema crítico para el éxito de la transformación de una idea en un proyecto. Otras habilidades como la motivación o la automotivación también serán consideradas en trabajos futuros. La investigación se centrará en la metodología de pensamiento de diseño para generar ideas viables, donde el cliente es el foco principal desde el primer punto del marco lógico del proyecto. La metodología será implementada en un Proyecto de Investigación Educativa.

Como líneas de trabajo futuras para el estudio 2, "Assessing transversal competences as decisive for Project management", se propone considerar un enfoque en el que diferentes grupos de interés propongan otras ponderaciones y estudiar así la intersección de las valoraciones realizadas con estos pesos sea el punto o alternativa más atractivo para su financiación. También será necesario considerar el grado de madurez del proyecto para poder tomar en cuenta los proyectos que están maduros, con una gran cantidad de información de entrada, pero también otros en que los datos son escasos y, por lo tanto, las entradas de la matriz son limitadas, algo que suele ocurrir en las etapas iniciales de cada proyecto.

Las líneas futuras de trabajo para el estudio 3, "Studying the relationship between teamwork competition and successful innovative Projects" , versarán sobre el análisis exhaustivo de los roles de equipo para poder analizar con mayor detalle el equilibro que suponen los distintos roles y su complementariedad en parejas. 
También la diferencia entre actuar por adelantado proponiendo equipos con un equilibro de composición frente a otros en los que se analice con posterioridad la presencia de estos roles y su relación con el éxito de los proyectos que propongan.

Adicionalmente, se plantean como líneas de investigación futuras de esta tesis doctoral las siguientes:

- El análisis de agrupamientos para encontrar posibles relaciones entre los grupos

- La continuación de esta línea de trabajo dentro de las líneas actuales de investigación que la autora está desarrollando en su grupo de investigación GIOS (Grupo de Investigación de Organizaciones Sostenibles) de la UPM ya que el enfoque fundamental de este grupo es el estudio y el diseño de organizaciones que contribuyen a la sostenibilidad social, ambiental y económica. Las líneas actuales de investigación del grupo GIOS en las que la autora está trabajando son la siguientes:

- Medioambiente y ODS en la empresa.

- Gases renovables.

- Gestión de proyectos sostenibles.

- Impacto social

- ODS17: Alianzas para conseguir los objetivos

- Innovación educativa: Formalización del conocimiento en relación a nuevas formas de trabajo en red / plataformas organizacionales / Alianzas. Incorporación de nuevas técnicas formativas en esta dirección en formación oficial (grado y máster). Innovación en la docencia para la generación Z.

- Cuestiones de género y diversidad en las Organizaciones

- Evaluación y gestión de equipos

Los resultados de esta tesis guardan por tanto gran relación con las líneas de trabajo de su grupo de investigación y se podrán crear sinergias que potencien una futura línea de trabajo combinando resultados y futuras líneas de trabajo en la evaluación de quipos, el impacto de los equipos en los proyectos y la influencia de los roles y la diversidad en las organizaciones. 
DESARROLLO MODELO DE CREACIÓN DE EQUIPOS DE TRABAJO ASOCIADO A PROYECTOS INNOVADORES EXITOSOS

Pá g i n a 137 


\section{CAPÍTULO 6 \\ BIBLIOGRAFÍA}




\section{Bibliografía}

- Abernathy, W.J. and Clark, K. (1985), "Innovation: mapping the winds of creative destruction", Research Policy, Vol. 22 No. 2, pp. 3-22, doi: 10.1016/0048-7333(85)90021-6.

- Alberola, J. M., del Val, E., Sanchez-Anguix, V., Palomares, A., \& Dolores Teruel, M. (2016). An artificial intelligence tool for heterogeneous team formation in the classroom. Knowledgebased System, 101, 1-14.

- Amabile, T. M. (1998). A model of creativity and innovation in organizations. In B. M. Staw, \& L. L. Cummings (Vol. Eds.), Research in organizational behaviour: 10, (pp. 123-167). Greenwich, CT: JAI Press.

- Amabile, T. M., \& Gryskiewicz, N. (1989). The creative environment scales: The work environment inventory. Creative Research Journal, 2(1), 231-254.

- Amabile, T. M., \& Pratt, M. G. (2016). The dynamic componential model of creativity and innovation in organizations: Making progress, making meaning. Research in Organizational Behaviour, 36, 157-183.

- http://actuaupm.blogspot.com.es/ access on 22nd of May, 2017.

- Amiguet, L. (2017). "O navegamos juntos o nos hundimos". Periódico: La Vanguardia. Recuperado de: http://www.lavanguardia.com/lacontra/20170923/431475216101/onavegamos-juntos-o-nos-hundimos-juntos.html

- Aritzeta, A., Swailes, S., \& Senior, B. (2007). Belbin's team role model: Development, validity and applications for team building. Journal of Management Studies, 44(1), 96-118.

- Baer, J., \& McKool, S. S. (2009). Assessing creativity using the consensual assessment technique. In C. Schreiner (Ed.). Handbook of research on assessment technologies, methods, and applications in higher education (pp. 65-77). PA: IGI Global. https://doi.org/10.4018/978-1-60566-667-9.ch004.

- Batey, M., Furnham, A., \& Safiullina, X. (2010). Intelligence, general knowledge and personality as predictors of creativity. Learning and Individual Differences, 20, 532-535.

- Belbin, M. (1981). Management Teams; why they succeed or fail. Great Britain: Biddls Ltd., Guilford and King's Lynn.

- Belbin, M. (2018). Recuperado de: https://www.belbin.es/roles-de-equipo/

- Bernardo Llamas, M. Dolores Storch de Gracia, Luis F. Mazadiego, Juan Pous, Julian Alonso. "Assessing transversal competences as decisive for Project management". Revista Thinking Skills \& Creativity. Estado: Publicado. (Thinking Skills and Creativity 31 (2019) 125137).

- Borrell, F. (2004). Cómo trabajar en equipo: y crear relaciones de calidad con jefes y compañeros. Editorial: Gestión 2000.

- Byrge, C., \& Hansen, S. (2008). The creative platform: A didactic for sharing and using knowledge in interdisciplinary and intercultural groups. Conference proceedings SEFI: European Association for Engineering Education. 
- Çetin Demirel, N., Demirel, T., Deveci, M. and Vardar, Gö (2017), "Location selection for underground natural gas storage using Choquet integral", Journal of Natural Gas Science \& Engineering, Vol. 45 No. 1, pp. 368-379, doi: 10.1016/j.jngse.2017.05.013.

- Charyton, C. (2014). An overview of the relevance of creative engineering design: Background. Creative engineering design assessment. London: Springer1-10.

- Chesbrough, H. W. (2003). Open Innovation: The new imperative for creating and profiting from technology. Boston: Harvard Business School Press.

- Chen, C.C., Shih, H.S., Shyur, H.J. and Wu, K.S. (2012), "A business strategy selection of green supply chain management via an analytic network process", Computers and Mathematics with Applications, Vol. 64 No. 10, pp. 2544-2557.

- Cheng, E.W.L. and Li, H. (2004), "Contractor selection using the analytic network process", Construction Management and Economics, Vol. 22 No. 4, pp. 1021-1032.

- Cheng, E.W.L. and Li, H. (2005), "Analytic network process applied to project selection", Journal of Construction Engineering and Management, Vol. 131 No. 4, pp. 459-466.

- Chiocchio, F. (2015). Defining project teams: A review of conceptual underpinnings. In F. Chiocchio, F., Kelloway, K., \& Hobbs, B. (Eds.) (2015). The psychology and management of project teams. Oxford, UK: Oxford University Press.

- Cohen, Y., Ornoy, H., \& Keren, B. (2013). MBTI personality types of project managers and their success: A field survey. Project Management Journal, 44(3), 78-87.

- Córdoba, J. R., \& Piki, A. (2012). Facilitating Project management education through groups as systems. International Journal of Project Management, 30, 83-93.

- Craft, A., \& Jeffrey, B. (2008). Creativity and performativity in teaching and learning: Tensions, dilemmas, constraints, accommodations and synthesis. British Educational Research Journal, 34(5), 577-584.

- Cropley, A. (2006). Creativity: A social approach. Roeper review. Spring, 28(3), 125-130 2006.

- Cropley, D., \& Cropley, A. (2010). Recognizing and fostering creativity in technological design education. International Journal of Technology and Design Education, 20, 345-358. https://doi.org/10.1007/s10798-009-9089-5.

- Crosier, D., Purser, L., \& Smidt, H. (2007). Trends V: Universities shaping the European Higher Education Area. Brussels, Belgium: European Universities Association ISBN: 9789078997023.

- Daly, S. R., Yilmaz, S., Christina, J. L., Seifert, C. M., \& Gonzalez, R. (2012). Design heuristics in engineering concept generation. Journal of Engineering Education, 101, 601629.

- Daly, S. R., Mosyjowski, E. A., \& Seifert, C. M. (2014). Teaching creativity in engineering courses. Journal of Engineering Education, 103(3), 417-449. 
- Davies, D., Jindal-Snape, D., Collier, C., Digby, R., Hay, P., \& Howe, A. (2013). Can creative learning environments in education - A systematic literature review. Thinking Skills and Creativity, 8, 80-91.

- Denson, C. D., Lammi, M. D., Susan, D., \& Amico (2015). Developing instrumentation for assessing creativity in engineering design. Journal of Technology Education, 27(1), 23-40.

- Dillenbourg, P. (1999). What do you mean by collaborative learning? In P. Dillenbourg (Ed.). Collaborative-learning: Cognitive and computational approaches (pp. 1-19). Oxford, United Kingdom: Elsevier.

- Duhigg, C. (2016). "What google learned from its quest to build the perfect team". Magazine: The New York Times.

- Drummond, C. (2017). Un estudio de Google revela qué caracteriza al equipo de trabajo perfect. Recuperado de: http://www.ticbeat.com/empresa-b2b/un-estudio-de-google-revelaque-caracteriza-al-equipo-de-trabajo-perfecto/

- Engineering Accreditation Commisssion (2014). 2015-2016 Criteria for accrediting engineering programs. United States: ABET.

- Esquivias, M. (2004) Creatividad: definiciones, antecedentes y aportaciones. Revista Digital Universitaria, 5 (1), 2-17.

- Ewin, N., Luck, J., Chugh, R., \& Jarvis, J. (2017). Rethinking project management education: A humanistic approach based on design thinking. Procedia Computer Science, 121, 503510.

- Field, A.P.(2009). Discovering statistics using SPSS, 3rd edition. London: Sage. Additional material.

- Fischer, S., Oget, D., \& Cavallucci, D. (2016). The evaluation of creativity from the perspective of subject matter and training in higher education: Issues, constraints and limitations. Thinking Skills and Creativity, 19, 123-135.

- Gabriel, A., Monticoloa, D., Camargoa, M., \& Bourgault, M. (2016). Creativity support systems: A systematic mapping study. Thinking Skills and Creativity, 21, 109-122.

- Gil, F. (2012). Charla Desarrollo de equipos de trabajo. Investigación y práctica actual. Universidad Complutense de Madrid. BLC Human.

- Gómez, B. (2016). 10 razones para trabajar en equipo. Recuperado de: http://www.entrepreneur.com/article/267218

- Gordon, J., Halasz, G., Krawczyk, M., Leney, T., Michel, A., Pepper, D., et al. (2009). Key competences in Europe: Opening doors for lifelong learners across the school curriculum and teacher education. Warsaw, Poland: Center for Social and Economic Research.

- Guilford, JP (1985) A 60-year perspective on psychological measurement. Applied psychologial measurement Vol $9 \mathrm{~N}^{\circ} 4$ Pags 341-349

- Hangcheng Liu (2015), Comparing Welch's ANOVA, a Kruskal-Wallis test and traditional ANOVA in case of Heterogeneity of Variance. VCU Theses and Dissertations 
- Hartman, F. (2008). Preparing the mind for dynamic management. International Journal of Project Management, 26(3), 258-267.

- Hong, E., Hartzell, S. A., \& Greene, M. T. (2009). Fostering Creativity in the Classroom: Effects of teacher's epistemological beliefs, motivation, and goal orientation. The Journal of Creative Behavior, 43(3), 192-208.

- Jahnke, I., Haertel, T., \& Wildt, J. (2017). Teacher's conceptions of student creativity in higher education. Innovations in Education and Teaching International, 54(1), 87-95.

- Jaskyte, K., \& Kisieliene, A. (2006). Determinants of employee creativity: A survey of Lithuanian non-profit organizations. Voluntas, 17(2), 133-141.

- Jesus García-García, M., Arranz Manso, G., Blanco Cotano, J., Edwards, M., Hernández, W., Mazadiego, L., et al. (2010). eCompetentis: una herramienta para la evaluación de competencias genéricas. Revista de Docencia Universitaria, 8(1), 111-119.

- Jung, C. G. (1921). Psychological types, collected works, Vol. 6. Princeton, NJ: Princeton University Press.

- Jung, C. G. (1990). Psychological types. Princeton, NJ: Princeton University Press.

- Kagan, S. (1989). The structural approach to cooperative learning. Educational Leadership, 47(4), 12.

- Kamel, J.A.N., Martins, C.V., Pessanha, M.B. et al. Creativity and innovation for corporate happiness management. Braz J Sci Technol 4, 1 (2017). https://doi.org/10.1186/s40552017-0038-7

- Kampylis, P., Berki, E., \& Saariluoma, P. (2009). In service and prospective teachers' conceptions of creativity. Thinking Skills and Creativity, 4, 15-29. https://doi.org/10.1016/j.tsc.2008.10.001.

- Kelly, J. M. (2013). Engineering Education in the 21st century: Creativity, collaboration, invention. International Journal of Information and Education Technology, 3(2), 240-244.

- Key Issues for Management of Innovative Projects (2017) (edited by Bernardo Llamas, M. Dolores Storch de Gracia and Luis F. Mazadiego (Intech Open, ISBN 978-953-51-3468-8) (Author of the chapter "Handling Innovative People")

- Key Issues for Management of Innovative Projects (2017) (edited by Bernardo Llamas, M. Dolores Storch de Gracia and Luis F. Mazadiego (Intech Open, ISBN 978-953-51-3468-8)

- Kuusisto, E., \& Tirri, K. (2015). Disagreements in working as a team: A case study of Gifted science students. Revista de Educación, 368, 279-303.

- Liberatore, M.J. and Nydick, R.L. (2008), "The analytic hierarchy process in medical and health care decision making: a literature review”, European Journal of Operational Research, Vol. 189 No. 1, pp. 194-207.

- Llamas, B. and Cámara, C. (2014), "Application of multicriteria algorithm to select suitable areas for storing CO2: CO2SiteAssess software”, Energy Procedia, Vol. 63 No. 1, pp. 49774986. 
- Llamas, B., Castañeda, M.C., Laín, C. and Pous, J. (2017), "Multi-criteria method to select ideal salt domes as stores for compressed air underground", International Journal of Energy Research, Vol. 41 No. 14, pp. 2108-2120, doi: 10.1002/er.3771.

- Lledó, Pablo (2017). "Director de proyectos: cómo aprobar el examen PMP sin morir en el intento" 6th Edition

- Long, H. (2014). An empirical review of research methodologies and methods in creativity studies (2003-2012). Creativity Research Journal, 26(4), 427-438. https://doi.org/10.1080/10400419.2014.961781.

- $\quad$ Lupuleac, S., Lupuleac, Z.-L., \& Rusu, C. (2012). Problems of assessing team roles balance - Team design. Procedia Economics and Finance, 3, 935-940.

- Lyubomirsky, S. (2008). The how of happiness: A scientific approach to getting the life you want. New York: Penguin Press.

- Kruskal, Wallis (1952). Use of ranks in one-criterion variance analysis. Journal of the American Statistical Association 47 (260): 583-621.

- Kutner, M.H., Nachtsheim, C.J., Neter, J.,Li, W., et al. (2005). Applied Linear Statistical Models, 5th edition. Analysis of Variance, 690-699.

- M. Dolores Storch de Gracia, David Moya Perrino and Bernardo Llamas. "Multicriteria Methodology and Hierarchical Innovation in the Energy Sector. The Project Management Institute Approach" (Article Id: MD617610)": Revista: Management Decision. Estado: Publicado (Septiembre 2018).

- Markham, S.K. and Lee, H. (2013), "Product development and management association's 2012 comparative performance assessment study", Journal of Product Innovation Management, Vol. 30 No. 3, pp. 408-429, doi: 10.1111/jpim.12025.

- Maxwell, J. C. (2001). The 17 Indisputable Laws of Teamwork. Editorial Caribe.

- Mayer, R. E. (1999). Fifty years of creativity research. 25 In R. J. Sternberg (Ed.). Handbook of creativity (pp. 449-460). Cambridge: University Press.

- McWilliam, E., \& Dawson, S. (2008). Teaching for creativity: Towards sustainable and replicable pedagogical practice. Higher Education, 56, 633-643. https://doi.org/10.1007/s10734-008-9115-7.

- Meade, L.M. and Presley, A. (2002), "R\&D project selection using the analytic network process", IEEE Transactions on Engineering Management, Vol. 49 No. 1, pp. 59-66.

- Meredith Belbin, R. (2010a). Management Teams - Why they succeed or fail (third edition). Oxford, United Kingdom: Elsevier.

- Meredith Belbin, R. (2010b). Team roles at work (2nd edition). Oxford: Elsevier.

- Meslec N., Lucian Curseu Petru (2015) “Are balanced groups better? Belbin roles in collaborative learning groups, Learning and individual differences, Volume 39, April 2015, Pages 81-88.

- Moder, K. (2007). How to keep the Type I Error Rate in ANOVA if Variances are Heteroscedastic. Austrian Journal of Statistics, 36(3), 179-188. 
- Moder, K. (2010). Alternatives to F-Test in One Way ANOVA in case of heterogeneity ofvariances (a simulation study). Psychological Test and Assessment Modeling, Volume 52, 2010 (4), 343-353

- Mohanty, R.P., Agarwal, R., Choudury, A.K. and Tiwari, M.K. (2005), "A fuzzy ANP-based approach to R\&D project selection: a case study", International Journal of Production Research, Vol. 43 No. 24, pp. 5199-5216.

- Monreal, C. (2000). Qué es la creatividad. Madrid: Biblioteca Nueva.

- Mourgues, C., Tan, M., Hein, S., Elliott, J. G., \& Grigorenko, E. L. (2016). Using creativity to predict future academic performance: An application of Aurora's five subtests for creativity. Learning and Individual Differences, 51, 378-386. https://doi.org/10.1016/j.lindif.2016.02.001.

- Müller, R., \& Rodney Turner, J. (2006). Matching the project manager's leadership style to project type. International Journal of Project Management, 25, 21-32.

- Myers-Briggs, I. (1962). Manual: The Myers-Briggs type indicator. Palo Alto, CA: Consulting Psychologists Press.

- Nisel, S. and Özdemir, M. (2016), "Analytic hierarchy process \& analytic network process in sport: a comprehensive literature review", International Journal of the Analytic Hierarchy Process, Vol. 8 No. 3, pp. 405-429, doi: 10.13033/ijahp.v8i3.448.

- Objetivos de Desarrollo Sostenible (15 de enero de 2021), https://www.un.org/sustainabledevelopment/es/objetivos-de-desarrollo-sostenible/

- Ojiako, U., Ashleigh, M., Chipulu, M., \& Maguire, S. (2011). Learning and teaching challenges in project management. International Journal of Project Management, 29, 268278.

- Olson, D.L. (2001), "Comparison of three multicriteria methods to predict know outcomes", European Journal of Operational Research, Vol. 130 No. 3, pp. 576-587.

- Opricovic, S. and Tzeng, G.H. (2004), "Compromise solution by MCDM methods: a comparative analysis of VIKOR and TOPSIS", European Journal of Operational Research, Vol. 156 No. 2, pp. 445-455.

- Osterwalder, A. (2010). Business model generation. New Jersey, United States: John Wiley \& Sons.

- Pant, I., \& Baroudi, B. (2008). Project management education: The human skills imperative. International Journal of Project Management, 26, 124-128.

- Patari, E., Karell, V., Luukka, P. and Yeomans, J.S. (2018), "Comparison of the Multicriteria decision-making methods for equity portfolio selection: the US evidence", European Journal of Operational Research, Vol. 265 No. 2, pp. 655-672.

- Piffer, D. (2012). Can creativity be measured? An attempt to clarify the notion of creativity and general directions for future research. Thinking Skills and Creativity, 7, 258-264.

- Peters, S. J., \& Gates, J. C. (2010). The teacher observation form: Revisions and updates. The Gifted Child Quarterly, 54, 179-188. https://doi.org/10.1177/0016986210369258. 
- Plambech, T., \& Konijnendijk van den Bosch, C. C. (2015). The impact of nature on creativity - A study among Danish creative professionals. Urban Forestry \& Urban Greening, 14, 255263.

- Plucker, J. A., Beghetto, R. A., \& Dow, G. T. (2004). Why isn't creativity more important to educational psychologists? Potential, pitfalls, and future directions in creativity research. Educational Psychologist, 39, 83-96.

- PMI, Project Management Institute (PMI) (2017), A Guide to the Project Management Body of Knowledge (PMBOK Guide. $6^{\text {th }}$ Edition), Project Management Institute, PA.

- Pohekar, S.D. and Ramachandran, M. (2004), "Application of multi-criteria decision making to sustainable energy planning - a review", Renewable and Sustainable Energy Reviews, Vol. 8 No. 4, pp. 365-381.

- Pollack, J. (2007). The changing paradigms of project management. International Journal of Project Management, 25(3), 266-274.

- RAE, (2018). Real Academia Española. Diccionario de la lengua española. Recuperado de: http://dle.rae.es/?id=WcgmTVE|WchhwHP (definición de rol)

- RAE, (2018). Real Academia Española. Diccionario de la lengua española. Recuperado de: http://dle.rae.es/?id=G09HIAP (definición de equipo)

- Ramazani, J., \& Jergeas, G. (2015). Project Managers and the journey from good to great: The benefits of investment in project management training and education. International Journal of Project Management, 33, 41-52.

- Randelovic, M., Stankovic, J., Kuk, K., Savic, G. and Randelovic, D. (2018), "An approach to determining the importance of model Criteria in certifying a city as business-friendly", Interfaces, Vol. 48 No. 2, pp. 156-165.

- Randhawa, K., Wilden, R. and Hohberger, J. (2016), "A bibliometric review of open innovation: setting a research agenda", Journal of Product Innovation Management, Vol. 33 No. 6, pp. 750-772.

- Robinson, K. (2011). Out of our minds - Learning to be creative. United Kingdom: Capstone Publishing Ltd.

- Rogers, C.R. (1954). Toward a Theory of Creativity. A review of general semantics, 11 (4), 249-260.

- Proctor, R. M. J., \& Paul, C. B. (2004). Measuring cognitive and dispositional characteristics of creativity in elementary students. Creativity Research Journal, 16, 421-429. https://doi.org/10.1080/10400410409534553.

- Runco, M. A. (2014). Creativity: Theories and themes: Research, development, and practice. Elsevier.

- Saaty, T.L. (1977), "A scaling method for priorities in hierarchical structures", Journal of Mathematical Psychology, Vol. 5 No. 3, pp. 234-281.

- Saaty, T.L. (1980), The Analytic Hierarchy Process, McGraw-Hill, New York, NY. 
- Saaty, T.L. (1996), Decision Making with Dependence and Feedback: The Analytic Network Process, RWS Publications, Pittsburgh, PA.

- Saaty, T.L. (2006), Fundamentals of Decision Making and Priority Theory with the Analytic Hierarchy Process, Vol. VI, RWS Publications, Pittsburgh, PA.

- San Cristobal, J.R. (2011), "Multi-criteria decision-making in the selection of a renewable energy project in Spain: the Vikor method", Renewable Energy, Vol. 36 No. 2, pp. 498-502.

- Sancho-Thomas, P., Fuentes-Fernandez, R., \& Fernandez-Manjón, B. (2009). Learning teamwork skills in university programming courses. Computers \& Education, 53, 517-531.

- Sarkar, P., \& Chakrabarti, A. (2008). Studying engineering design creativity - Developing a common definition and associated measures. In J. Gero (Ed.). Studying design creativity. Springer Verlag.

- Sarkar, P., \& Chakrabarti, A. (2011). Assessing design creativity. Design Studies, 32, 348383.

- Scott, G., Leritz, L. E., \& Mumford, M. D. (2004). The effectiveness of creativity training: A quantitative review. Creativity Research Journal, 16(4), 361-388.

- Schmoldt, D.L., Kangas, J., Mendoza, G.A. and Pesonen, M. (2001), "The analytic hierarchy process in natural resource and environmental decision making", Springer Science + Business Media, Amsterdam.

- Schumpeter Joseph Alois, Capitalismo, socialismo y democracia, traducción de José Díaz García y Alejandro Limeres, Página indómita, Barcelona, 2015, 2 vols., vol. I, 409 pp. ISBN volumen I 978-84-943664-I-3.

- Shalley, C. E., \& Perry-Smith, J. E. (2001). Effects of social-psychological factors on creative performance: The role of informal and controlling expected evaluation and modeling experience. Organizational Behavior and Human Decision Processes, 84(1), 1-22. https://doi.org/10.1006/obhd.2000.2918.

- Simonton, D.K. (1984). Genius, creativity and leadership. Cambridge: Harvard University Press.

- Simonton, D.K. (1988). Scientific genius: A psychology of science. New York: Cambridge University Press.

- Sipahi, S. and Timor, M. (2010), "The analytic hierarchy process and analytic network process: an overview of applications", Management Decision, Vol. 48 No. 5, pp. 775-808.

- Spanish Ministry of Education http://www.mecd.gob.es/servicios-al-ciudadanomecd/estadisticas/educacion/universitaria/estadisticas/alumnado/Series.html, Access on 01st November 2018.

- Stanko, M.A., Fisher, G.J. and Bogers, M. (2017), "Under the wide umbrella of open innovation", Journal of Product Innovation Management, Vol. 34 No. 4, pp. 543-558.

- Starkey, E., Toh, C. A., \& Miller, S. R. (2016). Abandoning creativity: The evolution of creative ideas in engineering design course projects. Design Studies, 47, 47-72. 
- Stein, M.I. (1962). Creativity as an intra and interpersonal process. En S.J. Parnes y Harding (Coor.), A source book of creativity, I. II (pp. 85-92). New York: Scribner.

- Subramanian, N. and Ramanathan, R. (2012), "A review of applications of analytic hierarchy process in operations management", International Journal of Productions Economics, Vol. 138 No. 2, pp. $215-241$

- Tena, M. (2010). Aprendizaje de la competencia creatividad e innovación en el marco de una titulación adaptada al espacio europeo de educación superior. Formación Universitaria, $3(2), 11-20$.

- Teo, L. K. C., \& Waugh, R. F. (2010). A Rasch measure of fostering creativity. Creativity Research Journal, 22, 206-218. https://doi.org/10.1080/10400419.2010.481534.

- Thomas, J., \& Mengel, T. (2008). Preparing Project managers to deal with complexity Advanced project management education. International Journal of Project Management, 26, 304-315.

- Thomas, J., George, S. and Cicmil, S. (2013), Project Management Implementation as Management Innovation: A Closer Look, ISBN: 978-1-62825-031-2, Project Management Institute, PA.

- Thornberry, N. E., \& Weintraub, J. R. (1983). The project manager: What it takes to be a good one. Project Management Quarterly, 14(1), 73-76.

- Vaidya, O.S. and Kumar, S. (2006), "Analytic hierarchy process: an overview of applications", European Journal of Operational Research, Vol. 169 No. 1, pp. 1-29.

- Vargas Hernandez, H., Schmidt, L. C., Kremer, G. O., \& Lin, C.-Y. (2014). An empirical study of the effectiveness of selected cognitive aids on multiple design task. Design Computing and Cognition'12. Springer227-246.

- Wallin, M.W. and Von Krogh, G. (2010), "Organizing for open innovation: focus on the integration of knowledge", Organizational Dynamics, Vol. 39 No. 2, pp. 145-154.

- Welsh, G. S. (1975). Creativity and Intelligence: A personality Approach. Chapel Hill, North Carolina: Institute for Research in Social Science. University of North California at Chapel Hill.

- West, J., Salter, A., Vanhaverbeke, W. and Chesbrough, H. (2014), "Open innovation: the next decade", Research Policy, Vol. 43 No. 5, pp. 805-811.

- World Energy Council (2016), World Energy Trilemma Index, ISBN: 978-0-946121-59-5, World Energy Council, London, in partnership with Oliver Wyman

- Wuensch, K. (2009). Simulating Data for a Three-Way Independent Samples ANOVA. 8 May 2015. Web.

- Wyn, J. (2009). Touching the future: Building skills for life and work. Australian Education Review. Melbourne: Australian Council for Educational Research Press55.

- Yazdi, M. and Zarei, E. (2018), "Uncertainty handling in the safety risk analysis: an integrated approach based on Fuzzy fault tree analysis", Journal of Failure Analysis and Prevention, Vol. 18 No. 2, pp. 392-404. 
- Yu-Shan, C., Hung-Chang, L., Yu-Hung, C., \& Wan-Hsuan, Y. (2018). Effects of creative components and creative behaviour on design creativity. Thinking Skills and Creativity, 29, 23-31.

- Zeng, L., Proctor, R. W., \& Salvendy, G. (2011). Can traditional divergent thinking tests be trusted in measuring and predicting real-world creativity? Creativity Research Journal, 23(1), 24-37.

- Zheng, X., Ritter, Sarah, C. and Miller, S.R. (2018), "How concept selection tools impact the development of creative ideas in engineering design education", Journal of Mechanical Design, Vol. 140 No. 5, p. 052002, doi: 10.1115/1.4039338.

- Zhou, C. (2012a). Teaching engineering students creativity: A review of applied strategies. Journal on Efficiency and Responsibility in Education and Science, 5(2), 99-114.

- Zhou, C. (2012b). Learning engineering knowledge and creativity by solving projects. International Journal of Engineering Pedagogy (iJEP), 2, 26-31. 